Florida International University FIU Digital Commons

$11-12-2015$

\title{
Association Between Childhood Sexual Abuse and HIV-Related Risk Factors for HIV-Positive Haitian Women
}

Marie Sandra Severe

Florida International University, mseve002@fiu.edu

DOI: $10.25148 /$ etd.FIDC000177

Follow this and additional works at: https://digitalcommons.fiu.edu/etd

Part of the Community Health Commons, Domestic and Intimate Partner Violence Commons, Gender and Sexuality Commons, Inequality and Stratification Commons, Medicine and Health Commons, Substance Abuse and Addiction Commons, and the Theory, Knowledge and Science Commons

\section{Recommended Citation}

Severe, Marie Sandra, "Association Between Childhood Sexual Abuse and HIV-Related Risk Factors for HIV-Positive Haitian Women" (2015). FIU Electronic Theses and Dissertations. 2279.

https://digitalcommons.fiu.edu/etd/2279 


\section{FLORIDA INTERNATIONAL UNIVERSITY}

Miami, Florida

A dissertation submitted in partial fulfillment of the requirements for the degree of

DOCTOR OF PHILOSOPHY

in

PUBLIC HEALTH

by

Marie Sandra Severe

2015 
To: $\quad$ Interim Dean Mark Williams

Robert Stempel College of Public Health and Social Work

This dissertation, written by Marie Sandra Severe and entitled Association between Childhood Sexual Abuse and HIV-Related Risk Factors for HIV-Positive Haitian Women, having been approved in respect to style and intellectual content, is referred to you for judgment.

We have read this dissertation and recommend that it be approved.

$\begin{array}{r}\text { H. Virginia McCoy } \\ \hline \text { Elena Bastida } \\ \hline \text { Messy G. Dévieux, Major Professor }\end{array}$

Date of Defense: November 12, 2015

The dissertation of Marie Sandra Severe is approved

Interim Dean Mark Williams Robert Stempel College of Public Health and Social Work

Dean Lakshmi N. Reddi University Graduate School

Florida International University, 2015 
(C) Copyright 2015 by Marie Sandra Severe

All rights reserved. 


\section{DEDICATION}

I dedicate this dissertation to the special people in my life who reminded me that this journey was not designed to be perfect, but rather it was perfectly and divinely

designed for me. To those wonderful people in my life; I dedicate this dissertation to you. I wish you God's blessings and infinite love! 


\section{ACKNOWLEDGMENTS}

I must begin by thanking my major professor, Dr. Jessy G. Dévieux for her patience and push throughout the dissertation phase of my doctoral journey, as well as her wealth of knowledge and resources. I am so blessed to have had her be such an important part of my academic career. I would also like to thank the members of my committee: Dr. H. Virginia McCoy for her kindness and direction, as well as her eternal warmth and smile, Dr. Elena Bastida for her commitment and leadership, and Dr. Maria Elena Villar, for her wonderful feedback and constant encouragement. I would like to thank Dr. Terri Jennings for her amazing assistance with the statistics. She simplified things in a way that made me comfortable and confident in moving forward. To my editor, Dr. Deanne Samuels, thank you for your advice, encouragement, and expertise in getting me over the hurdle and into the next phase.

Now to my classmates-Team Awesome! You all have no idea just how much your support has meant to me during this doctoral journey! I was so proud to see each of you complete the dissertation and earn those three letters. We all finished at different times, but we stood by each other every step of the way. From the moment we entered the program at Florida International University, we depended on each other to talk, to research, to complain, to work, and to laugh. We became more than friends—we became a little family that grew beyond the confines of a classroom. From weddings, to babies, to new careers, to international travel—we were there for each other. Now that I finally made it to the other side, I hope I made you just as proud as each of you has made me. I love you dearly Annie Frankel, Mike Melchior, and Christi Batista Navarro! To my other 
two classmates who adopted me later in the writing phase-Tania Rivera and Pascale Jean! Thank you so much for looping me in to your world! Thank you for your encouragement, calls, and selflessness...oh, and the laughs...thank you for the laughs! I am so proud of you two!

Many thanks and much love to my family and closest friends who were there before a Ph.D. was even a part of the grand plan—my mom, my uncle, my grandmother, my siblings, my aunts and other uncles, my cousins, B@TU, SC, and my homegrown loves. One thing that has amazed me in life is that God saw fit to bless me with what seems like an infinite number of people to love and dote on me no matter what. The support I receive from these people is something I treasure and honor. If only everyone in the world knew the love and support I know, dare I write it, we would live in such a better place.

Lastly, thank you to the wonderful people who supported me at Miami Children’s Hospital when I began my doctorate and to the ones at Jackson Health System when I finally finished it. 


\title{
ABSTRACT OF THE DISSERTATION \\ ASSOCIATION BETWEEN CHILDHOOD SEXUAL ABUSE AND HIV-RELATED RISK FACTORS FOR HIV-POSITIVE HAITIAN WOMEN
}

by

\author{
Marie Sandra Severe
}

Florida International University, 2015

Miami, Florida

Professor Jessy G. Dévieux, Major Professor

Childhood sexual abuse (CSA) is one of the least studied HIV-related risk factors in Haiti although research in the United States and Europe has clearly established the link between childhood trauma and HIV risk behaviors. Understanding the role and impact of CSA on HIV-positive Haitian women is likely to strengthen future HIV prevention and treatment efforts aimed at this vulnerable group.

The current study was a cross-sectional examination of baseline data collected during a randomized trial of a cognitive-behavioral stress management (CBSM) intervention in Haiti. The purpose of this study was to analyze the association between CSA and sexual risk behaviors, alcohol use, and social support in a group of Haitian women, ages 17-55 ( $\mathrm{n}=229)$, who are HIV-positive alcohol users living in Haiti. The outcomes investigated were the respondents' level of exposure to CSA and their current HIV-related risk factors. The Theory of Gender and Power provided the theoretical 
framework for variable selection and associative exploration. Statistical tests included descriptive analyses, chi-square tests, analysis of variance (ANOVA), and correlations.

Results showed that women who were exposed to some level of sexual abuse during childhood had less favorable attitudes towards condom use than women who reported no exposure to sexual abuse during childhood $[F(2,217)=5.10, p=.007]$. There were no differences between exposure groups for the remaining sexual risk behaviors: multiple partners, knowledge of HIV, and sexual self-efficacy. Women who were exposed to CSA also reported higher levels of alcohol use than reported by the women in the non-exposure group. Finally, there were no differences between exposure groups for social support.

Group differences in attitudes towards condom use and levels of alcohol use among HIV-positive Haitian women demonstrate that HIV-positive individuals have different past and present experiences that affect their current beliefs and behaviors. Examining women at the beginning of their diagnosis for childhood trauma and providing targeted interventions for coping with that trauma presents a valuable research opportunity. The findings of the current study suggest that more research is required to understand the association between CSA and HIV-related risk factors in this subset of the HIV-positive population. 


\section{TABLE OF CONTENTS}

CHAPTER

PAGE

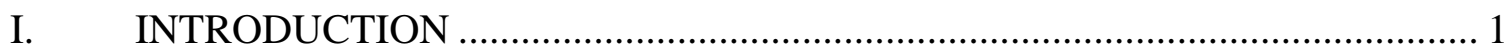

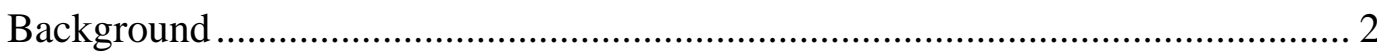

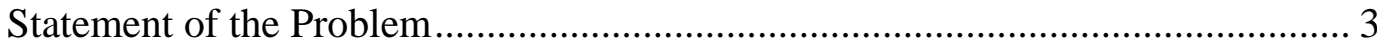

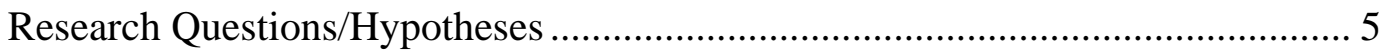

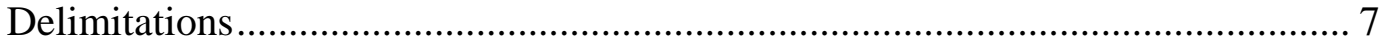

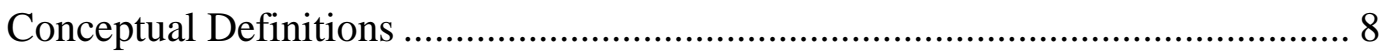

II. LITERATURE REVIEW ...................................................................... 11

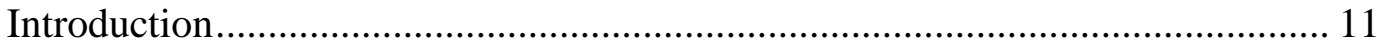

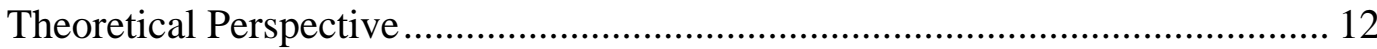

Childhood Sexual Abuse................................................................................. 21

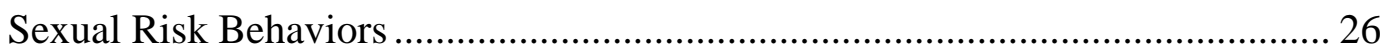

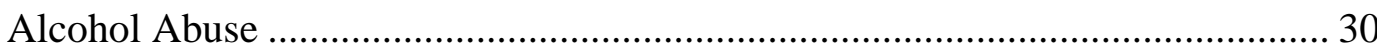

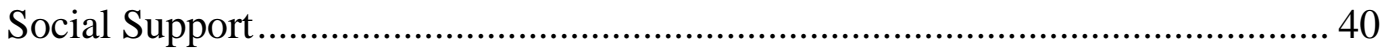

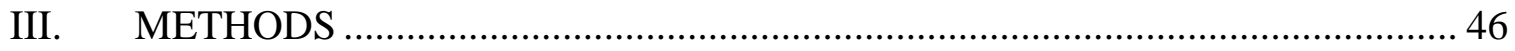

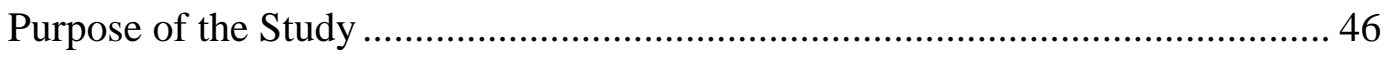

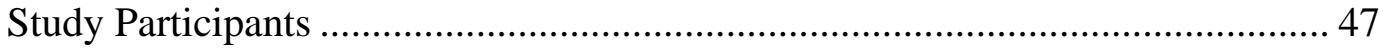

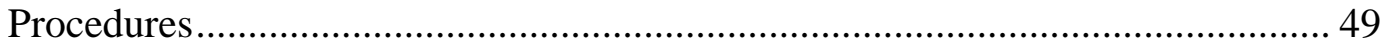

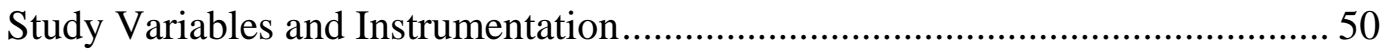

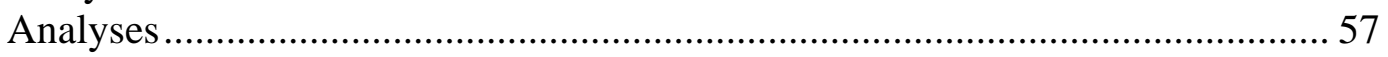

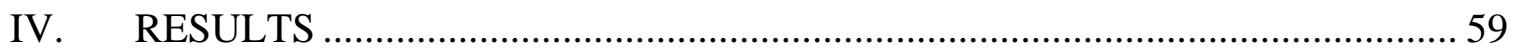

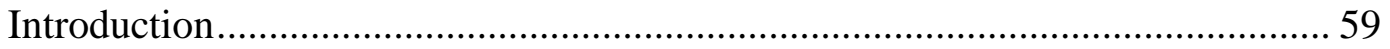

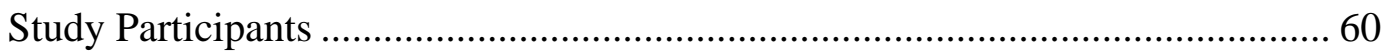

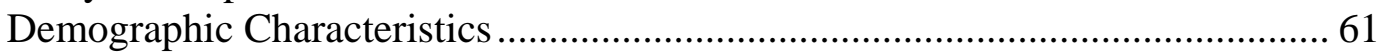

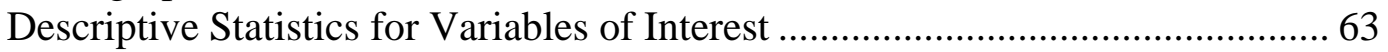

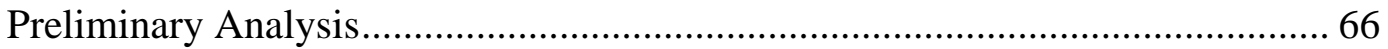

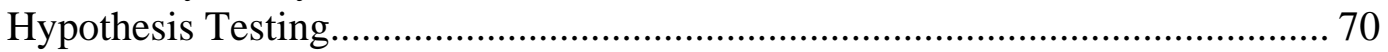

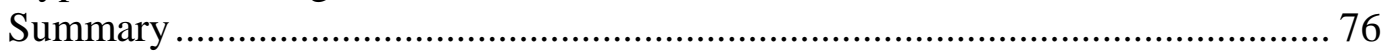

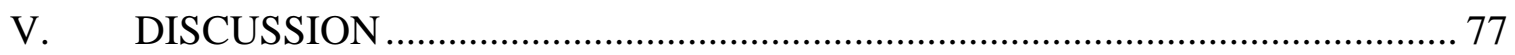

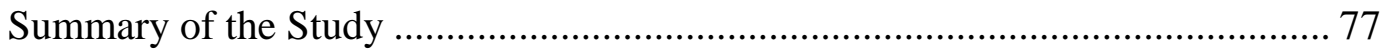

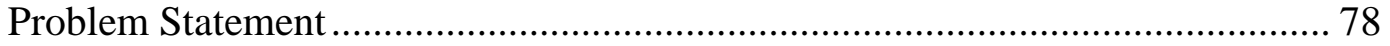

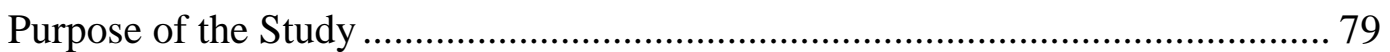

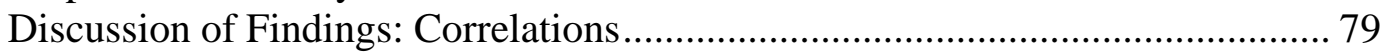

Discussion of Findings: Research Questions ................................................. 82

Implications for Public Health and Recommendations ..................................... 91

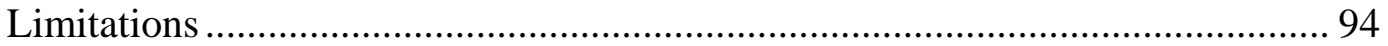




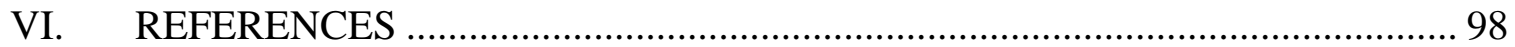

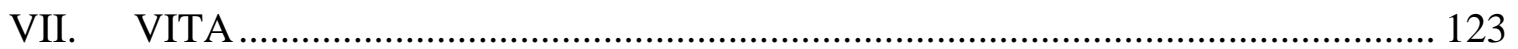




\section{LIST OF TABLES}

TABLE

PAGE

1. Proposed Model Conceptualizing the Influence of the Theory of Gender and Power on Women's Health ................................................................................. 15

2. Theory of Gender and Power (Adapted from Wingood \& DiClemente, 2002).... 16

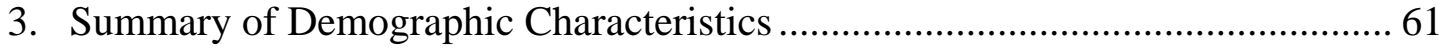

4. Descriptive Characteristics and Summary of Variables of Interest ..................... 63

5. Statistical Outcomes for Correlational Analysis of Variables ............................. 68

6. Descriptive Characteristics of Sexual Risk Behaviors by CSA Group................. 70

7. Post-Hoc Analyses for Condom Attitudes Scores between Groups ..................... 71

8. Descriptive Characteristics of Level of Alcohol Use by CSA Group .................. 73

9. Post-Hoc Analyses for Level of Alcohol Use between Groups............................ 74

10. Descriptive Characteristics of Perceived Social Support by CSA Group.............. 75 


\section{CHAPTER I \\ INTRODUCTION}

The number of women with human immunodeficiency virus (HIV) living in Haiti has significantly increased since the year 2000, even though the overall HIV prevalence rate for the country is declining (UNAIDS, 2014; UNAIDS, 2013a; UNAIDS, 2008). According to the latest Joint United Nations Programme on HIV/AIDS (UNAIDS) Gap Report (2014), of the 130,000 adults (ages 15+) living with HIV in Haiti in 2013, 74,000 of them (60\%) are women. This proportion represents an increase from $46 \%$ in 2000 and 53\% in 2007 (UNAIDS, 2013a; UNAIDS, 2008). Retrospective analyses have indicated that some of the most common risk factors associated with HIV infection among Haitian women living in Haiti include multiple lifetime sexual partners, lack of condom use within or outside of monogamous relationships, lack of education, and economic hardship (Logie, Daniel, Newman, \& Loutfy, 2012; Rosenberg, Seavey, Jules, \& Kershaw, 2011; Fawzi et al., 2010; Fawzi et al., 2003; Deschamps \& Pape, 1996). While these risk factors appear to be the most common among Haitian women infected with HIV, other risk factors, such as childhood sexual abuse, may also contribute to the prevalence of HIV among this population.

Childhood sexual abuse (CSA) is one of the least studied HIV-related risk factors in Haiti and other low-resource settings, even though research in the United States and Europe have clearly established the link between childhood trauma, CSA, and high risk sexual behaviors (Senn \& Carey, 2010; Whetten et al., 2008; Malow, Dévieux, \& Lucenko, 2006; Malow et al., 2006; Myers et al., 2006; Wyatt, Myers, \& Loeb, 2004; Wyatt et al., 2004; Wyatt et al., 2002; Whetten et al., 2008). Wyatt and colleagues 
(2004) found that "women who report early and chronic sexual abuse have a 7-fold increase in HIV-related risk behaviors and markers of risk compared with no abuse histories” (p. 660). Research also indicates that CSA is a significant risk factor for HIVpositive women across all racial groups (Wyatt et al., 2002). Understanding the role and impact of CSA and other related risk factors on Haitian women living with HIV is likely to strengthen future HIV prevention and treatment efforts aimed at this vulnerable group.

The current study was a cross-sectional examination of baseline data collected during a randomized trial of a cognitive-behavioral stress management (CBSM) intervention for simultaneously enhancing safer sex practices, adherence to anti-retroviral (ARV) medication, and reducing alcohol or other drug (AOD) use in a predominantly poor urban population in Haiti. The current study examined the association between sexual abuse during childhood and current risky sexual behaviors, level of alcohol use, and social support of HIV-seropositive Haitian women. The study also analyzed the demographics of the study population in order to determine if there was a need to control for demographic variables.

\section{Background}

According to the most recent UNAIDS Global Report, an estimated 130,000 adults (ages 15+) living in Haiti were living with HIV in 2013 which represents an adult prevalence rate of 2.0\% (UNAIDS, 2014). Prior to the 2013 estimates, Haiti was already experiencing a steady decline in its adult HIV prevalence rate which was $2.9 \%$ in 2001 and 2.2\% in 2007 (UNAIDS, 2013a; UNAIDS, 2008). Even with the decline, Haiti still had the second highest HIV prevalence rate in the Caribbean in 2013. Bahamas had the highest rate, with an adult HIV prevalence rate of 3.2\% in 2013 (UNAIDS, 2014; 
UNAIDS, 2013b; UNAIDS, 2010a; UNAIDS, 2010b; UNAIDS, 2010c). The Caribbean has the second highest HIV seropositive rates in the world—second only to sub-Saharan Africa (UNAIDS, 2014; UNAIDS, 2013a; UNAIDS, 2013b). Further analysis of existing data shows that more women are living with HIV in Haiti than men (UNAIDS, 2014).

Since the 1980s, Haitian women living in Haiti and infected with HIV have primarily contracted the disease through heterosexual contact (UNAIDS, 2013b; De Cock, Jaffe, \& Curran, 2012; Dévieux, et al., 2009; Deschamps, 2000; Padian, 1987; Pape \& Johnson, 1993; Pape et al., 1990). Additional research indicates that injection drug use and blood transfusions are infrequent in this population (Cock, Jaffe, \& Curran, 2012; Deschamps, 2000; Adrien, Boivin, Tousignant, \& Hankins, 1990; Collaborative Study Group of AIDS in Haitian-Americans, 1987; Pape et al., 1986). As previously mentioned, $60 \%(74,000)$ of the individuals living with HIV in Haiti are women (UNAIDS, 2014). Given this information, it is important to examine the various contextual and social factors that may be contributing to the rising percentage of Haitian women contracting HIV through heterosexual contact when the overall prevalence rate in the country is declining. The factors examined in this study are childhood sexual abuse, HIV-related risk behaviors (detailed below), level of alcohol use, and the women's social support, which include their perception of current social supports, the balance of power or relationship control in sexual decision-making with their primary partners, as well as their susceptibility to violence in those relationships.

\section{Statement of the Problem}

The primary purpose of this study is to analyze the association between childhood sexual abuse (CSA) and HIV-related risk behaviors (e.g. number of lifetime 
partners, condom attitudes, HIV-related knowledge, and sexual self-efficacy) in a group of Haitian women who are HIV-positive alcohol users living in Haiti. Additionally, this study aims to examine the association between CSA and other HIV-related risk factors including level of alcohol abuse, and social support in this group of women.

Significance of the study. Currently, there are no studies that specifically examine the association between CSA and HIV-related risk factors for HIV positive women living in Haiti. When discussing HIV infection, risk reduction and prevention efforts in Haiti, it is imperative to address the risk factors that may have an impact on sexual risk behaviors. Understanding the psychological impact CSA has had on victims and how their coping strategies translate into their current risk behaviors, attitudes, and relationships is essential to truly making a positive impact on the overall health of Haitians. By analyzing childhood sexual abuse among HIV-positive alcohol using Haitian women, the doors open to not only discussions surrounding the development of interventions that may be helpful to the study population, but may also translate into discussions on prevention efforts for the rest of the population that is at risk for HIV infection.

Interventionists can expand the results of this study to include discussions on the role childhood sexual abuse plays in the lives of women who currently live with HIV and who possibly still exhibit high risk behaviors in order to develop interventions that provide such women with coping strategies that may positively affect negative beliefs, encourage safer sex practices where applicable, and promote positive relationships within their support networks. Likewise, interventionists may be able to provide uninfected 
persons with coping strategies to deal with childhood sexual abuse that may reduce their risk for HIV infection.

\section{Research Questions/Hypotheses}

Given the limited literature on the impact of CSA on HIV-related risk factors for HIV-positive women living in Haiti, this study is designed to answer the following research questions:

Question 1: What is the difference in the sexual risk behaviors (e.g. sex with multiple partners, condom attitudes, knowledge of HIV, and sexual self-efficacy) of participants who had exposure to CSA compared to those participants who did not have any exposure to CSA?

- Hypothesis \#1: Participants who had exposure to CSA will exhibit greater sexual risk behaviors than those participants who did not have any exposure to CSA.

- Null Hypothesis \#1: Participants who had exposure to CSA will not exhibit statistically greater sexual risk behaviors than those participants who did not have any exposure to CSA.

Question 2: What is the difference in the level of alcohol use by participants who had exposure to CSA compared to those participants who did not have any exposure to CSA?

- Hypothesis \#2: Participants who had exposure to CSA will have higher levels of alcohol use than those participants who did not have any exposure to CSA. 
- Null Hypothesis \#2: Participants who had exposure to CSA will not have higher levels of alcohol use than those participants who did not have any exposure to CSA.

Question 3: Is there a relationship between CSA and social support among HIVpositive women living in Haiti?

o Hypothesis \#3.1: Participants who had exposure to CSA will have lower perceptions of social support (family, friends, partners and doctors) than those participants who did not have any exposure to CSA.

o Null Hypothesis \#3.1: Participants who have exposure to CSA will not have lower perceptions of social support (family, friends, partners and doctors) than those participants who did not have any exposure to CSA.

o Hypothesis \#3.2: Participants who had exposure to CSA will exhibit lower degrees of relationship power with primary partners than those participants who did not have any exposure to CSA.

o Null Hypothesis \#3.2: Participants who had exposure to CSA will not exhibit lower degrees of relationship power with primary partners than those participants who did not have any exposure to CSA.

o Hypothesis \#3.3: Participants who had exposure to CSA will be more susceptible to violence in their relationships with primary 
partners than those participants who did not have any exposure to CSA.

o Null Hypothesis \#3.3: Participants who had exposure to CSA will not be more susceptible to violence in their relationships with primary partners than those participants who did not have any exposure to CSA.

\section{Delimitations}

The data used in this study is from the parent study titled, "Intervening with Haitian HIV-Positive Alcohol Users: An Environmental Psychosocial Framework,” which was conducted by the AIDS Prevention Program at Florida International University. The study was a five-year randomized controlled HIV risk-reduction intervention study that was implemented among HIV-positive adults with high-risk behaviors living in a resource-constrained setting.

The scope of this current study is limited to baseline data and does not analyze the follow up data that was collected over the course of the five-year period of the study. The advantage of using baseline data, particularly with the sample size of the parent study, is that the dataset is complete and includes the largest sample size possible for analysis. Additionally, a cross-sectional study of this kind allows for analysis of the association between childhood sexual abuse and the related risk factors.

The current study focuses on HIV-positive Haitian women living in Haiti although the parent study collected data on men and women. The choice to focus on data that represents the female population of the parent study is due to the increasing number 
of new HIV infections among women in a country where HIV continues to be a public health concern.

\section{Conceptual Definitions}

For the purposes of this study, the following words and phrases have particular meanings as detailed below. Other terms that are not frequently used but may require definitions will be explained as they are introduced.

Childhood Sexual Abuse. Childhood sexual abuse is the involvement of a child in sexual activity that he or she does not fully comprehend, is unable to give informed consent to, or for which the child is not developmentally prepared and cannot give consent, or that violates the laws or social taboos of society. Childhood sexual abuse is evidenced by this activity between a child and an adult or another child who by age or development is in a relationship of responsibility, trust or power, with the activity being intended to gratify or satisfy the needs of the older person (National Child Traumatic Stress Network, 2015; World Health Organization, 1999).

Childhood Trauma (Abuse). Childhood trauma is a repeated pattern of damaging interactions between parent(s) or other significant adults and a child that becomes typical of the relationship. These interactions include physical, sexual, emotional, or verbal abuse (AAP, 1992). Childhood trauma also includes child abuse in all its forms with child abuse or maltreatment constituting all forms of physical and/or emotional ill-treatment, sexual abuse, neglect, or negligent treatment or commercial or other exploitation, resulting in actual or potential harm to the child's health, survival, development, or dignity in the context of relationship, trust, or power (WHO, 1999). 
Cross-Sectional Study. A cross-sectional study is an observational study that examines the relationship between a health-related state (in this case, incidents of childhood sexual abuse) and other variables of interest (HIV-related risk behaviors) as they exist in a defined populations at a single point in time (PHAST, 2011).

HIV-Related Risk Behaviors. In this study, HIV-related risk behaviors refer to behaviors that place an individual at risk for contracting or transmitting HIV: sex with multiple partners, poor attitudes about condom use, poor knowledge of HIV, low sexual selfefficacy in primary relationships, and alcohol abuse.

Mediating Factor. For the purposes of this study, a variable (marital status, education, age) that affects the direction and/or strength of the relationship between an independent variable and a dependent variable.

Power Imbalance. An imbalance in a relationship where one individual feels controlled by the other. For the purposes of this study, power imbalance and relationship control are used interchangeably.

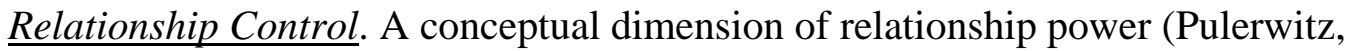
Gortmaker, \& DeJong, 2000) that focuses on the sense of control or decision-making an individual has in her primary partner relationships (Teitelman, Ratcliffe, MoralesAleman, \& Sullivan, 2008): This definition also includes partner influence over the relationship. For the purposes of this study, power imbalance and relationship control are used interchangeably.

Sexual Self-Efficacy. A person's perceived ability to behave in ways that will successfully prevent HIV transmission (Randall, 2008); “confidence in one’s ability to use protective behaviors or safe-sex practices to: (1) refuse engaging in any type of sexual behavior, (2) 
communicate with partner about condom use, and (3) purchase and use condoms” (Basen Engquist et al., 1999, p. 26).

Social Support. The perception and actuality that an individual is cared for, has assistance available from other people, and that he/she is part of a supportive social network. Susceptibility to Violence. One's risk or chances of experiencing physical or emotional violence in primary partner relationship.

The next chapter will review past and current literature on the subjects relevant to the research questions discussed above, namely, sexual risk behaviors (including knowledge and practice, condom use, and sexual self-efficacy), level of alcohol use, and social support (perception of social support from family, friends, primary partners, and doctors, relationship control, and susceptibility to violence), and childhood sexual abuse. 


\section{CHAPTER II}

\section{LITERATURE REVIEW}

\section{Introduction}

Individuals exposed to trauma during childhood such as childhood sexual abuse often experience negative health and behavioral outcomes including HIV transmission (LeGrand et al, 2015, Willie et al., 2015; O’Cleirigh, Safren, \& Mayer, 2012;

Machtinger, Wilson, \& Haberer, 2012). Studies have also found that exposure to CSA is more prevalent among people living with HIV across different HIV risk groups compared to the general population (LeGrand et al., 2015, Willie et al., 2015, Borwein, 2013;

O’Cleirigh, Safren, \& Mayer, 2012; Machtinger, Wilson, \& Haberer, 2012; Whetten et al., 2008). The consequences of CSA do not end with contracting HIV. Recent studies have reported that people living with HIV/AIDS (PLWH) who have been exposed to CSA still exhibit more at-risk sexual behaviors after infection than PLWH who were not exposed to CSA (Parcesepe, 2015; O’Cleirigh, Safren, \& Mayer, 2012; Pence et al., 2012). These “at-risk behaviors” and poor health outcomes include many of this study’s variables of interest namely unprotected sex with multiple partners, increased alcohol use, and intimate partner violence. The rising number of new HIV infections among women across the globe, including Haiti. (Parcesepe, 2015; UNAIDS, 2014; Machtinger, Wilson, \& Haberer, 2012; Pence et al., 2012) combined with the fact that women are most often the victims of CSA (Parcesepe, 2015; O’Cleirigh, Safren, \& Mayer, 2012), underscores the importance of studying the link between CSA and current HIV-related risk factors. 
The following literature review will be organized into sections that delineate and reflect the scope of the problem and examination of the major research questions as they pertain to childhood sexual abuse, sexual risk behaviors, alcohol use, and social support within the population of interest. A thorough review of the literature has been conducted in each area. Discussion will include the outcomes, trends, and recommendations as presented by these valuable studies. The considerable body of literature to present covering the link between childhood sexual abuse and sexual risk behaviors that lead to HIV, the nature and consequences of intimate partner violence, and the impact of HIV in Haiti will be presented. However, some topics such as childhood sexual abuse in Haiti have sparse literature available. For detailed information on these and the other measures used to define each construct of the study, refer to Chapter III.

\section{Theoretical Perspective}

The theory that serves as the theoretical foundation for this study is the Theory of Gender and Power (TGP; Connell, 1987; Wingood \& DiClemente, 2002). Researchers Gina Wingood and Ralph DiClemente have applied TGP in HIV/AIDS research to understand women's HIV-related risk (in comparison to men's HIV-related risk) in the context of gender inequality and unequal access in order to develop effective HIV prevention programs targeted towards women (Wingood \& DiClemente, 2002).

Theory of Gender and Power. Originally developed by Robert Connell (1987), TGP is a social structural model that utilizes three overlapping structures that exist at societal and institutional levels to better understand gender-based inequities and disparities (Wingood \& DiClemente, 2002). These structures are the sexual division of labor, the sexual division of power, and cathexis (examination of social norms and 
affective attachments). Specifically for public health intervention, Wingood and DiClemente (2002) adapted an extended version of TGP in order “ $\ldots$ to examine the exposures, the social and behavioral risk factors, and the biological properties that increase women's vulnerability for acquiring HIV” (p. 313). In the extended version of the theory, the three structures generate different exposures and risk factors that influence women's risk for HIV. Wingood and DiClemente define the exposures as external variables that may influence a woman's sexual risk behavior, thereby increasing her likelihood of becoming infected with HIV.

Having limited family support is one important exposure defined by theory (Wingood \& DiClemente, 2002). Limited family support can lead to a number of exposures including partner violence, lack of financial support, unwanted dependence, homelessness, and abuse, both physical and mental, as well as childhood and adult abuse. In their version of TGP, Wingood and DiClemente add weight to this assertion by stating that exposures as described in the theory denote variables that come from within a woman and influences her risk for HIV, such as beliefs that do not support condom use and limited self-efficacy. For women who have already tested HIV-positive and have experienced childhood sexual abuse, there are assumptions that their exposure to sexual risk behaviors will continue, even after infection (Clark, Valera, \& Wilson, 2015; Chariyeva et al., 2013; Ncube et al., 2012; Kalichman et al., 2001). The following includes a proposed model and its expansion developed by Wingood and DiClemente (2002) to detail the extended version of TGP.

Proposed Models of TGP. Table 1 illustrates the three structures and their influence on gender roles. Although the women in this study are already HIV-positive, 
they still exhibit one or more of the characteristics that women at risk present, at each of the societal levels (Table 1). Additionally, one or more of the socioeconomic risk factors that describe the most vulnerable women at each structure also apply to this study population. 
Table 1

Proposed Model Conceptualizing the Influence of the Theory of Gender and Power on Women's Health

\begin{tabular}{|c|c|c|c|c|c|c|}
\hline Societal Level & $\begin{array}{l}\text { Institutional } \\
\text { Level }\end{array}$ & $\begin{array}{l}\text { Social } \\
\text { Mechanisms }\end{array}$ & Exposures & $\begin{array}{l}\text { Risk } \\
\text { Factors } \\
\end{array}$ & $\begin{array}{l}\text { Biological } \\
\text { risk factors }\end{array}$ & Disease \\
\hline & & $\begin{array}{l}\text { Manifested as } \\
\text { unequal pay; } \\
\text { produces }\end{array}$ & & & \multirow{6}{*}{$\begin{array}{l}\text { Anatomical } \\
\text { features } \\
\text { Hormones }\end{array}$} & \multirow{6}{*}{ HIV } \\
\hline $\begin{array}{l}\text { Sexual division of } \\
\text { labor }\end{array}$ & $\begin{array}{l}\text { Worksite, } \\
\text { school, and } \\
\text { family }\end{array}$ & $\begin{array}{l}\text { economic } \\
\text { inequities for } \\
\text { women }\end{array}$ & $\begin{array}{l}\text { Economic } \\
\text { exposures }\end{array}$ & $\begin{array}{l}\text { Socio- } \\
\text { economic } \\
\text { risk factors }\end{array}$ & & \\
\hline & & $\begin{array}{l}\text { Manifested as } \\
\text { imbalances in } \\
\text { control; } \\
\text { produce }\end{array}$ & & & & \\
\hline $\begin{array}{l}\text { Sexual division of } \\
\text { power }\end{array}$ & $\begin{array}{l}\text { Relationships, } \\
\text { medical } \\
\text { system, media }\end{array}$ & $\begin{array}{l}\text { inequities in } \\
\text { power for } \\
\text { women }\end{array}$ & $\begin{array}{l}\text { Physical } \\
\text { exposures }\end{array}$ & $\begin{array}{l}\text { Behavioral } \\
\text { risk factors }\end{array}$ & & \\
\hline & & $\begin{array}{l}\text { Manifested as } \\
\text { constraints in } \\
\text { expectations; } \\
\text { produce }\end{array}$ & & & & \\
\hline $\begin{array}{l}\text { Cathexis: social } \\
\text { norms and affective } \\
\text { attachments }\end{array}$ & $\begin{array}{l}\text { Relationships, } \\
\text { family, church }\end{array}$ & $\begin{array}{l}\text { disparities in } \\
\text { norms for } \\
\text { women }\end{array}$ & $\begin{array}{l}\text { Social } \\
\text { exposures }\end{array}$ & $\begin{array}{l}\text { Personal } \\
\text { risk factors }\end{array}$ & & \\
\hline
\end{tabular}

NOTE: The public health level includes exposures, risk factors, biological risk factors, and disease. The social/behavioral sciences level includes risk factors, biological factors, and disease. The medical level includes biological factors, and disease. 
Table 2

Theory of Gender and Power (Adapted from Wingood \& DiClemente, 2002)

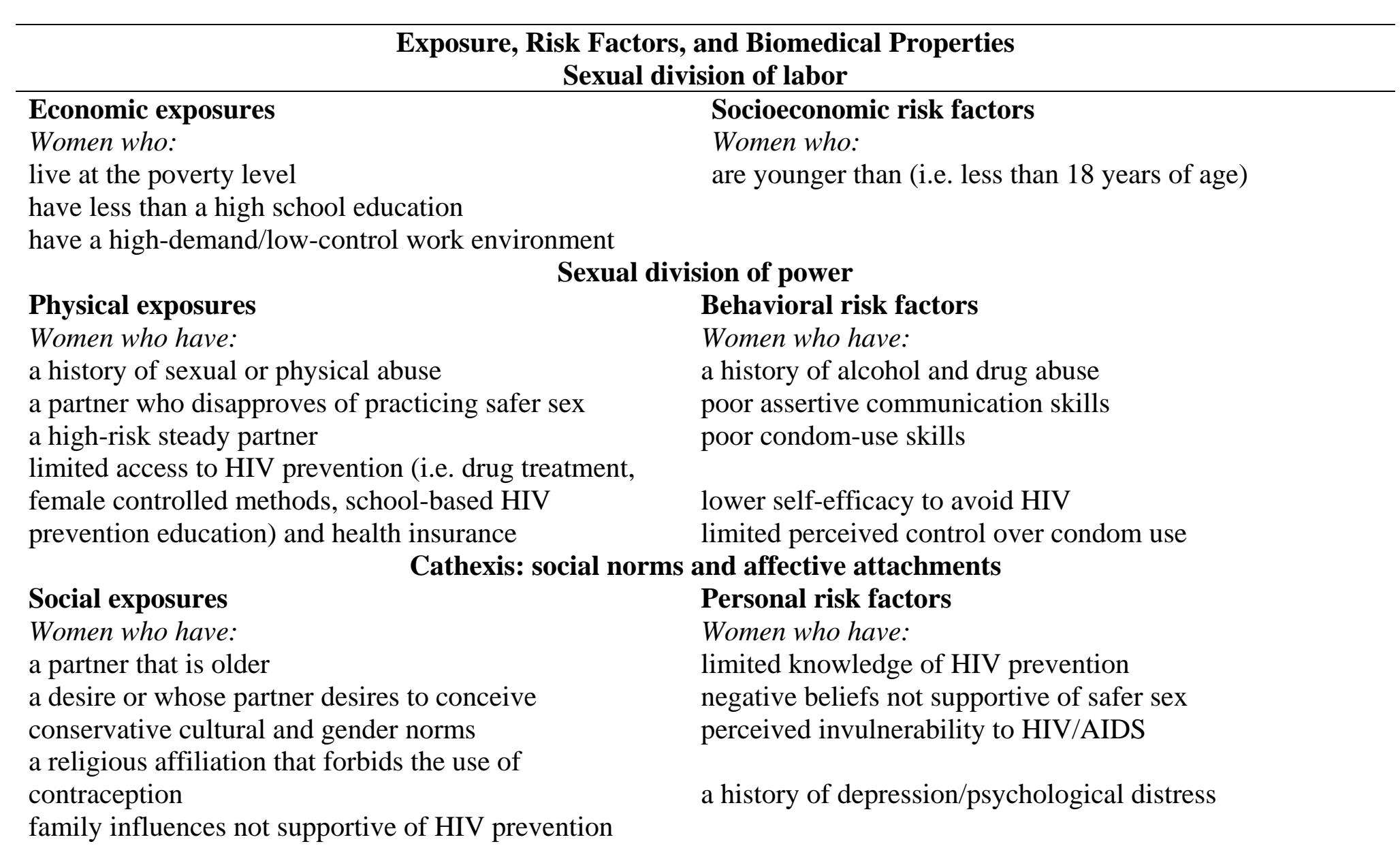

\section{Anatomical and biomedical properties}

Biological properties

HIV is transmitted more efficiently from men to 
women than women to men, as women are the receptive partner during sexual intercourse

STDs aside from HIV are also transmitted more

efficiently from men to women than women to men, and they can increase women's vulnerability to HIV

STDs are more asymptomatic in women; thus,

women may be less likely to seek treatment for STDs

and more likely to develop STD-related

complications (i.e. HIV) 
Table 2 details the examples of economic exposures. The sexual division of labor delves into the segregated notion of "men’s work" and "women's work” where "women’s work” remains undervalued. Wingood and DiClemente (2002) relate the issues associated with the sexual division of labor to HIV by purporting that as women are forced to become more dependent on men for economic security, the gap of economic inequity between men and women is widened, which puts women at a greater risk for HIV.

With the second structure, the sexual division of power, there is unbalanced power between the sexes. At the institutional level, Wingood and DiClemente (2002) describe the sexual division of power as "being maintained by social mechanisms such as the abuse of authority and control in relationships” (p. 320). Women in situations where the male partner has primary control of the relationship usually depend on the security of finances and typically experience "sexual degradation” (Wingood \& DiClemente, 2002, p. 320). The sexual division of power manifests itself through physical exposures and behavioral risk factors. The literature indicates that as the sexual division of power shifts in favor of the man in a relationship rather than being equally distributed between the man and woman, the woman's "sexual choices and behavior become constrained, thereby increasing her risk for HIV” (Wingood \& DiClemente, 2002, p. 320). The authors provide examples of physical exposures attributed to the imbalance of the sexual division of labor such as having an abusive or high-risk sexual partner, exposure to sexually explicit media that degrades women, and lack of access to condoms or appropriate treatment. Behavioral risk factors include using alcohol or drugs, reduced ability to negotiate safe sex, and the self-perception of powerlessness (Wingood \& DiClemente, 2002). 
The third and final structure is affective attachments and social norms. This structure refers to societal expectations of appropriate behavior for women as well as their emotional and sexual attachments to men. These societal expectations influence how women perceive themselves and may have an impact on their behavior. At the institutional level, this structure is demonstrated by the differences between women's and men's expression of their sexuality. Chiefly, women are subjected to stricter sexual norms than their male counterparts. For example, according to these norms, women are expected not to engage in premarital sex, are only to have sex for procreation, and should not touch their own bodies (Wingood \& DiClemente, 2002). The authors linked this concept of affective attachments and social norms to women's increased risk for contracting HIV by positing that women who do accept these beliefs are more likely to experience adverse health outcomes. These women are less likely to know about HIV prevention, have negative attitudes and beliefs about condoms, and have a history of depression or some form of psychological trauma (Wingood \& DiClemente, 2000).

Table 2 and its elaboration of the exposures, risk factors, and biological properties critical to TGP on women's health are most important in the current proposed study that involves HIV-positive Haitian women who are also alcohol users. Table 2 (as adapted) describes the types of women and circumstances that increase their vulnerability to HIV infection based on each structure.

According to the Central Intelligence Agency World Fact Book (2013), Haiti is the poorest country in the Western Hemisphere with $80 \%$ of the population (9.8 million) living in poverty, a $52.9 \%$ literacy rate, $40.6 \%$ unemployment (with two-thirds of the population underemployed), and only 6\% of the GDP going to health expenses. 
Therefore, under the sexual division of labor structure of the TGP, a large number of Haitian women living in Haiti experience the following economic exposures: live at the poverty level, have less than the equivalent of a high school education, have no employment or are underemployed, and have limited or no health insurance.

A review of the physical exposures and behavioral risk factors listed under the sexual division of power highlights a behavioral risk factor specific to the women in this study—a history of alcohol or drug abuse. Finally, under the structure of norms and affective attachments, there are social exposures and personal risk factors that are applicable to Haitian women living in Haiti, independent of their participation in the parent study. The applicable social exposures include women who have a desire or whose partners desire to conceive and women who have conservative cultural and gender norms. Negative beliefs not supportive of safer sex represents the applicable personal risk factor for women in this study. For instance, women often have negative associations with condom use, including the belief that it leads to genital disease (Conserve, Whembolua, \& Surkan, 2014; Malow et al., 2000; Ulin, Cayemittes, \& Metellus, 1995). Additionally, cultural norms may predispose them to an increased risk for HIV infection. Specifically, childbearing is an essential part of Haitian culture, which is $80 \%$ Roman Catholic-a religion known for its practice of conservative norms (Marc et al., 2010; Malow et al., 2000). With childbearing being so important, condom use is likely to decrease.

The Theory of Gender and Power [on women’s health] provides a useful framework for this study in that it includes all of the elements needed to understand the behaviors, risk factors, and societal expectations that impact women's ability to take control of their health and the consequences associated with those actions. Most 
importantly, Wingood and DiClemente’s (2002) work in applying the TGP to women’s risk for acquiring HIV is important in guiding prevention efforts for reducing the spread of HIV infection to uninfected persons.

\section{Childhood Sexual Abuse}

There is strong evidence to indicate that childhood sexual abuse is an important risk factor for HIV infection among women (LeGrand et al., 2015; Willie et al., 2015; O’Cleirigh, Safren, \& Mayer, 2012; Machtinger, Wilson, \& Haberer, 2012; Jones et al., 2010b, Zieler, et al., 1991). However, there is limited research on the subject in lowresource settings such as Haiti, Mongolia, Latin America, the Caribbean, and Francophone African countries (Parcesepe et al., 2015; Longman-Mills et al., 2013; Lanius, Vermetten, \& Pain, 2010; Whetten et al., 2008; Masinda \& Muhindo, 2004; DeJong et al., 2001). Where the research does exist in third world or low-resource settings such as parts of Asia, the Middle East, and English-speaking African countries like Rwanda and South Africa, it primarily focuses on childhood trauma due to war, famine, and natural disasters, with some research dedicated to sexual abuse in South Africa (LeGrand et al., 2015; Richter et al., 2014; Lanius, Vermetten, \& Pain, 2010; Masinda \& Muhindo, 2004). High HIV prevalence rates (although declining), sexual risk behaviors, poverty, low education rates, and power imbalances in sexual relationships (which will be discussed later in this literature review) continue to be significant HIVrelated risk factors for Haitian women living in Haiti (Dévieux et al., 2015; Cayemittes, 2013; Malow et al. 2000; Deschamps \& Pape, 1996; Ulin, Cayemittes, \& Metellus, 1995). Nonetheless, with research on childhood sexual abuse as it relates to HIV/AIDS 
being limited in the country, as with so many other low-resource countries, there is likely vulnerability in prevention and intervention efforts that have yet to be addressed.

Relationship between HIV and childhood sexual abuse. Studies have long established that victims of CSA exhibit greater sexual risk behaviors than persons who have not experienced CSA (Parcesepe et al., 2015; O’Cleirigh, Safren, \& Mayer, 2012; Sikkema et al. 2013; Pence et al., 2012; Jones, et al., 2010b; Whetten, 2006; McCauley et al, 1997). The few studies conducted in developing countries on the matter have also produced the same results, indicating the pervasiveness of higher levels of sexual risk behaviors among victims of CSA, regardless of country of origin (Parcesepe et al., 2015; Richter et al., 2014; Longman-Mills et al., 2013; Tomaszewski, 2012). Jones and colleagues (2010b) noted that the accepted hypothesis is that CSA "results in a sense of powerlessness that may undermine the self-efficacy critical to navigating relationships, including sexual relations, increasing the likelihood that alcohol, for example, may be used to cope with impending sexual encounters” (p. 668). For various reasons, including numbing the pain, gaining acceptance, and punishing oneself, victims of sexual abuse are more likely to abuse drugs and alcohol, have multiple sexual partners, and have more incidents of unprotected sex than non-victims (Jones et al., 2010b). In turn, victims of CSA are more likely to contract HIV than those who have not experienced CSA.

Closer examination of the relationship between childhood trauma and the sexual risk behaviors of women (both HIV-negative and HIV-positive) has been presented through multiple studies over the years (LeGrand et al., 2015; Brezing, Ferrara, \& Freudenrich, 2014; Schwartz et al., 2014; Whetten et al., 2008; Paxton et al., 2006; Wyatt, Myers, \& Loeb, 2004; Cohen et al., 2000). For instance, Brezing, Ferrara, and 
Freudenrich (2015) conducted a review of literature on the syndemic illness of HIV and trauma. The purpose of the literature review was to propose a trauma-informed model of care to target the aggregation of HIV and trauma that exacerbates the negative health effects of both HIV and trauma. In their research, Brezing and her colleagues (2015) noted that HIV-positive individuals reported a history of childhood physical or sexual abuse 1.5-2 times greater than the general population. Specially, $66 \%$ of HIV-infected women reported a history of childhood physical to sexual abuse. HIV-positive women experienced intimate partner violence at a rate of $55.3 \%, 5$ times more than the general population. They also had post-traumatic stress disorder (PTSD) at a rate of 30\%, in comparison to $15 \%$ in the general population (Brezing et al., 2015). When specifically examining at gender differences, 55\% of HIV-infected women experienced acute stress disorder compared to 38\% of men. Burgos-Soto and colleagues (2014) reported similar results in their study, with HIV-infected women exhibiting a higher frequency of lifetime physical and sexual abuse than did uninfected women.

And in their 2006 study, Whetten and colleagues found that 25\% of HIV-infected individuals were sexually abused before the age of 13; one-third experienced lifetime sexual abuse; and, more than $50 \%$ experienced sexual or severe physical abuse by the time of the study.

Prior to these studies, Wyatt, Myers, and Loeb (2004) noted the same findings in their examination of three studies that investigated the relationship between trauma and the sexual risk behaviors of women. All three studies established that traumatic experiences are prevalent among people living with HIV, as well as among those who are at risk for infection, including a report that $31 \%$ of HIV-positive women and $27 \%$ of 
HIV-negative women who were at high risk for HIV infection reported childhood sexual abuse (Cohen et al., 2000). One study in particular by Paxton and colleagues (2004) examined childhood trauma, other traumas, and psychosocial variables as predictors of risk behaviors in a multi-ethnic sample of women who were both HIV-negative and HIVpositive. Their research found that women who experienced some level of trauma were 5.1 times more likely to engage in risky behaviors than those who had not experienced trauma.

With data and a myriad of studies to support the strong association between CSA and lifetime of high-risk behaviors including alcohol and drug use and multiple partners (Sikkema et al. 2013; O’Cleirigh, Safren, \& Mayer, 2012; Pence et al., 2012; Brown, Lourie, Zlotnick, \& Cohn, 2000; Cohen et al., 2000; Zierler et al., 1991), Wyatt, Myers, and Loeb (2004) stressed the importance of addressing trauma when working with women who are HIV-positive. The researchers stated that trauma is prevalent in this population and "early exposure (e.g. CSA), current exposure, and perpetration exacerbate risk by affecting sexual decision-making and psychological adjustment” (p. 403).

In 2008, Sikkema and colleagues attempted to address the influence of trauma by conducting a randomized controlled trial (RCT) comparing a 15-session coping group intervention to a 15-session therapeutic support group to determine the effects of a coping intervention for people living with HIV/AIDS and who had a history of CSA. The results indicated that participants in the trauma coping arm of the RCT decreased the frequency of unprotected sexual intercourse significantly more than the participants in the therapeutic arm of the intervention at all follow-up points. More recently, Sikkema and colleagues (2013) conducted a yearlong RCT on the effectiveness of a group intervention 
entitled Living in the Face of Trauma (LIFT) to address coping with HIV and childhood abuse. In this randomized trial of 247 participants, researchers found that participants in the coping intervention reduced their traumatic stress and use of avoidant coping strategies more than participants in the support intervention. While the results of these studies are promising, there is still a lack of HIV interventions that effectively address and include coping strategies for CSA (Sikkema et al., 2013; Sikkema et al., 2008; Wyatt, Myers, \& Loeb, 2004; Wyatt et al., 2002).

HIV interventions that effectively incorporate coping strategies are important to disease management because traumatic events overall, mental illness, distrust, and stigma all link to poorer adherence to medication regimens and HIV risky behavior (O’Cleirigh, Safren, \& Mayer, 2012; Pence et al., 2012; Whetten et al., 2008). Research has concluded that there is, in fact, enough evidence to indicate that HIV-positive persons in the U.S. and Western Europe have a substantially greater history of trauma than that of the general population (LeGrand et al., 2015; Borwein et al., 2014; Parcesepe et al., 2014; LongmanMills et al., 2013; Whetten et al., 2008).

As discussed, the majority of studies conducted in the United States, Canada, and Western Europe highlight the fact that there is a great need to increase research in poorer nations to determine ways to improve disease outcomes and quality of life (Parcesepe et al., 2015; Longman-Mills et al., 2013; Lanius, Vermetten, \& Pain, 2010; Whetten et al., 2008; Sikkema et al., 2008; Malow et al., 2006; Myers et al., 2006; Masinda \& Muhindo, 2004; Wyatt, Myers, \& Loeb, 2004; Wyatt et al., 2004; Wyatt et al., 2002; DeJong et al., 2001). These and other recent studies underscore the need to address CSA and various levels of trauma when addressing HIV risk reduction programs, regardless of the 
racial/ethnic background of the participants. Additionally, addressing the severity of abuse may help interventionists tailor programs that target very specific issues affecting HIV-related risk behaviors (Sikkema et al., 2013; Sikkema et al., 2008; Myers et al., 2006). In order to begin this type of work in nations with fewer resources, such as Haiti, one must attempt to understand how CSA affects the HIV-related risk behaviors among individuals living with HIV in these countries.

In this study, childhood sexual abuse among Haitian women was examined in association with HIV-related factors such as sexual risk behaviors (e.g. number of lifetime partners, condom use, HIV-related knowledge, and sexual self-efficacy), levels of alcohol use, and social support.

\section{Sexual Risk Behaviors}

The "Mortality, Morbidity, and Utilization of Services Survey: Haiti 2012" or EMMUS-V (Cayemittes, 2013) studied approximately 14,287 women (ages 15-49) and 9,493 men (ages 15-59) living in Haiti who completed surveys that assisted in estimating socio-economic, demographic, and medical indicators in the country, including items related to HIV/AIDS. In the EMMUS-V, a small percentage (2\%) of women interviewed had multiple partners over the twelve months prior to the survey. However, only $43 \%$ of those women reported using condoms during their last sexual encounter (Cayemittes, 2013). In addition, while few studies reported a strong association between HIV infection and multiple partners among Haitian women, the majority of available literature confirmed that partner infidelity is common within the population. In essence, Haitian women tended to have unprotected sex with non-monogamous primary partners which contributes to the heterosexual transmission of HIV in the country (Dévieux et al., 2015; 
Rahill, Joshi, \& Hernandez, 2015; Malow et al., 2006; Malow, 2000). In recent years, high rates of sexual abuse and forced sex, combined with poverty-induced transactional sex has also contributed to unprotected sex among the female population in Haiti, leading to an increase in HIV transmission ((Dévieux et al., 2014; Malow, Rosenberg, Lichtenstein, \& Dévieux, 2010)

Lack of education and low HIV knowledge has also proven to be a contributor to the high rates of HIV among women in Haiti. According to the Office of the Special Envoy for Haiti (OSEH, 2012), the illiteracy rate for adults, 13 and over (as defined by OSEH), prior to January 2010, was 57.24\% (59.14\% of women and $55.27 \%$ of men). Many factors account for the high illiteracy rates in Haiti, beginning with the primary education system. These include lack of access to schools for those living in rural areas, space in public schools for basic education, poor education quality due to funding issues, and the fees parents must pay to enroll their children in the public school system (OSEH, 2012). Naturally, these issues have long-lasting effects that carry into adulthood, such as the inability to understand public health materials, reliance on verbal transmission of information which can often be skewed, and embarrassment that may influence an individual's desire to ask questions about his/her health.

As noted earlier, women are most affected by the high illiteracy rates once they reach adulthood. The United States Institute of Peace (USIP) (2012) reiterates the fact that almost $60 \%$ of Haitian women cannot read and write. More specifically, nearly $25 \%$ of women in urban areas have completed secondary school, while only $2 \%$ of women in rural areas have done the same. 
Globally, there is a strong initiative to increase access to education for women and girls, especially in developing countries like Haiti. The danger of not doing so is voiced by Dr. Paul Farmer, United Nations (UN) Deputy Special Envoy for Haiti and co-founder of Partners in Health. Dr. Farmer states: "When girls are not educated, eventually by and large mothers will not be educated. And when mothers are not educated, they often live in poverty. And when they live in poverty, their children are vulnerable to all sorts of illnesses, including easily preventable ones. So the downside of not having girls’ education is enormous...you will never break the cycle of poverty or disease without educating girls. It won’t happen” (Farmer, 2012, p. 1). These mothers have daughters who grow up with a lack of the same information, creating a vicious cycle of misinformation and/or lack of action that undoubtedly affects many aspects of their lives including reproductive health.

Prime examples of misinformation and/or lack of action are evident in reports and articles over the years that examine the beliefs Haitian women have about HIV testing, transmission, and condom use. For instance, Malow and colleagues (2000) surveyed 101 Haitian women about their beliefs on condom use. In general, the women reported that they believed they were susceptible to HIV yet they had relatively little HIV-related anxiety. They acknowledged that there were inadequate levels of communication regarding safer sex practices as well as a lack of confidence in their ability to negotiate safer behaviors in sexual encounters or their ability to introduce condom use. Dévieux and colleagues (2009) found similar results in their study that examined the knowledge, attitudes, and behaviors of a high-risk sample of women attending the main HIV testing and treatment facility in Haiti. In their study of over 43,000 women entering the center 
between March 1999 and December 2004, the researchers found that both HIV-positive and HIV-negative women had favorable attitudes towards HIV testing and knowing their results. However, approximately $50 \%$ of both groups had inaccurate beliefs about the transmission of HIV, including the belief that it could be transmitted by mosquitoes or through supernatural means.

In the study, HIV-positive women were even less knowledgeable about the actual modes of HIV transmission compared to HIV-negative women. For instance, only 58\% of HIV-positive women were able to answer accurately the questions about sexual HIV transmission in comparison to $60.5 \%$ of HIV- negative women. Additionally, HIVpositive women in this same study were more likely to engage in sexually risky behaviors than their HIV-negative counterparts (Dévieux et al., 2009). Other studies that have surveyed similar populations of Haitian women have also found that the participants often associated condoms with a greater risk of genital disease and admission of infidelity or HIV infection (Conserve, Whembolua, \& Surkan, 2014; Severe et al., 2014; Malow et al., 2000; Ulin, Cayemittes, \& Metellus, 1995). As noted in these studies, Haitian women living in Haiti have knowledge of aspects of HIV, but there remains a gap in practice. Furthermore, there is a failure to act on protecting oneself among those who have greater knowledge of HIV transmission.

Underscoring these study results, the EMMUS-V (2013) found that of the women interviewed, 99.8\% had heard of HIV. The majority of these respondents recognized that the following methods reduce the risk of contracting HIV: using condoms (85\%) and reducing the number of sexual partners (92\%). Ninety-one percent also knew that a healthy-looking person could still be a carrier of the virus, and 81\% knew at least two 
methods of prevention. Nonetheless, only 55\% knew that the virus could not be spread through mosquitoes, 70\% knew that it could not be transmitted supernaturally, and 77\% knew that one could not contract the disease by sharing meals with an infected person. In this category of knowledge of HIV transmission, only $37 \%$ of the respondents had "thorough knowledge” of HIV transmission. Women who have thorough knowledge as described in the EMMUS-V are women who: 1) know that consistent condom use during each episode of sexual intercourse and limiting sex to one faithful, uninfected partner reduces the risk of contracting HIV, 2) know that a healthy-looking person may still have the virus; and 3) reject both local misconceptions (mosquitoes and supernatural methods) as means of contracting HIV. Seventy-five percent of women surveyed also felt that it was normal for a woman to refuse to have sex with her partner if she knew he had sex with other women. Similarly, 91\% of women felt that a woman had the right to insist her partner wear a condom during sex if she knew her partner had a sexually transmitted infection (STI; Cayemittes, 2013).

However, with regard to HIV risk behaviors and prevention, knowledge did not always transfer to practice among the women surveyed. While the vast majority of female respondents (88\%) knew of a place they could go for HIV testing, only $47 \%$ had been tested and received results and 50\% had never taken a test for HIV. These facts are illustrative of the gap between knowledge and practice in this population, which only exacerbates the risk for HIV infection.

\section{Alcohol Abuse}

Excessive alcohol use, defined by the Center for Disease Control and Prevention (CDC) as drinking 15 or more drinks per week by men, eight or more drinks per week by 
women, or binge drinking (4-5 or more drinks per occasion), has been a longstanding public health concern because it lowers inhibitions, increases engagement in risky sexual behaviors, and may lead to addiction (CDC, 2015). Alcohol abuse is considered one of the most common and costly forms of drug abuse that is a major contributing factor to as many as 200 diseases and injury conditions (WHO, 2015; Molina, Gardner, Souza-Smith, Whitaker, 2014). Alcohol use accounts for 5.1\% of the global burden of disease, suggesting that it accounts for as many deaths and disability as tobacco and hypertension (WHO, 2015; Room, Babor, \& Rehm, 2005; Krug, 2002). Alcohol use also has farreaching impact that contribute to public endangerment, such as drunk driving that leads to accidental injuries, domestic violence, fetal alcohol syndrome, neuropsychological impairment, poor medication adherence, economic and loss of productivity, and psychiatric comorbidity (CDC, 2015; Magnusson et al., 2012; Brady \& Back, 2012; Enoch, 2011; Hasin, Stinson, Ogburn, \& Grant, 2007; Room, Babor, \& Rehm, 2005; Cook, 1998). In an effort to combat alcoholism, advocates and interventionists have developed partnerships and programs to assist individuals struggling with alcohol dependence that are split into three general categories: brief intervention, specialized treatment programs, and mutual help groups (Molina, Gardner, Souza-Smith, Whitaker, 2014; Room, Babor, \& Rehm, 2005). These interventions and programs have been successful in identifying factors that lead to alcohol abuse in order to begin the process of healing and breaking their addiction.

Factors. Key to understanding alcohol abuse is determining what factors may lead individuals to turn to alcohol as a coping mechanism or escapism. Research indicates that some of the major factors that contribute to alcohol abuse include past and current 
physical, emotional, and psychological trauma including CSA, stress, environmental surroundings, family history, and for the younger population, peer pressure and early access (Brady \& Back, 2012; Hughes et al., 2007; Kilpatrick et al., 2000; Zieler et al., 1991). The inability to intervene and address these factors immediately upon identification may lead to serious ramifications for a person who does not have the resources or the support system necessary to overcome those issues (Hunter-Reel, McCrady, \& Hildebrandt, 2009; Marlatt \& Witkiewitz, 2005). According to the Marlatt \& Witkiewitz Relapse Model (2005) and an extension of that model in 2009 by HunterReel, McCrady, \& Hildebrandt (2009), research has shown that positive social support highly predicts long-term abstinence for alcohol abuse among other addictive behaviors. For individuals who have positive and strong social support, they will likely seek ways to handle the daily requirements of living while also bearing the burden of psychological concerns that may serve as impediments to a healthy existence. While there are positive ways to deal with such concerns, such as exercise, therapy, and integrated support systems (Hunter-Reel, McCrady, \& Hildebrandt, 2009; Marlatt \& Witkiewitz, 2005; Folkman \& Moskowitz, 2003; Folkman, 1997), these options are often unavailable or inaccessible, leading many to individuals turn to "negative" coping methods such as alcohol use, which may ultimately transition into alcohol abuse. The outcomes associated with alcohol abuse are well documented and show the inevitable decline of one's overall health and increase in dependence (CDC, 2015; Magnusson et al., 2012; Brady \& Back, 2012; Enoch, 2011; Rehm et al., 2010; Hasin, Stinson, Ogburn, \& Grant, 2007; Room, Babor, \& Rehm, 2005; Cook, 1998). Research also shows that alcohol does not eradicate 
the issues that may have led to users' abuse of the substance. Rather, it exacerbates the problems.

Outcomes. Many individuals may use alcohol as an option or quick solution to minimizing what they may consider a debilitating problem that "will not go away" or a problem that has become ingrained in the psyche, including early childhood experiences, traumatic incidents, and stress (Bressert, 2013; Brady \& Back, 2012). However, it is not a permanent solution, and the outcomes of alcohol abuse can be devastating. Some of the primary negative outcomes of alcohol abuse include deterioration of health (SAMHSA, 2015; CDC, 2015; Rehm et al., 2010; Room, Babor, \& Rehm, 2005), loss of income and workplace issues, and increased sexual risk behaviors (CDC, 2015; Rehm et al., 2010; Hasin, Stinson, Ogburn, \& Grant, 2007; Room, Babor, \& Rehm, 2005; Cook, 1998). Evidence of physical deterioration due to alcohol abuse is overwhelming. Alcohol attacks the liver, a vital organ in the body. It also contributes to over 60 medical conditions that range from cardiovascular and gastrointestinal diseases to neuropsychiatric disorders and cancer (SAMHSA, 2015; Rehm et al., 2010; Room, Babor, \& Rehm, 2005). As a result, alcohol abusers tend to have a myriad of presenting health concerns.

Loss of income is also an inevitable outcome of alcohol abuse (CDC, 2014; United States Department of Health and Human Services (USDHHS), 2000). First, an alcohol user must fund his or her addiction. Maintaining desired alcohol levels can become a costly venture for society and personally for the individual (NIAAA, 2015; CDC, 2014). The National Institute on Alcohol Abuse and Alcoholism (NIAAA; 2015) estimates that nearly 88,000 people die from alcohol-related causes annually, making it the third leading cause of preventable death in the United States. Along those lines, in 
2013, alcohol-impaired driving fatalities accounted for 10,076 deaths, which is $30.8 \%$ of overall driving fatalities (2015). Additionally, NIAAA continues to cite a landmark 2006 CDC study that found that excessive alcohol consumption cost the United States $\$ 223.5$ billion in 2006, or about $\$ 1.90$ per drink (NIAAA, 2015; CDC 2006). An alcohol abuser's ability to hold on to gainful employment may also be jeopardized. Alcohol abuse may cause excessive tardiness, violence in the workplace, decreased functioning and production, and an increase in critical errors that may affect the overall operation of a company. Seventy-two percent of the total societal cost of alcohol consumption in the United Sates is attributed to low workplace productivity and workplace-related issues (CDC, 2014).

Alcoholism or excessive alcohol consumption contributes to reduced inhibitions and increased risky sexual behaviors that, when combined, contribute to the overall burden of the disease (SAMHSA, 2015; CDC, 2015; Rehm et al., 2010; WHO, 2005; Scheidt et al., 1995; Shillington, Cottler, Compton, \& Spitznagel, 1995). Because of its contribution to decreased faculties, alcohol is often implicated as a contributing factor to unprotected sex and subsequent HIV seroconversion (Geetanjali et al., 2015; Schneider, Chersich, Neuman, \& Parry, 2012; Baliunas et al., 2010; Steele \& Josephs, 1990; O’Leary, 2009; Dingle \& Oei, 1997). Research shows that an individual under the influence of alcohol is more likely to engage in sexual behavior that puts the individual at greater risk for contracting STIs, including HIV. Specifically, alcohol may have a direct physiological impact on risk behaviors that leads to lowered inhibitions or a reduction in cognition that may cause individuals to disregard relevant risk-related information when deciding whether or not to use condoms (Geetanjali et al., 2015; Schneider, Chersich, 
Neuman, \& Parry, 2012; Baliunas et al., 2010; Steele \& Josephs, 1990; O’Leary, 2009;

Dingle \& Oei, 1997). Research on the relationship between HIV and alcohol use also suggests that alcohol may have a direct biological effect on the immune system. Not only does this possibly increase the likelihood of contracting STIs that may increase the risk of HIV infection, but it may also facilitate the increased risk of contracting HIV itself (Schneider, Chersich, Neuman, \& Parry, 2012; Hahn \& Samet, 2010; Meyerhoff, 2001; Szabo, 1997 Bagasra et al. 1996).

In a study on alcohol use and risky sexual behavior among college students, Cooper (2002) found that drinking was strongly related to having multiple or casual sex partners (NIAAA, 2015; CDC, 2015). Likewise, early onset of alcohol use also contributes to an increase in sexual risk behaviors (SAMHSA, 2015; CDC, 2015; Rehm et al., 2010; Grant, Stinson, \& Harford, 2001; Gruber, DiClemente, Anderson, \& Lodico, 1996). The early onset of drinking has been associated with untreated or undiagnosed psychiatric disorders, antisocial behaviors, family history of alcoholism, and increased risk of succumbing to peer pressure (Kendler \& Myers, 2012; Jenkins et al., 2011; Grant, Stinson, \& Harford, 2001; Grant \& Dawson, 1997). The effects of alcohol abuse are not specific to any one race, gender, or ethnicity. They transcend these social constructs.

Effects of alcohol use on HIV-positive persons. The relationship between HIV and alcohol use is well established in the research literature (Bagby et al., 2015; Rehm et al., 2011; Baliunas et al., 2010; Hahn \& Samet, 2010; Fisher, Bang, \& Kapinga, 2007; Kalichman et al., 2007; Cook, 2005). As noted by Bagby and colleagues (2015), “HIV disease and alcohol independently influence the human immune system, so it stands to reason that, together, their influence may be additive” (p. 287). This is an important 
reference because research shows that HIV-infected person also have higher rates of heavy drinking that those in the general population (Bagby et al., 2015, Galvan et al., 2002). For individuals who are living with HIV, the use of alcohol may lead to significantly declining health (Bagby et al., 2015; Baum et al., 2010; Hahn \& Samet, 2010) or maladaptive coping strategies (Malow, Rosenberg, \& Dévieux, 2009).

Essentially, HIV-positive individuals who abuse alcohol have multiple comorbidities. For instance, a longitudinal study of 231 HIV-positive adults (of whom 126 were alcohol users) found that alcohol significantly accelerated the progression of the disease due to direct effects on CD4 cells and reduced adherence to antiretroviral treatment (ART) (Baum, 2010). One study found that HIV-positive individuals were 50-60\% more likely to have chronic obstructive pulmonary disease (COPD) than HIV-negative subjects (Chrothers et al., 2006), and a 2012 study found that cardiovascular diseases were still prevalent and progressed faster in HIV-positive individuals that in their HIV-negative counterparts (Neuman, Schneider, Nanau, \& Parry, 2012). HIV-positive individuals frequently have to deal with impairment in cognition and life function. In a recent study that measured the life function of alcoholics, HIV-positive persons, and HIV-positive alcoholics, the HIV-positive alcoholics with depressive symptoms showed poorer selective cognitive and life functioning (Sassoon et al., 2012).

Alcohol consumption has also proven to cause non-suppression of the HIV viral load due to decreased ART adherence (Bagby et al., 2015; Wu et al., 2011; Hahn \& Samet, 2010). In addition to the promotion of disease progression and non-suppression of viral load, the survival rate for people living with HIV/AIDS decreases overall (Bagby et al., 2015, Braithwaite et al., 2015). One of the main factors contributing to the decreased 
lifespan is that the immunosuppressive effect on the individual can increase opportunistic infections (e.g. tuberculosis and bacterial pneumonia), severity of infections (e.g. viral hepatitis), and risk of cancers (Molina et al. 2010; Szabo et al. 2009). For chronic drinkers, it can cause chronic inflammation (Bagby et al., 2015, Neuman, Schneider, Nanau, \& Parry, 2012; Hahn \& Samet, 2010; Molina et al. 2010; Szabo et al. 2009). Vitamin deficiencies, malnutrition, or other substance use may also accelerate these illnesses. For example, among the HIV-positive study participants in the Baum and colleagues (2010) study who drank alcohol, a significant number of them also used other substances that promote disease progression including powder cocaine (49 out of 126 alcohol users), crack-cocaine (74 out of 126 alcohol users), and marijuana (57 out of 126 alcohol users). Lastly, the impact of alcohol on HIV disease, may affect the body's ability to metabolize ART due to enzymatic induction and enzymatic inhibition (Neuman, Schneider, Nanau, \& Parry, 2012; Hahn \& Samet, 2010).

HIV and alcohol use among Haitians. Alcohol use among Haitians is an understudied subject, both as a single public health concern, as well as how it relates to issues such as HIV and medication adherence (Malow et al., 2013). Nonetheless, there are studies that show the need for interventions that will address the multiple HIV risk factors, including alcohol use in Haiti among various populations, for example, among youth. For instance, one study noted that increased economic and political instability along with the breakdown of traditional systems in the county has contributed to increased levels of substance use among adolescent boys (Dévieux et al., 2014). The higher levels of substance use have subsequently led to multiple sex partners and early sexual debut, resulting in an increased HIV levels (Dévieux et al., 2014). In their study, 
Malow and colleagues (2013) found that alcohol use, depression, negative coping, and poor social support are among the factors that have been identified as significant drivers of the HIV epidemic (2013). This is in addition to "low health literacy, lack of education, and strong beliefs in alternative medicine practices” that may further contribute to poor HIV medication adherence in Haiti (Malow et al., 2013, p. 1222). Studies have also shown that alcohol use is associated with domestic violence in Haiti. In a national survey conducted in Haiti, it was reported that $16 \%$ of women who were married or in a cohabiting union at the time of the survey experienced sexual violence and that alcohol use by the cohabiting male partner was a risk factor for partner sexual abuse” (Conserve et al., 2014; Gage, 2006). Due to limited data on the difference in alcohol use between HIV-positive and HIV-negative populations in Haiti, prevalence numbers on the subject are not reported. Malow, Rosenberg, and Dévieux (2009) reason that data on alcohol and drug use risk reduction is limited in low-resource settings such as Haiti due to lack of infrastructure. The article cites Gage and Hutchinson (2006) who note that alcohol use has been implicated in the high rate of intimate partner violence in Haiti, however it still remains an understudied factor in risky sexual behaviors (Malow, Rosenberg, \& Dévieux, 2009).

Where the subject is studied, researchers have found that among HIV-positive men and women living in Haiti, there is a significant risk of alcohol abuse, especially among the poorer population (Dévieux et al., 2014; Malow et al., 2013). Impoverished men and women in Haiti tend to have limited resources or limited knowledge of health resources or education that promote positive and healthy options to dealing with their diagnosis (Malow et al., 2013; Malow, Rosenberg, \& Dévieux, 2009). Alcohol is readily 
accessible and relatively inexpensive, offering a reliable "escape” from the burdens of life, even though its long-term consequences far outweigh its short-term benefits. The issues surrounding alcohol dependence in a population of HIV-positive individuals is that it leads to lower medication adherence and continued risky sexual behavior which may result in transmission of HIV to uninfected persons or "reinfection" for those already infected (Malow et al., 2013).

On January 12, 2010, the largest earthquake ever recorded in Haitian history, which was centered 15 miles southwest of the Haitian capital of Port-au-Prince, devastated several parts of the country. An estimated three million people were affected by the 7.0 magnitude earthquake including over 220,000 deaths, 300,000 injuries, and an unprecedented 2.3 million displaced individuals (United Nations Development Programme, 2015; United Nations Global Compact, 2010; Margesson \& Taft-Morales, 2010). Amid the devastation, many people faced incomprehensible physical and emotional trauma. Many studies suggest that exposure to a natural disaster is related to subsequent increase in alcohol consumption (Keyes et al., 2012; Cerdá \& Galea, 2011; Kishore et al., 2008; Vetter et al., 2008).

As previously discussed, HIV-infection is also associated with increased alcohol consumption when compared to the general population (Bagby et al., 2015, Galvan et al., 2002). In combining these two points and examining the effects of alcohol use in an HIVseropositive population following a natural disaster, Dévieux and colleagues (2013a) examined alcohol use among HIV-seropositive adults in Haiti after the devastating earthquake that occurred. These researchers found that female hazardous drinkers, defined as having a score $\geq 8$ on The Alcohol Use Disorders Identification Test (AUDIT; 
Saunders et al., 1993; Maisto et al., 2000), reported higher levels of post-traumatic stress symptoms. Study participants who indicated problems with alcohol use prior to the earthquake were more likely to suffer from PTSD in comparison to those who did not indicate issues with alcohol use.

Despite these findings and the work that has gone into decreasing HIV infection in Haiti, alcohol use continues to be an HIV-related risk factor that requires more focus both for prevention and ongoing intervention.

\section{Social Support}

Social support is the perception and actuality that an individual is cared for, has assistance available from other people, and that he/she is part of a supportive social network. Social support is one of the most important components of disease management in HIV prevention and intervention (Breet, Kageee, \& Seedat, 2014; Cortes, Hunt, \& McHale, 2014; Casale \& Wild, 2013). Research shows that social support in a protective factor for mental and physical well-being among various populations (Kingori, Haile, \& Ngatia, 2015; Glick \& Golden, 2014; Casale \& Wild, 2013; Casale \& Wild, 2012). Individuals who demonstrate positive social support tend to have higher medication adherence, are more likely to disclose their HIV status to partners and loved ones, have lower transmission rates, stronger immune systems and better health, and are less likely to be socially isolated (Kingori, Haile, \& Ngatia, 2015; Amirkhanian, 2014; Glick \& Golden, 2014; De et al., 2013; Casale \& Wild, 2013; Rao et al., 2012). Without social support, individuals who are HIV-positive are more likely to experience high rates of stress, anxiety, depression, guilt, shame, and substance use (Kingori, Haile, \& Ngatia, 2015; Cortes, Hunt, \& McHale, 2014). Perceived social support is defined as "the level of 
satisfaction that a person has in relation to his/her need for support, information, and reciprocity” (Cortes, Hunt, \& McHale, 2014, p. 2275). It is important that HIV-positive individuals perceive that they have social support. Having high levels of perceived availability of support is widely associated with positive health and coping outcomes (Breet, Kgee, \& Seedat, 2014; De et al., 2013; Rao et al., 2012; Bekele et al., 2012; Kalichman et al., 2000). For the purposes of this study, social support is inclusive of the perceived availability of social support from family friends, doctors, and loved ones, balance of power and/or control in primary partner relationships, and susceptibility to violence in relationships.

Fawzi and colleagues (2012) conducted a group intervention using curriculumbased psychosocial support groups in central Haiti to analyze the impact of psychosocial support in an HIV-affected population. They also measured the psychological symptoms, psychosocial functioning, social support, and HIV-related stigma of study participants. Researchers compared the baseline results with outcomes one year later. There was a significant reduction in psychological distress, social isolation, and HIV-related stigma a year later. Another study conducted by Naslund and colleagues (2014) echoed such findings when they implemented a community program to improve retention in care among patient with HIV in southern Haiti. This intervention included hospital staff, patients, and community groups that facilitated ART distribution, tracked progress and medication adherence, and provided support. Hospital staff and patients reported easier management of medication, reduced workload, and overall greater support among the groups. Other studies in Haiti and other low-resource settings or urban populations, including the ones described above, underscore the importance of the provision of 
positive social support through community-based care, support groups, and familial support. This also includes the very perception that an individual has the support of the loved ones and doctors while dealing with HIV (Li et al., 2015; Bowleg et al., 2013; Fawzi et al., 2012; Bekele et al., 2012; Koenig, Léandre, \& Farmer, 2004).

In addition to understanding how perceived social support and actual social support affects health, a review of literature that examines the association of childhood sexual abuse with perceived availability of social support is also critical. Studies found that individuals who had exposure to CSA and other forms of trauma in childhood report significantly lower levels of social support in adulthood including appraisal, belonging, and self-esteem support and higher levels of stigma, discrimination, and post-traumatic stress (McQuaid et al., 2015; Sperry \& Widom, 2013; Seedat, 2012). Conversely, Machtinger and colleagues found that women with HIV showed increased health outcomes when social support was improved (2015). These studies stress the importance of developing social support-geared interventions that incorporate CSA when working to improve health outcomes of various HIV-infected populations.

Another important aspect of social support is the balance of control and power in relationships as well as one's susceptibility to violence in said relationships. There is overwhelming research that shows an imbalance of power in relationships and intimate partner violence is highly correlated with HIV risk (Parcesepe et al., 2015; Borwein et al., 2014; Malow et al., 2013; Teitelman, Ratcliffe, Morales-Aleman, \& Sullivan, 2008; Kershaw et al., 2006). Substantial research has also been conducted in relationship control and intimate partner violence between men and women and their relationship to HIV in Haiti (Conserve, Whembolua, \& Surkan, 2014; Dévieux et al., 2013b; Malow et 
al., 2010; Gage \& Hutchinson, 2006; Gage, 2005). Research has shown that relationship control and women's susceptibility to violence in Haiti were attributed to lack of education, history of exposure to violence, traditional factors, partner's need for control, alcohol use, and female-dominated financial decision-making (Conserve, Whembolua, \& Surkan, 2014; Dévieux et al., 2013b; Malow et al., 2010; Gage \& Hutchinson, 2006; Gage, 2005). Moreover, gender inequality and high levels of sexual violence increase the HIV risk among Haitian women (Rahill, Joshi, \& Hernandez, 2015; Logie, Daniel, Newman, \& Loutfy, 2012; Purcell, 2012; Malow et al., 2010; Boesten \& Poku, 2009; Kershaw et al., 2006).

In Haiti, partner relationships tend to manifest a historical and social gender inequality that has evolved over time yet remains a significant part of the Haitian culture today (Dévieux et al., 2013b; Purcell, 2012; Boesten \& Poku, 2009; Kershaw et al., 2006). This reality is evident in household roles and finances, sexual relationships, and education. In many areas of Haiti, women are often the breadwinners of their maledominated households. Despite this significant role, they are still subject to subservience, particularly among the rural and poor (Purcell, 2012; Rendon, 2011; SUNY, 2010; Gage, 2005; Fuller, 1999; Charles, 1995). In other words, a woman may bring in the majority of the income and even be responsible for how the family spends that money to support itself, but the male is the authority in the household, often reinforcing female subordination (Padgett \& Warnecke, 2011; Gage, 2005; Charles, 1995). These women not only bring in the majority of the income due to the informal labor force dominated by women, but they are also responsible for child rearing and meeting the husbands' needs (Padgett \& Warnecke, 2011; Colin, n.d.). In instances where the man is the financial 
provider or breadwinner, the woman still has the most influence in the home concerning decision-making. She determines how to manage the finances, rear the children (men typically act as disciplinarians), and keep the family stable. The considerable involvement and role a Haitian woman has in her home is somewhat counter to the fact she may not be the formal authority figure in her household (Rendon, 2011; Colin, n.d). This inequality is most often manifested in women’s sexual relationship with primary partners.

In Haiti, a great deal of value is placed on unions between men and women. While formal unions such as legal marriage are preferable, many couples are unable to marry, primarily due to financial hardship. Instead, many couples enter into an informal union called plasaj (Purcell, 2012; Fawzi, 2010; Boesten, 2009). In a plasaj, a woman enters into a long-term union with an unmarried man to support their children and family. The imbalance between men and women in a plasaj is that the man may enter into several similar common law unions without consequence. As it stands, the practice of males having multiple sex partners is a generally accepted practice within the Haitian culture whether it is within or outside of a plasaj (Severe et al., 2014; Dévieux et al., 2013b; Purcell, 2012; OECD, 2012; Magee et al., 2006; Fuller, 1999; Charles, 1995; Ulin, Cayemittes, \& Metellus, 1995). Meanwhile, the woman is expected to remain monogamous (Padgett \& Warnecke, 2011; Boesten, 2009; Fawzi, 2010; Fuller, 1999; Ulin, 1995). Because women do place such high value on being in some form of a union, they tend to overlook the infidelity of their partners (Padgett \& Warnecke, 2011; Ulin, 1995). It is most important to note that when men enter into a plasaj with multiple women, it forces their primary partners into subordinate positions with limited ability to 
express disagreement with such arrangements. This arrangement leads to an increased risk of violence as well as the spread of STIs and HIV (Conserve, Whembolua, \& Surkan, 2014; Gage \& Hutchinson, 2006; Gage, 2005; Fuller, 1995) due to the men having multiple sex partners. The safest course of action for women in such situations would be either to refrain from sex or to ensure consistent condom use with their primary partners who they suspect are having unprotected sex with other women. However, this course of action comes with consequences. Women tend not to address these issues with their partners for fear of retaliation, loss of financial support, and accusations that they-the women—are the ones having the sexual relations outside the union (Severe et al., 2014; Conserve, Whembolua, \& Surkan, 2014; Gage \& Hutchinson, 2006; Malow, 2000; Fuller, 1999; Ulin, 1995).

Many women are also reluctant to deny their partners sex, out of obligation to grow their families. High fertility is of value because Haitians consider children 'gifts from God' and those children are likely to increase the chances of economic security for the parents as they enter old age. Finally, women fear that if they do not acquiesce to their partners' desires, the men will go elsewhere for sex (SUNY, 2010; Ulin, 1995). As a result, many women continue to have unprotected sex with their partners who have multiple partners themselves, thereby, increasing their risk for HIV infection.

This chapter reviewed and discussed literature that provided context for the current study as it relates to childhood sexual abuse, sexual risk behaviors, alcohol abuse, social support, and key demographic factors for the population of interest. The next chapter will demonstrate how the measures and instrumentation used in this study are most appropriate for analysis. 


\section{CHAPTER III}

\section{METHODS}

\section{Purpose of the Study}

This study was a cross-sectional examination of baseline data collected between September 2009 and November 2013 as a part of an original (parent) study titled “Intervening with Haitian HIV-Positive Alcohol Users: An Environmental Psychosocial Framework” and funded by the National Institute on Alcohol Abuse and Alcoholism (NIAAA). The original study was a five-year randomized controlled trial adaptation of a Cognitive Behavioral Stress Management (CBSM) intervention designed to simultaneously enhance safer sex practices, adherence to antiretroviral (ARV) medication, and reduce alcohol or other drug use. The study sought to implement an HIV risk-reduction intervention strategy that could be used with HIV-positive adults with high-risk behaviors living in a resource-constrained setting, in this case, Port-au-Prince, Haiti. The Florida International University Institutional Review Board approved the study.

The purpose of this current study was to analyze the association between sexual abuse during childhood and the risky sexual behaviors and attitudes of Haitian women who were infected with HIV. The study also examines the association between CSA and level of alcohol use and CSA and social supports (namely perceived social supports, relationship control/balance of power in partner relationships, and susceptibility to violence) in the same population. In detail, the study examined how childhood sexual abuse affected the current behaviors and lives of HIV-positive Haitian women. In addition to the primary purpose of this study, demographic information from the study 
population was analyzed in order to determine if marital status, education, or age were potential confounders to consider in the research.

\section{Study Participants}

For the parent study, participants were recruited from the Groupe Haïtien d'Etude du Sarcome de Kaposi et des Infections Opportunistes Centers (GHESKIO) in Port-auPrince, Haiti. The GHESKIO Centers offer patient care, training for medical professionals and community leaders, and conduct research for leading diseases in Haiti including HIV/AIDS, STIs, tuberculosis (TB), and diseases associated with diarrhea. Potentially eligible participants at GHESKIO received a pre-screening interview and were provided with the informed consent process by research staff. Inclusion criteria for the parent study was the following: 18-60 years of age; fluency in spoken Haitian Creole; documentation of HIV seropositivity; at least one episode of unprotected anal or vaginal sex in the past 90 days; recent alcohol consumption by self-report; currently not cognitively impaired; and, no current symptoms of a major psychiatric disorder, including psychosis. There were no exclusion criteria of sex or gender.

Participants were recruited in cohorts of sixteen. Once a single sex cohort of 16 males or 16 females had been consented, participants completed baseline assessments then were randomized in equal numbers to either the experimental group or the wait-list control group. Participants in a given cohort followed the same assessment schedule in both conditions; they were interviewed at baseline, then within a week post-intervention, and at 3, 6, and 12 months post intervention. While the group assigned to the experimental condition participated in the small group CBSM intervention within a week of completing their baseline assessment, those randomized to the wait-list control group 
received the intervention after the 6-month assessment point. The parent study used a prospective, randomized by cohort, two-group, intent-to-treat design with repeated measures over time.

The primary outcome for the parent study was a reduction in sexual risk behaviors and the secondary outcomes were reductions in alcohol and other drug use, improved adherence to ARV medication, to utilization of HIV primary care services and enhanced psychosocial health. The main outcome for this study was to analyze the association between CSA and HIV-related sexual risk behaviors, alcohol abuse, and current social supports.

For the current study, a total of 393 Haitian men and women completed baseline data as part of the parent study. The study participants answered questions from 25 different instruments with over 200 items capturing demographic data and measuring alcohol consumption, dependence symptoms, post-traumatic stress disorder, adherence to antiretroviral therapy, CSA, drug and sexual risk behavior, and other important environmental and social factors. Of the 393 participants who completed baseline data, 242 (approximately 62\%) were women. For the purposes of this study, no additional recruitment was necessary, and there were no direct risks or benefits to the participants who were enrolled in the parent study. The researcher only analyzed information collected at baseline for the 229 women who participated in the study and completed the Childhood Trauma Questionnaire. With the exception of gender, inclusion criteria remained the same as that of the parent study. The Florida International University Institutional Review Board (IRB) granted approval for the current study through expedited review. 


\section{Procedures}

Quantitative data were collected from September 2009 through November 2013 by trained interviewers using the CAPI systems. Items included information about sexual behaviors, alcohol and non-alcohol drug use, abuse, and mental health, using various methods such as Likert scales, true-false, multiple choice, and fill-in style questions (detailed below). Due to likely low literacy rates and potential problems with concentration and attention, questions were read aloud to the participants. AudioComputer Assisted Self Interview (A-CASI) technology was employed whenever possible, including for some of the more sensitive topics. Using A-CASI, participants were able to simultaneously view items on a computer screen while also hearing them through headphones. The technology provides standardized measurement, computercontrolled branching, automated consistency and range checking, and multilingual administration of questionnaires. It also assists participants who have lower reading skills complete measures with greater ease. Studies with various populations including alcohol and other drug (AOD) abusers have concluded that A-CASI provides valid and more accurate reporting of high-risk behaviors (Spear, Shedlin, Gilberti, Fiellin, \& McNeely, 2015; Caldwell \& Gryczynski, 2012; Katz et al., 2005). Participants responded by touching the screen in privacy so that any embarrassing answers were not heard or seen by another person. Afterwards, the data was transferred from the A-CASI system and maintained in relational DBF files useable by the major statistical software programs.

Although 242 women completed the baseline assessment, 13 participants did not answer questions related to childhood sexual abuse or were missing data. Therefore, only data collected on 229 of these individuals were included for analysis. 
SPSS Statistics Version 20.0 (IBM, 2011) was used to run all statistical tests and complete all analyses.

\section{Study Variables and Instrumentation}

Independent variables and measures. The occurrence of CSA and demographic information are the independent variables in this study. In the parent study, CSA was measured using a revised version of the Childhood Trauma Questionnaire (CTQ; Bernstein \& Fink, 1997), a 28-item -report inventory that provides brief, reliable, and valid screening for histories of abuse and neglect. It enquires about five types of maltreatment - emotional, physical, and sexual abuse, and emotional and physical neglect. For the parent study, the CTQ underwent an adaptation process to remove culturally inappropriate items. Through that process, the 28-item survey was adapted to a 5-item questionnaire focusing solely on sexual abuse. Participants were asked about their experiences with sexual abuse during their childhood, including: if someone touched her in a sexual way or made her touch the person; if she was threatened into doing something sexual with someone; if someone made her do or watch sexual things; if she was molested; and, if she believes she was sexually abused. All five questions utilized a fivepoint Likert scale with responses ranging from “never true” to "very often”. The CTQ is considered very reliable with a 0.88 test-retest value and an internal consistency rating, or validity, ranging between 0.80 and 0.97 for the 28 -item protocol. The 5 -item version utilized for the parent study has an internal consistency rating of 0.832 .

The Demographics were adapted from the Centers for Disease Control and Prevention’s Interventions for HIV-Seropositive IDUs—-Research and Evaluation (INSPIRE; CDC, 2001) which assesses general questions about the participants' lives. A 
number of variables considered as possible covariates needing statistical control—age, ethnicity, education, socioeconomic status (SES), religious affiliation, current living situation, and relationship status_-were in the parent study, and subsequently, this study.

Dependent variables and measures. The dependent variables and the corresponding instruments (which are detailed below) used to measure each variable are summarized as follows:

- Multiple sexual partners - measured by Drug and Sexual Risk Behavioral Assessment (DS Measure)

- HIV-related knowledge — measured by the Assessment of HIV Risk Behavior (AHRB)

- Attitudes about safer sex—measured by the Condom Attitudes Scale-Adapted (CAS-A)

- Sexual self-efficacy—measured by the AIDS Risk Reduction Model Questionnaire-Revised (ARRM-Q)

- Alcohol abuse - measured by the Alcohol Use Disorders Identification Test (AUDIT)

- Perceived social support-measured by Perceived Availability of Support (PAS)

- Power and balance in relationship — measured by the Sexual Relationship Power Scale (SRPS)

- Partner violence and/or abuse - measured by the Sexual Relationship Power Scale (SRPS) 
Below is a detailed description of the assessment instruments (as notated by acronym next to each dependent variable above) that were used in analyzing selected dependent variables, including information on the reliability and validity of each instrument. The parent study utilized a multitude of instruments to gather relevant data from study participants. However, for the purpose of this study, the researcher only analyzed data collected using the following assessment instruments:

Drug and Sexual Risk Behavioral Assessment (DS Measure; CDC INSPIRE; 2001; Tross, 2008) is adapted from a combination of instruments including the baseline assessment questions collected from the CDC INSPIRE study and the Sexual Experiences and Risk Behavior Assessment Schedule (SERBAS) utilized in the NIDACTN-0018 trial (Tross, 2008). The SERBAS is a widely used sexual risk behavior assessment with good evidence of reliability and validity, ranging from .40-.90 among various high risk populations including women at high risk for HIV (Ehrhardt et al. 2002a; Ehrhardt et al. 2002b; Meyer-Bahlburg et al., 1991; Sohler et al., 2000; Tross, 2008). The combination of assessment questions, which comprises the DS measure, includes 72 items for females asking about alcohol and other drug use and specific sexual behavior with the three most recent sexual partners. It measures the number and proportion of unprotected sex acts with unknown serostatus or HIV-negative sex partners. The questions yield a combination of responses including “yes/no”, multiple Likert scales, and open-ended questions. For the purpose of this study, only one question from the DS measure will be analyzed. This question is an open-ended question that asks the respondents to provide the number of sexual partners they have had over a three-month period. The answers were not rated or scored, and only reported as stated by the 
respondent. The internal consistency rating of the DS Measure used for the parent study among Haitian men and women is 0.848 .

An adapted version of The Assessment of HIV Risk Behavior (AHRB; Fisher et al., 2006) was used for the parent study, and subsequently, this study. The AHRB is a knowledge questionnaire that assesses Information, Motivation, and Behavioral Skills (IMB) constructs using a computer-delivered format. It is an 11-item questionnaire with response options “true/false/don’t know/refuse to answer/not applicable” for questions such as: "If an HIV positive person has sex with another HIV positive person, they don't need to use condoms," "If an HIV positive person is taking their pills (meds) or on combination therapy, they can't give HIV to anybody," and "Combination therapy is pretty much a cure.” “True/Don’t Know” responses are scored with a one (1) while "False” responses were scored with a two (2). "Not applicable” responses are not scored and subsequently, not included in the analysis. Two of the eleven questions received reversed scoring where "true" was rated with a one (1) and false received a score of two (2). The minimum score for this tool is eleven (11) and the maximum score is twenty-two (22). Higher scores indicate greater HIV knowledge. The parent study measured the AHRB internal consistency rating at 0.687.

Condom Attitudes Scale (CAS; Sacco, Levine, Reed, \& Thompson, 1991) was adapted (CAS-A) for this study. The original CAS is an instrument that measures attitudes about condom use as an AIDS-relevant behavior and their relation to selfreported condom use both past and present. The CAS has nine subscales for a total of 57items. The total CAS reports a test-retest correlation of 0.86 . Two studies were conducted to check for reliability and validity of the subscales and total scale. All 
coefficient alphas of the final items for both studies were between 0.75 and 0.92 , yielding acceptable internal consistency across the board. The twenty items that were utilized for the CAS-A showed adequate psychometric properties in measuring perceived barriers to condom use for preventing HIV/STDs. The internal consistency of the CAS-A for the parent study was determined to be 0.802 . The CAS-A utilizes a 7-point Likert scale with the responses “disagree strongly/disagree somewhat/agree somewhat/agree strongly/don’t know/refuse to answer/not applicable.” In this study, only the responses “disagree strongly/disagree somewhat/agree somewhat/agree strongly” are considered and assigned scores of 1-4 with reverse coding where appropriate. Sample questions include: "I am concerned about catching another sexually transmitted disease," and "Using condoms shows my partner I care about him/her.” The total score was derived by adding the total points for each question with the maximum score being 70. A higher score indicates a more positive attitude toward condom use.

The AIDS Risk Reduction Model Questionnaire-Revised (ARRM-Q; Gibson, Lovelle, Drache, Young, \& Chesney, 1992) was adapted and utilized to evaluate selected HIV-related risk outcomes. The ARRM-Q was developed to measure HIV-specific constructs hypothesized to predict HIV risk behaviors. With an internal reliability ranging from $0.69-0.81$, constructs include perceived susceptibility (perceived risk for contracting HIV), AIDS-related anxiety (anxiety about becoming HIV infected), sexual self-efficacy (confidence to adopt and maintain HIV preventive behaviors), and personal attitudes toward condoms and sexual attitudes. The parent study only used five questions from the Communication Scale of the ARRM-Q, which evaluates HIV related risk variables that are hypothesized to be predictive of HIV risk behavior. Specifically, the 
five questions ask a participant whether she feels comfortable speaking with her partner about various topics, including monogamy, condom use, his sexual activity, his diagnosis of an STI or HIV, and getting tested for HIV. All questions use a 7-point Likert scale with the responses “disagree strongly/disagree somewhat/agree somewhat/agree strongly/don’t know/refuse to answer/not applicable.” In this study, only the responses “disagree strongly/disagree somewhat/agree somewhat/agree strongly” were considered and assigned scores of 1-4. The total score was derived by adding the total points for each question with the maximum score being 20. Higher scores indicate more comfort communicating with the sexual partner about safer sex. The Communication Scale of the ARRM-Q has an internal consistency rating of 0.659 .

The Alcohol Use Disorders Identification Test (AUDIT; Saunders et al., 1993) is a 10-item survey that measures alcohol consumption, dependence symptoms, and personal and social harm reflective of drinking over the past 30 days. A score of eight on the AUDIT suggests problem-level drinking (Maisto et al., 2000). The total score is derived by pre-established scoring rules for the AUDIT that assigns scores of $0-4$ for responses to questions $1-8$ and scores of $0-2$ for responses to questions $9-10$. The maximum score for the AUDIT is 40 . Scores of eight (8) and above indicate a strong likelihood of hazardous or harmful alcohol consumption. Sample questions include: "How many drinks containing alcohol do you have on a typical day when you are drinking,” with response options "never/monthly/less than monthly/weekly/daily or almost daily" and "Have you or someone else been injured as a result of your drinking" with response options “never/yes, but not in the last year/yes, during the last year.” The 
AUDIT has demonstrated good content, criterion and construct validity and reliability (alphas from .77 to .83; Bohn et al., 1995).

Perceived Availability of Support (PAS; Koenig et al., 2006) is a 10-item selfreport scale. This instrument taps perceived social support provided by others in several domains including tangible support and guidance. For the purposes of this study, only the first eight questions are utilized. The other two questions are references to individuals who may/may not provide support to respondents and respondents' general opinions on trust. The eight questions use an 8-point Likert scale with the response options: “definitely not/probably not/possibly/probably yes/definitely yes/don’t know/refuse to answer/not applicable.” In this study, only the responses “definitely not/probably not/possibly/probably yes/definitely yes" are considered and assigned scores of 1-5. The total score was derived by adding the total points for each question with the maximum score being 40. Higher scores indicate more perceived support. The parent study found the PAS to have an internal consistency rating of 0.714 .

The Sexual Relationship Power Scale (SRPS; Pulerwitz et al., 2000, 2002) is a 23-item scale that measures power in sexual relationships and investigates the role of relationship power in sexual decision-making and HIV risk. The SRPS contains two subscales that address two conceptual dimensions of relationship power: Relationship Control and Decision-making Dominance. Because this study population is all women, only questions one through fifteen were analyzed. The responses for these selected questions utilize a 7-point Likert scale with the responses "strongly agree/agree/disagree/strongly disagree/don't know/refuse to answer/not applicable.” In this study, only the responses "strongly agree/agree/disagree/strongly disagree” are 
considered and assigned scores of 1-4, respectively. The scores for each question are combined to give a total score with the maximum score possible being forty-nine (49). High scores represent higher sexual relationship power. Certain scores were reversescored if high scores would reflect low sexual relationship power. Additionally, in order to measure susceptibility to violence, one of the questions in this tool was analyzed separately: “If I asked my partner to use a condom, he would get violent.” This question uses the same Likert scale and scoring as described above. The SRPS possesses good internal reliability with a score of 0.84 (English version) and good predictive and construct validity. The parent study found the SRPS to have an internal consistency rating of 0.935 .

\section{Analyses}

Descriptive analyses were first conducted in order to gain a thorough picture of the distribution of the study population across the variables of interest and the demographic characteristics as described below. Chi-square tests, Analysis of Variance (ANOVA), and correlations were then used to investigate the effects of CSA on the HIV-related risk behaviors (sex with multiple partners, condom use, knowledge of HIV, and sexual selfefficacy), levels of alcohol abuse, and perceived social supports (which include power imbalance in relationships and susceptibility to violence in primary relationships). In addition, data analyses were also conducted on potentially mediating variables (marital status, education, and age) to determine if there was a need to control for any demographics in the dataset that could influence the outcome of the results.

ANOVA was the primary statistical test used to determine if there were any differences between the three groups in the sample: women who had no exposure to 
CSA, women who had some exposure to CSA, and women who had high exposure to CSA. ANOVA was most appropriate statistic for this study because the following assumptions were met:

1. The samples are drawn from normally distributed populations

2. The independent variable consists of three categorical groups.

3. All of the populations have a common variance.

4. The study has independence of observation meaning that there are different participants in each group with no participant being in more than one group. Essentially, participants were categorized based on whether they had no, some, or high exposure to CSA.

To ensure that ANOVA was the most appropriate test for each of the research questions, the researcher checked for outliers to ensure accuracy of results and conducted Tukey's HSD and Fisher's LSD post-hoc tests to determine which groups in the sample differed. A $\mathrm{p}<.05$ level of significance was used to determine if there was a significant relationship between the independent and dependent variables of this study.

\section{Power}

In order to detect statistically significant differences between the three CSA groups the study required a minimum sample size of 136 participants. This number was determined using an alpha of .05 , a power of $80 \%$, and a $95 \%$ confidence interval. The sample size was calculated using the G*Power 3 program which covers statistical power analyses for differential statistical tests (Erdfelder, E., Faul, F., \& Buchner, A., 1996).

In the next chapter, results of all statistical analyses are presented. Further discussion and potential impact of the results are addressed in Chapter V. 


\section{CHAPTER IV}

\section{RESULTS}

\section{Introduction}

The purpose of this study was to analyze the association between childhood sexual abuse and sexual risk behaviors, alcohol abuse, and social supports in a group of Haitian women who are HIV-positive alcohol users living in Haiti. The outcomes investigated were the level of childhood sexual abuse to which respondents were exposed and their current risk behaviors. Specifically, the study analyzed the number of multiple partners, attitude toward condom use, knowledge of HIV-related topics, sexual selfefficacy, level of alcohol use, and the social support, namely perceived social support from family, friends, primary partners, and doctors, relationship control, and susceptibility to violence, of the study population.

The study measured lifetime partners as number of partners throughout the respondent's lifetime, labeled as “multiple partners," including sex with both males and females. Data on condom attitudes, HIV-related knowledge, and a participants' ability to negotiate safer sex practices (sexual self-efficacy) addressed increased risk for HIV transmission to sexual partners. Alcohol abuse was measured by consumption, dependence symptoms, and personal and social harm because of drinking. Social support was addressed by assessing how much support respondents felt they received from key individuals in their lives as well as the emotional and physical nature of their relationships with primary partners. Additional data analyses were conducted on marital status, education, and age to determine if they were associated with the outcome variables and would therefore need to be controlled in the analyses. 


\section{Study Participants}

Participant information was obtained from an NIAA-funded study database that included males and females. For the purpose of this study, males were excluded from the dataset all female participants with complete data in the dataset were used in these analyses. Names, addresses, and other personally identifiable information were collected and stored separately from study data in order to ensure participant confidentiality. All identifying information was kept in locked cabinets in a locked room. No individual identifying information was available in the SPSS database utilized for this data analysis.

Subject recruitment for the NIAAA parent study was at the GHESKIO Centersin Port-au-Prince, Haiti by trained research staff who informed potentially eligible participants of the study. Those who were interested in the study were pre-screened to determine their eligibility prior to obtaining informed consent.

Once a participant met the inclusion criteria, the research staff proceeded with the informed consent process. Participants were given an overview of the study, what participation in the study would involve, and assurance of the confidentiality of all data obtained in the course of the study. They were also informed that eligible participants could refuse to participate in the study at any time. Individuals were also told that their participation in the study was completely independent of their treatment at GHESKIO and that their decision to participate would not affect their status at GHESKIO in any way. Interviewers read the consent forms aloud with each participant in a private setting and gave the participant the opportunity to ask any questions prior to the participant signing an informed consent form. The interviewer made certain that the participant 
understood and agreed to the terms of the study before signing. Once signed, the participant received a copy of the consent form.

In the parent study, a total of 393 Haitian men and women completed baseline data: 239 women and 154 men. Of the 239 women who completed baseline data, 10 were missing data on childhood sexual abuse. Therefore, all analyses were conducted with the 229 participants who had complete childhood sexual abuse data.

\section{Demographic characteristics}

The demographic characteristics of the final sample used in the study are shown in Table 3. The demographic data includes age, marital status, and education level. Table 3

Summary of Demographic Characteristics $(n=229)$

\begin{tabular}{lcc}
\hline & Frequency (n) & Percent \\
\hline Age & Mean = 33.89, SD = 7.83 & Range $=17-55$ \\
Marital Status & 57 & 24.9 \\
$\quad$ Single & 19 & 8.3 \\
$\quad$ Married & 27 & 11.8 \\
Separated & 11 & 4.8 \\
$\quad$ Widowed & 115 & 50.2 \\
Informal Union (“Plase”) & & \\
Education Level & 142 & 64.0 \\
$6^{\text {th }}$ Grade or Less & 70 & 31.5 \\
Some High School & 7 & 3.2 \\
High School Diploma & 2 & .9 \\
Some College & &
\end{tabular}


Partner HIV status. Participants reported certain social factors relevant to the study including primary partner HIV status, most important source of income, and feelings about trust about trust in other people. Of the 229 female participants included in this study, nearly one-fifth $(18.8 \%, n=43)$ responded that their partner was HIV-positive. Similarly, nearly one-fifth $(18.3 \%, \mathrm{n}=42)$ reported that their partner was HIV-negative. Nearly half of the respondents $(48.9 \%, \mathrm{n}=112)$ did not know their partner's HIV status, and $12.7 \%(n=29)$ admitted that their partner had not yet been tested. A small percentage $(1.3 \%, \mathrm{n}=3)$ of participants responded that the situation was not applicable to them.

Sources of social support. Data regarding the most important source of support was measured and analyzed. Among those who responded to this question ( $\mathrm{n}=217$ ), half of the individuals $(53 \%, \mathrm{n}=115)$ stated that their most important source of support was their current partner. Eighteen percent of the respondents $(n=39)$ reported that an expartner was their most important source of support, while only $9.7 \%(n=21)$ indicated that their mother was their most important support. The remainder of the respondents reported the following family members as their most important source of support: a father (8.3\%, $\mathrm{n}=18)$, a sibling $(4.6 \%, \mathrm{n}=10)$, a child $(2.8 \%, \mathrm{n}=6)$, or another relative $(0.5 \%, \mathrm{n}=1)$.

Feelings on Trust. Included in this study was information regarding participants' feelings on trust. Study participants were asked: Would you say that most people can be trusted or you can't be too careful in dealing with people? Among those who responded to the question ( $\mathrm{n}=224), 49.1 \%(\mathrm{n}=110)$ reported that they are cautious about trusting 
people sometimes. One-third $(n=75)$ reported that they were cautious about trusting people most of the time. The few remaining respondents reported more trusting feelings, including $15.7 \%$ ( $\mathrm{n}=36$ ) who responded that they do confide in people sometimes and $1.3 \%(n=3)$ who often confided in people.

\section{Descriptive Statistics for Variables of Interest}

Descriptive analyses were conducted to examine the variables of interest including exposure to childhood sexual abuse, sexual risk behaviors (sex with multiple partners, condom attitudes, knowledge of HIV, and sexual self-efficacy), levels of alcohol abuse, and social supports, including perception of social support (family, friends, partners, doctors), balance of power in relationships, and susceptibility to violence in primary relationships. Table 4 details the descriptive characteristics and summary of the variables of interest.

Table 4

Descriptive Characteristics and Summary of Variables of Interest

\begin{tabular}{lccccc}
\hline & N & Min Score & Max Score & Mean & SD \\
\hline Exposure to CSA & 229 & 5 & 25 & 9.83 & 4.92 \\
Multiple Partners & 225 & 0 & 54 & 3.45 & 6.990 \\
Condom Attitudes & 220 & 45 & 70 & 56.18 & 4.178 \\
Knowledge of HIV & 229 & 11 & 22 & 16.85 & 2.38 \\
Sexual Self-Efficacy & 215 & 9 & 20 & 13.59 & 1.76 \\
Alcohol Use & 217 & 1 & 40 & 13.55 & 9.23 \\
Perception of Social Support & 212 & 8 & 40 & 22.67 & 6.96 \\
Relationship Power/Control & 225 & 18 & 49 & 32.75 & 4.48 \\
Susceptibility to Violence & 224 & 1 & 4 & 2.49 & 0.66 \\
\hline
\end{tabular}


Exposure to CSA. To categorize sexual abuse into three groups - no exposure, some exposure, and high exposure - the five questions on the tool were each scored on a scale of 1-5 and summed to derive a composite for the CSA indicator (never true =1; rarely true $=2$; sometimes true $=3$; often true $=4$; very true $=5$ ). The composite scores ranged from 5-25 $(M=9.83 ; S D=4.92)$. Participants who responded "never true" to all five questions and were assigned a composite total score of five on the Childhood Trauma Questionnaire were labeled as having “no exposure” to CSA. Participants with a composite score of $6-15$, meaning they had some responses in the "rarely true" or "sometimes true" range, were labeled as having "some exposure” to CSA. Respondents who had a composite score of equal to or greater than 16, suggesting they had responded "often true" or "very often” to several questions, were categorized as having had "high exposure" to CSA. Based on this definition, the majority of respondents had some exposure to CSA (59\%, $n=135)$, while $27.1 \%(n=62)$ had no exposure to CSA and $14 \%$ $(\mathrm{n}=32)$ had high exposure to CSA.

Sexual risk behaviors. Items that fell under the category of sexual risk behaviors were based on reported behaviors, knowledge, perceptions, and attitudes. Composite scores for each risk behavior were calculated as detailed in Chapter III and include sex with multiple partners, condom attitudes, knowledge of HIV, and sexual self-efficacy. Approximately 98.3\% ( $\mathrm{n}=225)$ of the study participants reported the number of male and female sexual partners they had over a three-month period; 4 respondents did not provide data for this variable. The number of sexual partners ranged from 0 to 54 ( $M$ $=3.45 ; S D=6.99)$. More than half $(59.1 \%, \mathrm{n}=133)$ of the respondents reported having one sexual partner over the three-month period. The second highest group $(14.2 \%, \mathrm{n}=32)$ 
stated that they had two sexual partners during the period. The remainder of the study participants reported a range of partners from 0-54.

Participants were asked about their attitudes about condom use as an AIDSrelevant behavior and self-reported condom use both past and present. Composite scores ranged from 45 to $70(M=56.18 ; S D=4.178)$. The mean among respondents $(n=220)$ indicated more positive attitudes, on average, toward condom use.

HIV knowledge and self-efficacy were also assessed. The HIV knowledge composite score ranged from 11 to 22 , with a mean response score of $16.85(S D=2.376)$ indicting scores in the mid-range of knowledge of HIV for the entire sample $(n=229)$. Sexual self-efficacy results were also reported based on composite scores. The minimum score was 9 and the maximum score was $22(M=13.59$; $S D=1.76)$, indicating some level of comfort communicating with sexual partners about safer sex.

Levels of alcohol use. Study participants’ level of alcohol was measured using the Alcohol Use Disorders Identification Test (AUDIT), a 10-item survey that measures alcohol consumption, dependence symptoms, and personal and social harm reflective of drinking over the past 30 days. Given that the population was identified as alcohol users, this study focused on varying levels of alcohol use. Scores for alcohol use ranged from 1 to $40(M=13.55 ; S D=9.23)$. A score of 8 on the AUDIT suggests problem-level drinking. Of the 229 study participants, 141 had a score of 8 or more on the AUDIT tool.

Social support. Items that fell under the category of social support included perceptions of social support from family, friends, partners, and/or doctors, degrees of power within the relationship with a primary partner (relationship control), and 
susceptibility to violence, as reported by the respondents. Composite scores for each risk behavior were calculated as detailed in Chapter III.

The range of composite score for perceptions of social support ranged from 8 to $40(M=22.67, S D=6.96)$. A higher score indicated that participants felt that they received a high degree of tangible support and guidance from individuals who are a part of their social network. The relationship control variable measured the balance of power in respondents' sexual relationship and investigated the role of relationship power in sexual decision-making and HIV-risk. The scores for relationship control ranged from 18 to $46(\mathrm{M}=32.75 ; \mathrm{SD}=4.48)$, indicating that, on average, participants had equal or more control in their relationships with their primary partners as well as in the sexual decisionmaking process.

Susceptibility to violence was measured by the question: "If I asked my partner to use a condom, he would get violent.” The scores for the variable ranged from 1 to 4 ( $M=$ 2.49, $S D=0.66$ ). As described in Chapter III, the response options for this variable were strongly agree, agree, disagree, and strongly disagree. Of those participants who answered this question ( $\mathrm{n}=224), 5.4 \%(\mathrm{n}=12)$ strongly agreed and $43.8 \%(\mathrm{n}=98)$ agreed that if they asked their partner to use a condom, the partner would get violent. This number represents a total of $49.2 \%$ of the sample who responded in the affirmative. The remaining participants disagreed $(47.3 \%, \mathrm{n}=106)$ or strongly disagreed $(3.6 \%, \mathrm{n}=8)$ that their partner would get violent if asked to use a condom.

\section{Preliminary Analysis}

One-way ANOVA, chi-square tests, and correlations were conducted to analyze the relationship between CSA and potentially mediating/confounding variables (age, 
marital status, and education) to determine if there was a need to control for any of the demographics in the dataset. Significant results were reported $p=.05$.

A one-way ANOVA was conducted to analyze whether there were any age differences between the groups of participants who had no exposure to CSA, some exposure to CSA, and high exposure to CSA. There were no differences between the three CSA groups in age distribution $[F(2,226)=1.22, p=.298]$.

A chi-square test was conducted to assess the relationship between exposure to CSA and marital status. The relationship between these variables was not significant $\left[\chi^{2}=\right.$ 8.41, $p=.395]$. Finally, a chi-square test was conducted to examine the relationship between exposure to CSA and education. Based on the results of the test, the three groups did not differ on education $\left[\chi^{2}=6.29, p=.615\right]$.

In addition to the tests of differences, a correlational analysis using the Pearson product-moment correlation coefficients $(r)$ was conducted to analyze the association between the potentially confounding variables (age, marital status, and education) and key variables of interest (CSA, multiple partners, attitudes about condom use, HIV knowledge, sexual self-efficacy, alcohol use, perception of social support, relationship control, and susceptibility to violence). There were several small to moderate correlations between potentially confounding demographic variables and the key variables of interest. However, based on the results, these variables were not mediating factors in the research, and therefore, did not require controlling in the data analyses. For complete correlation data, see Table 5. 
Table 5

Statistical Outcomes for Correlational Analysis of Variables

\begin{tabular}{|c|c|c|c|c|c|c|c|c|c|c|c|c|c|}
\hline & & Age & MS & ED & CSA & MP & CA & HK & SSE & LAU & SS & $\mathrm{RC}$ & SV \\
\hline Correlation & Age & 1.00 & . $187 \dagger$ & -.082 & .082 & .050 & $-.175 \dagger$ & -.159 & -.144 & . 121 & .043 & .038 & -.07 \\
\hline \multirow[t]{11}{*}{ Coefficient } & MS & & 1.00 & $-.256 \ddagger$ & . 095 & -.043 & -.084 & -.026 & .036 & .017 & .009 & -.084 & -.106 \\
\hline & ED & & & 1.00 & -.122 & -.065 & $.254 \ddagger$ & $.293 \ddagger$ & .095 & .077 & .001 & . $188 \dagger$ & .018 \\
\hline & CSA & & & & 1.00 & .121 & $-.189 \dagger$ & $-.197 \dagger$ & -.107 & .195† & -.031 & -.127 & -.074 \\
\hline & MP & & & & & 1.00 & .029 & .058 & -.074 & $.453 \ddagger$ & $-.156^{*}$ & .034 & .119 \\
\hline & CA & & & & & & 1.00 & $.407 \ddagger$ & $.235 \ddagger$ & .036 & -.072 & $.229 \ddagger$ & $.147^{*}$ \\
\hline & HK & & & & & & & 1.00 & $.212 \dagger$ & $.135^{*}$ & .030 & $.299 \ddagger$ & $.243 \ddagger$ \\
\hline & SSE & & & & & & & & 1.00 & $-.144^{*}$ & .063 & -.065 & .059 \\
\hline & LAU & & & & & & & & & 1.00 & $-.207 \dagger$ & .095 & .074 \\
\hline & PSS & & & & & & & & & & 1.00 & .001 & -.062 \\
\hline & $\mathrm{RC}$ & & & & & & & & & & & 1.00 & $.482 \ddagger$ \\
\hline & SV & & & & & & & & & & & & 1.00 \\
\hline Significance & Age & & .005 & .221 & .214 & .458 & .009 & .016 & .035 & .076 & .532 & .575 & .297 \\
\hline \multirow[t]{3}{*}{ Level } & MS & & & $<.001$ & .153 & .521 & .212 & .700 & .604 & .802 & .902 & .212 & .113 \\
\hline & ED & & & & .070 & .336 & $<.001$ & $<.001$ & . 170 & 267 & .986 & .005 & .787 \\
\hline & CSA & & & & & .071 & .005 & .003 & .806 & .004 & .648 & .058 & .267 \\
\hline
\end{tabular}


MP

CA

HK

SSE

LAU

PSS

RC

SV
.668

.390
$<.001$

.285

$<.001$

.023

.611

.075

$<.001$

.598

.303

$<.001 \quad .029$

.002

.040

.666

$<.001<.001$

.371

.003

$.346 \quad .393$

$.163 \quad .279$

$990 \quad .369$

$<.001$

\footnotetext{
$*$ = Correlation is statistically significant at .05 level (2-tailed)

$\dagger=$ Correlation is statistically significant at .01 level (2-tailed)

$\ddagger=$ Correlation is statistically significant at $<.001$ level (2-tailed)

MS = marital status

$\mathrm{CA}=$ condom attitudes

PSS = perception of social support

$\mathrm{ED}=$ education level

HK = HIV knowledge

$\mathrm{RC}=$ relationship control

CSA $=$ childhood sexual abuse

SSE $=$ sexual self-efficacy

$\mathrm{SV}=$ susceptibility to violence
}

MP = multiple partners

LAU $=$ level of alcohol use 


\section{Hypothesis Testing}

This section presents the results of testing the hypotheses that childhood sexual abuse is associated with current HIV-related risk factors and behaviors in a group of Haitian women who are HIV-positive alcohol users living in Haiti.

Research Question 1: What is the difference in the sexual risk behaviors (e.g. sex with multiple partners, condom attitudes, knowledge of HIV, and sexual selfefficacy) of participants who had exposure to CSA compared to those participants who did not have any exposure to CSA?

Hypothesis 1: Participants who had exposure to CSA will exhibit greater sexual risk behaviors than those participants who did not have any exposure to CSA. These risk behaviors include sex with multiple partners, less positive attitudes about condom use, lower knowledge of HIV, and lower sexual self-efficacy.

Descriptive analyses were first conducted to examine the occurrence of HIV risk behaviors within the different CSA exposure groups. Table 6 details the characteristics of the sexual risk behaviors by CSA group.

Table 6

Descriptive Characteristics of Sexual Risk Behaviors by CSA Group

\begin{tabular}{lccccccccc}
\hline & \multicolumn{3}{c}{ No Exposure } & \multicolumn{3}{c}{ Some Exposure } & \multicolumn{3}{c}{ High Exposure } \\
& $\mathrm{N}$ & $M$ & $S D$ & $\mathrm{~N}$ & $M$ & $S D$ & $\mathrm{~N}$ & $M$ & $S D$ \\
\cline { 2 - 10 } & 61 & 2.67 & 4.90 & 133 & 3.58 & 7.08 & 31 & 4.45 & 9.71 \\
Multiple Partners & 59 & 57.61 & 4.13 & 132 & 55.56 & 3.91 & 29 & 56.10 & 4.87 \\
Condom Attitudes & 59 & 17.27 & 2.49 & 135 & 16.75 & 2.40 & 32 & 16.47 & 1.98 \\
Sexual Self- & 58 & 13.78 & 1.60 & 127 & 13.46 & 1.76 & 30 & 13.77 & 2.05 \\
Efficacy & & & & & & & & & \\
\hline
\end{tabular}


A one-way ANOVA was conducted to analyze the differences between participants who had no exposure to CSA, some exposure to CSA, and high exposure to CSA and their current sexual risk behaviors. There were no differences in multiple partners $[F(2,222)=.717, p=.489]$, knowledge of $\operatorname{HIV}[F(2,226)=1.53, p=.218]$, or sexual self-efficacy $[F(2,212)=.794, p=.45]$ among the three CSA groups. Statistically significant differences were found between the groups for condom attitudes $[F(2,217)=$ 5.10, $p=.007]$. Post-hoc analyses using Tukey’s Honest Significant Difference (HSD) test and the Least Significant Difference (LSD) test were conducted to determine where the differences between the groups existed. Table7 details these findings. Both tests showed that participants with no exposure to CSA differed significantly in their attitudes (more favorable) toward condom use from those who had some exposure to CSA.

Table 7

Post-Hoc Analyses for Condom Attitudes Scores between Groups

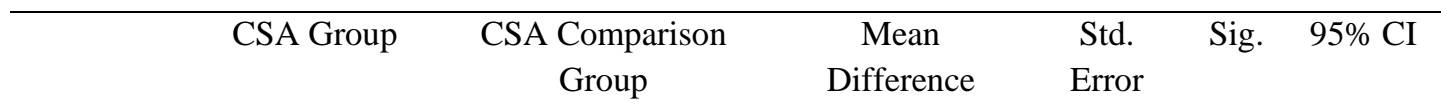

\begin{tabular}{|c|c|c|c|c|c|c|c|}
\hline & & & & & & & \\
\hline & & & & & & *LB & $* \mathrm{UP}$ \\
\hline Tukey & No Exposure & Some Exp & $2.05^{*}$ & .642 & .005 & .534 & 3.57 \\
\hline & & High Exp & 1.51 & .930 & .240 & -.689 & 3.70 \\
\hline & Some & No Exp & $-2.05 *$ & .642 & .005 & -3.57 & -.534 \\
\hline & 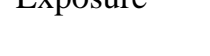 & High Exp & -.543 & .841 & .795 & -2.53 & 1.44 \\
\hline & High & No $\operatorname{Exp}$ & 2.05 & .930 & .240 & -3.70 & .689 \\
\hline & Exposure & Some Exp & 1.51 & .841 & .795 & -1.44 & 2.53 \\
\hline LSD & No Exposure & Some Exp & $-2.05^{*}$ & .642 & .002 & .784 & 3.32 \\
\hline & & High Exp & 1.51 & .930 & . 107 & -.327 & 3.34 \\
\hline
\end{tabular}




\begin{tabular}{|c|c|c|c|c|c|c|}
\hline \multirow{2}{*}{$\begin{array}{l}\text { Some } \\
\text { Exposure }\end{array}$} & No Exp & $-2.05 *$ & .642 & .002 & -3.32 & -.784 \\
\hline & High Exp & .543 & .841 & .519 & -2.20 & 1.12 \\
\hline \multirow{2}{*}{$\begin{array}{l}\text { High } \\
\text { Exposure }\end{array}$} & No Exp & -1.51 & .930 & 107 & -3.34 & .327 \\
\hline & Some Exp & .543 & .841 & .519 & -1.12 & 2.20 \\
\hline
\end{tabular}

*The mean difference is significant at the .05 level.

*LB = Lower Bound

*UP = Upper Bound

Research Question 2: What is the difference in the level of alcohol use by participants who had exposure to CSA compared to those participants who did not have any exposure to CSA?

Hypothesis 2: Participants who had exposure to CSA will have higher levels of alcohol use than those participants who did not have any exposure to CSA.

As with research question one, descriptive analyses were conducted to analyze the level of alcohol use within the three CSA exposure groups as described in Table 8. Based on selection criteria, all participants were identified as alcohol users. As previously mentioned, a score of eight or more on the Alcohol Use Disorders Identification Test (AUDIT; Saunders et al., 1993) suggests problem-level drinking (Maisto et al., 2000). Therefore, the variable of interest is level of alcohol use as opposed to solely whether the individual used alcohol or not. 
Table 8

Descriptive Characteristics of Level of Alcohol Use by CSA Group

Level of Alcohol Use

\begin{tabular}{lccc}
\cline { 2 - 4 } & $\mathrm{N}$ & Mean & Std. Deviation \\
\hline No Exposure to CSA & 59 & 10.46 & 8.05 \\
Some Exposure to CSA & 127 & 14.35 & 8.089 \\
High Exposure to CSA & 31 & 16.19 & 9.23 \\
\hline
\end{tabular}

A one-way ANOVA was conducted to analyze the differences between participants who had no exposure to CSA, some exposure to CSA, and high exposure to CSA and their level of alcohol use. Results indicated in Table 7 that there was a significant difference in the level of alcohol use between the three CSA groups $[F(2,214)$ $=.5 .26, p=.006]$. To further examine the relationship between exposure to CSA and level of alcohol use, post hoc tests were completed. Tukey’s HSD and the LDS tests showed that respondents with no exposure to CSA $(M=10.46, S D=8.05)$ scored significantly lower on the alcohol use measure than those respondents who had some exposure to CSA $(M=14.35, S D=9.69)$ as well as those who had high exposure to CSA $(M=13.55, S D=9.23)$. In essence, participants who had no exposure to CSA reported lower levels of alcohol use than their counterparts in both the some exposure and high exposure groups. There was not a significant difference in the level of alcohol use 
between respondents who had some exposure to CSA and those who had high exposure to CSA. For complete post hoc data, please see Table 9.

Table 9

Post-Hoc Analyses for Level of Alcohol Use between Groups

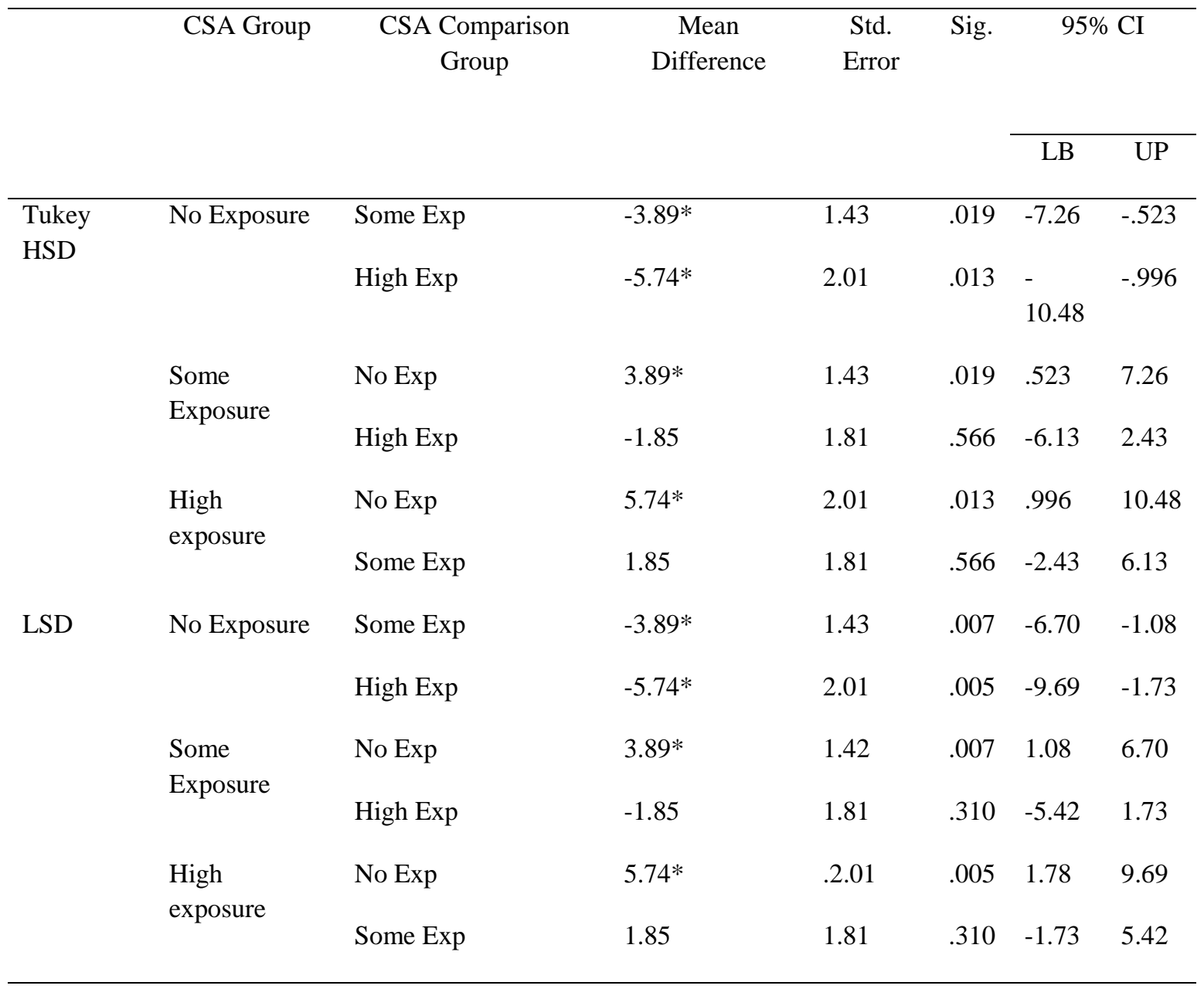

*The mean difference is significant at the .05 level.

Research Question 3: Is there a relationship between CSA and social support among HIV-positive women living in Haiti?

Hypothesis 3.1: Participants who had exposure to CSA will have lower perceptions of social support (family, friends, partners and doctors) than those participants who did not have any exposure to CSA. 
Hypothesis 3.2: Participants who had exposure to CSA will exhibit lower degrees of relationship power with primary partners than those participants who did not have any exposure to CSA.

Hypothesis 3.3: Participants who had exposure to CSA will be more susceptible to violence in their relationships with primary partners than those participants who did not have any exposure to CSA.

To provide an overview of the variables tested for this research question, descriptive analyses examined the perception of social support within the three CSA exposure groups. For the purposes of this study, social support included the participants' perception of social support from family, friends, partners, doctors, and other members of their social network, the balance of power in their relationships with primary partners (also defined as relationship control), and the participants' susceptibility to violence in their relationships with primary partners. Table 10 outlines the descriptive characteristics of the participants' social support by CSA group.

Table 10

Descriptive Characteristics of Perceived Social Support by CSA Group

\begin{tabular}{lcccccccccc}
\hline & \multicolumn{3}{c}{ No Exposure } & \multicolumn{3}{c}{ Some Exposure } & \multicolumn{3}{c}{ High exposure } \\
\cline { 2 - 11 } & N & $M$ & \multicolumn{1}{c}{$S D$} & N & $M$ & SD & N & $M$ & $S D$ \\
\cline { 2 - 10 } Perception of Support & 56 & 22.68 & 6.13 & 126 & 22.95 & 6.82 & 30 & 21.5 & 6.96 \\
Relationship Control & 61 & 33.26 & 4.33 & 133 & 32.69 & 4.34 & 31 & 32.03 & 5.33 \\
Susceptibility to & 60 & 2.53 & .650 & 133 & 2.44 & .656 & 31 & 2.61 & .667 \\
Violence & & & & & & & & & \\
\hline
\end{tabular}

For the final research question, one-way ANOVAs were completed to determine if a relationship existed between the three CSA groups and their perception of social 
support, the balance of power in their relationships, and their susceptibility to violence with primary partners. Statistical tests showed there were no statistically significant differences in perceived social support $[F(2,209)=.525, p=.592]$, relationship control $[F(2,222)=.782, p=.459]$, or susceptibility to violence $[F(2,221)=1.07, p=.367]$ between the three CSA groups.

\section{Summary}

This chapter presented the findings from a secondary analysis of an NIAAAfunded study data conducted by the researchers at Florida International University in collaboration with investigators at GHESKIO Centers. This secondary analysis examined the association between childhood sexual abuse and the HIV-related risk factors for HIVpositive Haitian women living in Haiti. The findings from the tests of the hypotheses as outlined were presented. The next and final chapter will discuss the results found in Chapter IV. In addition, a summary of the current study, implications for the field of public health, and recommendations for future research will be addressed. 


\section{CHAPTER V}

\section{DISCUSSION}

This final chapter summarizes and contextualizes the present study and reviews its purpose, significance, and the results reported in Chapter IV. Discussion regarding the limitations of the study, practical implications of the findings for public health, and recommendations for future research are included.

\section{Summary of the Study}

This study investigated the association between the exposure to childhood sexual abuse (CSA) and HIV-related risk factors including sexual risk behaviors (multiple partners, attitudes about condom use, HIV-related knowledge, and sexual self-efficacy), alcohol abuse, and social support (perceived availability of social support, relationship control, and susceptibility to violence) in a group of Haitian women ages 17-55 who are HIV-positive alcohol users living in Haiti. The Theory of Gender and Power (TGP; Connell, 1987; Wingood \& DiClemente, 2002), as presented by Wingood and DiClemente (2002) provided the theoretical framework for this study because of its coverage and understanding of women at risk for acquiring HIV.

The study analyzed how the level of exposure to sexual abuse during childhood affected the current HIV-related risk factors of the participants in the study population. Participants' age, marital status, and education were also analyzed in relation to exposure to CSA in order to establish any possible associations between exposure and sociodemographic characteristics. Correlation analyses were also conducted between the aforementioned sociodemographic characteristics and sexual risk behaviors, level of 
alcohol use, and social support of the respondents to determine if correlated variables were associated with the outcomes of the primary research questions.

\section{Problem Statement}

The number of women with HIV living in Haiti has significantly increased since the year 2000, even though the overall HIV prevalence rate for the country is declining. As recently as 2013, 60\% (74,000) of adults 15 years of age and older living in Haiti with HIV were women (UNAIDS, 2014). This number represents an increase from $46 \%$ in 2000 and 53\% in 2007 (UNAIDS, 2013a; UNAIDS, 2008). Studies have indicated that some of the most common risk factors associated with HIV infection among Haitian women living in Haiti include multiple lifetime sexual partners, lack of condom use within or outside of monogamous relationships, lack of education, and economic hardship (Logie, Daniel, Newman, \& Loutfy, 2012; Rosenberg, Seavey, Jules, \&

Kershaw, 2011; Fawzi et al., 2010; Fawzi et al., 2003; Deschamps \& Pape, 1996). While these risk factors appear to be the most common among Haitian women infected with HIV, other risk factors, such as childhood sexual abuse, may also contribute to the prevalence of HIV among this population based on research conducted in similar, lowresource settings (Parcesepe, 2015; Richter et al., 2014; Longman-Mills et al., 2013; Tomaszewski, 2012).

Unfortunately, CSA is one of the least studied HIV-related risk factors in Haiti, even though research in the United States and Europe have clearly established the link between childhood trauma, CSA, and high risk sexual behaviors (Senn \& Carey, 2010; Whetten et al., 2008; Malow, Dévieux, \& Lucenko, 2006; Malow et al., 2006; Myers et al., 2006; Wyatt, Myers, \& Loeb, 2004; Wyatt et al., 2004; Wyatt et al., 2002; Whetten 
et. al., 2008). Because research also indicates that CSA is a significant risk factor for HIV-positive women across all racial groups (Wyatt et al., 2002), understanding the role and impact of CSA on Haitian women living with HIV is likely to strengthen future HIV prevention and treatment efforts aimed at this vulnerable group.

\section{Purpose of the Study}

Currently there are no studies that examine the relationship between CSA and the HIV-related risk factors among HIV-positive Haitian women living in Haiti. Therefore, the primary purpose of this study was to analyze the association between CSA and the sexual risk behaviors (number of lifetime partners, condom attitudes, HIV-related knowledge, and sexual self-efficacy), level of alcohol use, and social support (perceived social support, relationship control, and susceptibility to violence) in a group of Haitian women who are HIV-positive alcohol users living in Haiti. The study also analyzed data on the demographic characteristics of the population such as age, marital status, and education to determine if these were confounding variables that required statistical control in the data analysis.

\section{Discussion of Findings: Correlations}

Below is a summary of the statistically significant findings from the data analyses conducted in Chapter IV, beginning with a discussion of the results from the correlational analysis of all variables including potentially confounding, independent, and dependent variables. There were several small to moderate correlations among the variables.

Age was negatively associated with condom attitudes, HIV-related knowledge, and sexual self-efficacy. In other words, older women tended to have less favorable attitudes towards condom use, less knowledge on HIV-related matters, and lower ability 
to negotiate condom use during sexual encounters. These findings were consistent with the research where older adults tend to have lower HIV-related knowledge and lower sexual self-efficacy (Ludwig-Barron, 2014; Negin et al., 2012). This is likely related to reduced fertility, low perceived susceptibility, and lack of knowledge of safe sex practices due to monogamy with a specific individual for an extended period of time where condoms may not have been used (Ludwig-Baroron, 2014). Women with higher education levels tended to: have more knowledge on HIV-related topics, have more favorable attitudes towards condom use, report greater perceived ability to negotiate condom use during their sexual encounters, and have equal or more balance of power or control in their relationships with primary partners. Previous research indicates mixed results; and therefore, is not fully consistent with the literature (Hargreaves et al., 2015; Miles et al., 2013; Amuri, Mitchell, Cockcroft, \& Anderson, 2011). Although there were several correlations between age, education and the other variables of interest, there was no evidence that these three demographic variables had a confounding or potentially mediating effect on the primary study variables.

Because the individuals in the study population were already alcohol users, the study analyzed data on their level of alcohol use. The greater an individual's score on the AUDIT tool (which suggests higher likelihood of an alcohol problem), the lower her perceived availability of social support from family, friends, and partners, the lower her perceived ability to negotiate condom use during sexual encounters, and the greater likelihood she had more sexual partners over the course of three months than her counterparts who had lower levels of alcohol use. Interestingly, individuals with greater levels of alcohol use tended to have greater knowledge of HIV-related topics. Studies 
have produced mixed results in determining the link between HIV-related knowledge and alcohol use (Chacon Ortiz et al., 2014; Zetola et al., 2014). Therefore, although interesting, this is not uncommon.

Participants with higher HIV-related knowledge tended to have greater confidence in their ability to negotiate safer sex during sexual encounters, had more control or experienced a greater balance of power in their relationships with primary partners, had more favorable attitudes towards condom use, had higher education, and tended to be younger. Participants with higher HIV-related knowledge were also more likely to believe they would be susceptible to violence if they asked their primary partners to use a condom. A possible explanation for this correlation could be that by being knowledgeable about HIV-related topics, these women may be more assertive in relationships with their partners; thereby, violating the culturally accepted norms that women should be submissive. The fact that they had greater self-efficacy, had more relationship control with primary partners, had higher levels of education, and tended to be younger seem to reinforce the view that their partners may feel more threatened by these factors that are counter to traditional cultural norms in Haiti, and therefore use violence as a form of control (Gage, 2015; Conserve, Whemboula, \& Surkan, 2014; Cayemittes et al., 2013; Gage \& Hutchinson, 2006; Gage, 2005).

These are interesting findings that can be explained /understood through the Haitian cultural lense and that of similar traditional societies (patriarchal) 
In addition to having higher levels of alcohol use, respondents with more sexual partners over a three-month period also had lower perceptions of the availability of social support in their lives. Respondents who had higher perceptions of their ability to negotiate safe sex or condom use during their sexual encounters were also more likely to have greater knowledge on HIV-related topics, have more favorable attitudes towards condom use, and have lower levels of alcohol use. They were reportedly younger as well. Individuals who had more favorable views of their availability of social support had fewer sexual partners over a three-month period and lower indications of an alcohol problem. Similarly, participants who had equal or more control in their relationships with primary partners had higher education, greater knowledge about HIV-related topics, and more positive attitudes towards condom use. Conversely, they tended to be more susceptible to violence in their relationships with primary partners.

There were quite a few variables highly correlated to condom attitudes. Women with more favorable attitudes towards condom use were more likely to have greater HIVrelated knowledge, to have greater perceived ability to negotiate safe sex, to have comparatively more control in their primary partner relationships, to be younger, and more likely to have a higher education. However, they had a greater perceived susceptibility to violence when asking a primary partner to use a condom than women who had less favorable attitudes towards condom use.

\section{Discussion of Findings: Research Questions}

Research Question 1: What is the difference in the sexual risk behaviors (e.g. sex with multiple partners, condom attitudes, knowledge of HIV, and sexual self- 
efficacy) of participants who had exposure to CSA compared to those participants who did not have any exposure to CSA?

Hypothesis 1: Participants who had exposure to CSA will exhibit greater sexual risk behaviors than those participants who did not have any exposure to CSA. These risk behaviors include sex with multiple partners, less positive attitudes about condom use, lower knowledge of HIV, and lower sexual self-efficacy.

The analyses indicated that exposure to childhood sexual abuse does result in less favorable attitudes towards condom use as a sexual risk behavior of interest. This finding supports previous studies that have established that victims of CSA exhibit higher sexual risk behaviors than persons who have not experienced CSA (Jones, et al., 2010b; Whetten, 2006; Paolucci \& Violato, 2001; McCauley et al., 1997). However, the results of the study found no difference in the relationship between level of exposure to CSA and multiple partners, knowledge of HIV, and sexual self-efficacy—the remaining behaviors organized under the sexual risk behaviors variable. This finding was despite the fact that level of CSA was highly correlated to condom attitudes and HIV-related knowledge. Although not statistically significant, there was a trend in association between CSA and multiple partners. This moderate correlation was close to the accepted level of significance $(p=0.05)$, indicating that a correlation might have been possible if there had been a greater number of participants. CSA was not closely correlated to sexual selfefficacy based on the correlation analysis.

In reviewing other studies, victims of CSA are more likely to have multiple sexual partners and have more incidents of unprotected sex (Sikkema et al., 2013; Jones et al., 2010b; Brown, Lourie, Zlotnick, \& Cohn, 2000; Cohen et al., 2000; Zierler et al., 1991). 
Therefore, the current study finding does not align with existing research on general sexual risk behaviors and behaviors specific to victims of childhood sexual abuse who are also infected with HIV (Banducci, Hoffman, Lejeuz, \& Koenen, 2014; Meade et al., 2011). Because some questionnaires were administered by an interviewer, participants may have succumbed to social desirability bias and felt pressure to respond to the questions in a way they perceived would be more positive to the assessor. Recent studies have found that utilizing self-administered surveys where individuals are allowed to answer questions privately can reduce social desirability bias and increase concurrent validity (Chang \& Krosnick, 2010). However, in a setting where the illiteracy rate for adults is nearly 60\% (CIA, 2013; USIP, 2012; OSEH, 2012) this method of survey administration would not be as effective as a face-to-face interview.

In addition to a possible over-estimation of the participants' ability to negotiate safer sex with primary partners (which would have affected the results of the data analysis), the finding that there was no link between CSA and sexual self-efficacy may indicate that the self-efficacy tool used was not culturally relevant to this specific population. In this case, it would be difficult to detect a link between CSA and sexual self-efficacy. Moreover, most of the study participants felt that asking a partner to use a condom would lead to violence, regardless of CSA exposure. Given this information, one could speculate that these women would not feel comfortable or would even avoid talking to their partners about monogamy, condom use, their sexual activities, HIV, and STIs-all topics that can be grouped under sexual self-efficacy. This coincides with the sexual division of power structure in the Theory of Gender and Power (Wingood \& DiClemente, 2002) where having a partner who disapproves of practicing safer sex 
(physical exposure) would be associated with behavioral risk factors such as poor assertive communication skills, poor condom use skills, lower self-efficacy to avoid HIV or STIs, and limited perceived control over condom use.

Ultimately, given that only one of the variables of sexual risk behaviors was statistically significant and there were inconsistencies noted in the remaining findings, Hypothesis 1 is partially supported. Although exposure to childhood sexual abuse did predict less favorable condom attitudes, the other three sexual risk behavior variables (HIV knowledge, multiple partners, and sexual self-efficacy) were not associated with childhood sexual abuse.

Research Question 2: What is the difference in the level of alcohol use by participants who had exposure to CSA compared to those participants who did not have any exposure to CSA?

Hypothesis 2: Participants who had exposure to CSA will have higher levels of alcohol use than those participants who did not have any exposure to CSA.

Participants in this study who had some exposure to CSA used significantly more alcohol than participants who did not have exposure to CSA. As discussed in the literature review, major factors that contribute to alcohol abuse include past and current physical, emotional, and psychological trauma including CSA, stress, environmental surroundings, family history (Magnusson et al., 2012; Enoch, 2011; Hughes et al., 2007; Kilpatrick et al., 2000). Additionally, prior research has shown that there is a correlation between women who were abused during childhood and contracting HIV, with alcohol being implicated in this association (Schacht et al., 2009). According to the TGP (Wingood \& DiClemente, 2002), women who have a history of physical or sexual abuse 
as a part of their physical exposures have behavioral risk factors that include using alcohol or drugs. This fact highlights the appropriateness of the theoretical framework used in developing the accepted hypothesis.

In further analyzing the data results, there were differences between individuals with no exposure to CSA and the two groups of individuals who had some exposure to CSA and high exposure to CSA. In essence, if an individual had exposure to CSA no matter how minimal, that individual was more likely to consume higher levels of alcohol than someone who did not have any exposure. This is a critical finding in the data because it shows that any exposure to CSA may have long-lasting effects well into adulthood. Previous studies support this finding in that women who were abused during childhood were more likely to report higher rates of alcohol abuse, recent alcohol use, intoxication, drinking-related problems, and alcohol dependence symptoms (Khoury, Bradley, Cubells, \& Ressler, 2010; Widom \& Hiller-Sturmhöfel, 2001; Kendler et al., 2000; Wilsnack, Vogeltanz, Klassen, \& Harris, 1997). For instance, Widom and HillerSturmhöfel (2001) noted in their study that women who experienced CSA reported alcohol consumption in the 30 days prior to the study interview, intoxication in the year before the study interview, one or more alcohol-related problems (e.g. fights with family members, work problems, home accidents, and problems with children) in the year before the study interview, and/or one or more symptoms of alcohol dependence (e.g. memory lapses while drinking, morning drinking, and inability to stop or reduce drinking over time) in the year before the study interview. In another study conducted by Khoury, Bradley, Cubells, \& Ressler (2010), not only were female participants who experienced childhood abuse more likely to use alcohol above any other substance than women who 
had not experienced CSA, but female participants who experienced CSA also had higher consumption levels of alcohol than their counterparts.

Based on the statistical findings, Hypothesis 2 is supported. Exposure to childhood sexual abuse does predict higher levels of alcohol use in a population of HIVpositive Haitian women. Additionally, the statistical findings showed that the mean alcohol scores (indicating a drinking problem) increased between the different exposure levels. Individuals who had high exposure to CSA had higher indications of a drinking problem than those with some exposure to CSA, and those with some exposure to CSA had higher indications of a drinking problem than those who had no exposure to CSA.

Research Question 3: Is there a relationship between CSA and social support among HIV-positive women living in Haiti?

Hypothesis 3.1: Participants who had exposure to CSA will have lower perceptions of social support (family, friends, partners and doctors) than those participants who did not have any exposure to CSA.

Hypothesis 3.2: Participants who had exposure to CSA will exhibit lower degrees of relationship power with primary partners than those participants who did not have any exposure to CSA.

Hypothesis 3.3: Participants who had exposure to CSA will be more susceptible to violence in their relationships with primary partners than those participants who did not have any exposure to CSA.

In this sample, exposure to childhood sexual abuse did not result in lower social support among HIV-positive Haitian women living in Haiti. A composite score for social support was not created due to the different tools used to assess the three constructs that 
made up social support. Instead, the concept of perception of social support was analyzed as three separate variables: perception of support from family, friends, partners, and doctors, degrees of relationship power (also defined as relationship control), and susceptibility to violence.

The study findings led to Hypothesis 3.1 being rejected. There was no difference between respondents' level of exposure to CSA and perception of social support from their primary support network. When examining correlational analysis, perception of social support from primary support networks did not correlate with CSA exposure either. This finding is in contrast to the literature which states that despite advances in medicine, individuals infected with HIV continue to experience high levels of discrimination and stigmatization in their community (Richter, 2015; Neufeld et al., 2012). However, in relation to CSA, a recent study by Richter and her colleagues (2015) found that women with a history of CSA reported significantly higher perceived social support compared to people without such experiences. The study postulates that these findings may reflect the support women received when they disclosed their CSA status. When disclosing their exposure to CSA, respondents found more favorable responses, which lessened the burden of stigma and stress about their HIV status (Richter, 2015). The literature also points out that people living with HIV and people who have experienced CSA are at risk for shame (Neufeld et al, 2012; Feiring, 2010; Persons, Sikkema, \& Hansen, 2010; Wilson, 2006; Tangey, 1995). Shame, in this context, is a marker of lower perceived social support. Neufeld and colleagues (2012) define shame as “a painful emotion resulting from negative self-evaluation following a perceived deviation from a social or moral code, and is accompanied by feelings of worthlessness, 
rejection, isolation, and the desire to disappear (p. 1064).” One reason this finding may not be statistically significant is the definition of social support used in the study that could have affected how the women responded. Additionally, there were similarities in scores across groups for perceived social support. This may have had an effect on the ability to derive statistically significant data when measuring differences between CSA groups. The similarities in responses may be attributed to participants' lack of disclosure of CSA exposure to social support networks, which was not measured in this study. It must also be noted that although there are numerous studies examining social support in HIV-infected populations and CSA-impacted populations, very few examine the effect the combination of HIV and CSA has on an individual's perceived social support.

The study findings also led to Hypothesis 3.2 being rejected. There was no evidence in the data analysis that supported the hypothesis that participants who had exposure to CSA would exhibit lower degrees of relationship power with primary partners or lower relationship control than those participants who did not have any exposure to CSA. This finding is despite the fact that CSA had a near significant association with relationship control $(p=.058)$. A significant correlation might have been possible if the sample size had been larger. The correlation might also have been affected by potential social desirability bias, which is discussed below.

Studies have also established that that there is an association between women's risk for HIV and male control in female/male relationships (Jewkes, Dunkle, Nduna, \& Shai, 2010; Dunkle et al, 2004; Pulerwitz, Gortmaker, \& DeJong, 2000). This finding is also supported by the Theory of Gender and Power which states that women who have less control or less balance of power in their relationships with primary partners are at an 
increased risk for HIV because their sexual choices and behavior become constrained (Wingood \& DiClemente, 2002). An alternative to this hypothesis might have been to examine the association between contraception use as a method of control in male/female relationships where the women are HIV-positive and have had exposure to CSA (Pettifor, Measham, Rees, \& Padian, 2004).

Finally, there was no statistically significant difference in respondents’ susceptibility to violence and their exposure to CSA. Therefore, Hypothesis 3.3 was not supported by the data. For the purposes of the study, relationship control and susceptibility to violence were analyzed separately although they are often combined in the literature. As previously reported, the percentage of participants who responded that their partners would get violent if asked to wear a condom was almost equal to the number of participants who responded that their partner would not become violent. This outcome could also be a result of respondents answering the questions more positively than their actual experiences because of social desirability bias that may be operating in face-to-face their interviews. An interesting outcome for this measure was that the mean response for all participants across the CSA exposure groups was 2.5 on a scale of 1-4. This number indicates that, on average, women in all CSA groups felt that their partners would get violent if they were asked to wear condoms. Therefore, even though there were no differences between the groups, the fact remains that the average woman in this study population has an average susceptibility to experience violence from their primary partners. Not only does this finding mirror studies that have found that there is an association between women's risk for HIV and intimate partner violence in primary relationships (Jewkes, Dunkle, Nduna, \& Shai, 2010; Dunkle et al, 2004; Pulerwitz, 
Gortmaker, \& DeJong, 2000), it is also underscored by the Theory of Gender and Power which states that women who are susceptible to or experience violence in relationships with primary partners are at an increased risk for HIV (Wingood \& DiClemente, 2002). Nonetheless, because the findings of this study did not find a difference between groups, an inference cannot be made about the association between CSA exposure and susceptibility to violence in this specific population.

Ultimately, given that none of the variables of social support were statistically significant and there were inconsistencies in the remaining findings, Hypotheses 3.1, 3.2, and 3.3 must all be rejected. Although previous studies did find relationships among the variables of interest, social support was not associated with childhood sexual abuse in this sample.

\section{Implications for Public Health and Recommendations}

The findings presented in the current study have substantial implications for the field of HIV prevention, education, and intervention. Specifically, the correlation between HIV-related risk factors and childhood sexual abuse offer a targeted opportunity for providing programs for specific groups within the HIV-infected population in Haiti. Additionally, the group differences in attitudes towards condom use and levels of alcohol use among HIV-positive Haitian women provide further evidence that there are various types of HIV-positive individuals who have different past and present experiences that affect their current beliefs and behaviors. For instance, the present study supported the hypotheses that women who had exposure to childhood sexual abuse had less favorable attitudes towards condom use and had significantly higher indications of alcohol abuse. Evaluating women at the time of their HIV diagnosis for a history of childhood trauma 
and the examining the impact of targeted interventions for coping with that childhood trauma represents a valuable research opportunity. Interventions designed an intervention program specifically for HIV-positive women living in Haiti who have had exposure to childhood trauma, particularly childhood sexual abuse are likely to benefit this group of very vulnerable women. Such interventions could determine how present HIV-related risk factors and behaviors are affected when childhood sexual abuse and HIV are the focus of an integrated treatment model. Sikkema and her colleagues (2006) developed and evaluated such an intervention which demonstrated the efficacy of a theoreticallybased group intervention for coping with trauma related to CSA among women and men living with HIV/AIDS.

The importance of developing culturally adapted interventions like this one is important because, as noted in several studies (Sikkema et al., 2013; Jones et al., 2010a; Sikkema et al., 2006; Wyatt, Carmona, Loeb, Ayala, \& Chin, 2002; Greenberg, 2001; Bensley, Van Eenwyk, \& Simmons, 2000), CSA has long been associated with sexual risk behavior and substance use. HIV-positive adults with a history of CSA and other childhood trauma engage in more HIV risk behaviors in comparison to individuals without such histories (Banducci, Hoffman, Lejeuz, \& Koenen, 2014; Meade et al., 2011; Sikkema, et al., 2006; Wyatt, Myers, \& Loeb, 2004). Nonetheless, empirically-based interventions that address CSA among HIV-infected persons are few in the literature (Banducci, Hoffman, Lejeuz, and Koenen, 2014; Meade et. al., 2011; Sikkema, et. al., 2006), and none exist in resource-constrained settings like Haiti. It is critical that researchers further the relationship between CSA and HIV-related risk factors in order to address poor health outcomes and continued transmission risk behavior. 
In regards to theory development and implications for future research, the current study supports the Theory of Gender and Power as a guiding framework and conceptual model for identifying factors that may influence a woman's risk for HIV infection and for specifically reinforcing the link between CSA and HIV. However, the present study findings and established studies (Banducci, Hoffman, Lejeuz, \& Koenen, 2014; Meade et al., 2011; Sikkema et al., 2006) suggest that there are different groups within the HIVinfected population with varying biological and environmental exposures that may need to be addressed within the context of the groups' cultural, social, and circumstantial norms. Currently, the Theory of Gender and Power (Wingood \& DiCliemente, 2002) only examines biological and environmental exposures that may lead to infection. The present study adds to the Theory of Gender and Power by examining the biological and environmental exposures that continue to affect the population post-exposure to HIV and other disease outcomes. Because advances in treatment and medication have added to the lifespan of individuals infected with HIV and other chronic conditions, it is important to develop or augment an existing theoretical model that can guide HIV prevention and treatment efforts, including reducing transmission risk and coping, among individuals who have already been infected and affected by the virus.

The findings in the current study add to the growing body of literature on the association between childhood sexual abuse and HIV-related risk factors among HIVpositive Haitian women living in Haiti. Dedicating funding to research that will address the needs and interventions necessary to improve the health outcomes of this subset of the HIV-positive population will undoubtedly have far-reaching implications for the 
treatment and long-term management of HIV in Haiti and similar settings where resources are limited.

\section{Limitations}

The present study has a number of limitations. The instrumentation and measures used in this study may be biased for several reasons. Primarily, the data collected was based on self-report. Participants may have responded to questions in a manner that reflected social-desirability bias.

Participants were asked to recall and categorize their experiences with CSA. Considering that the participants in the study ranged in age from 18-55, there was a potential for recall bias. They were asked to recall events dating back to childhood, meaning that a number of years may exist between the time of abuse and the current age of a participant. In addition, the various survey questions asked participants to recall experiences, feelings, and behaviors from different periods of time (e.g. childhood, the past 30 days, and the past 3 months) that could have resulted in confusion or inaccurate responses. This could have skewed data. However, because it is very difficult to determine which responses were based on actual experience or participants' memory, the responses cannot be discounted.

There were multiple instruments used that contained a variety of questions. These questions focused on different, although related, topics and behaviors (e.g. medication adherence, sexual risk behaviors, depression, coping skills, alcohol use, HIV, social support, and the January 2010 earthquake in Haiti) that could have proven overwhelming for participants, resulting in participant response fatigue (Egleston, Miller, \& Meropol, 2011; Galesic \& Bosnjak, 2009). According to Egleston and colleagues, response fatigue 
is more likely to occur when survey respondents provide untruthful or inconsistent responses in order to accelerate the survey period or reduce the burden of answering questions. It is important to note, however, that assessments for this study were conducted over two sessions and participants were could ask for breaks whenever needed or if they felt fatigued.

Certain measures may not have generated accurate data from the participants due to the sensitive nature of some of the questions (i.e. childhood sexual abuse, sexual activity, number of sexual partners over a three-month period, level of alcohol use, and violence in relationships). Therefore, the responses must be viewed with some level of caution.

This was a cross-sectional study, which has inherent limitations including the fact that the data analyzed was collected at a single point in time to examine the relationship between childhood sexual abuse and HIV-related risk factors as perceived by the participants at the specific time of the survey. The study design is also limited in its ability to draw valid conclusions about the possible causality between childhood sexual abuse, the HIV-related risk factors, and the potentially confounding demographic variables, which were ultimately determined to not have a confounding effect on the variables of interest. Multiple associations were found between the study variables, but due to the nature of cross-sectional studies, those associations were difficult to interpret.

The limitation of the cross-sectional design used for this study also warrants additional research due to issues with the "snapshot" perspective and temporality. Because of the nature of the cross-sectional design, longitudinal changes could not be observed. Additionally, the study only observed the female population, which excludes 
the ability to analyze the male perspective of the population. The ability to review data and outcomes as it relates to HIV-positive Haitian men who have experienced CSA would certainly add to the literature.

The study population was very specific; and therefore, the results are not generalizable to all HIV-positive women. Nonetheless, this limitation also provides an important opportunity to add to the body of literature regarding childhood sexual abuse among a vulnerable group of HIV-positive women living in resource-poor settings. Furthermore, this study will provide insight that may inform future interventions for this group of underserved women.

The participants were HIV-positive women who use alcohol and live in Haiti. The assumption is that these factors limit the findings of this study to a unique population. To counter this limitation, it is very important to reiterate that research has established a link between CSA and sexual risk behaviors (Sikkema et al. 2013; Jones et al., 2010b; Whetten, 2006; Paolucci \& Violato, 2001; McCauley et al., 1997). Therefore, although the sample might appear to be very specific, the findings may have implications for women with similar characteristics in other resource-constrained settings. What is limited in the body of research is the link between CSA and HIV-related risk factors, level of alcohol abuse, and social supports for HIV-positive Haitian women living in Haiti (Whetten et al., 2008). Therefore, the study may undoubtedly add to the body of knowledge.

Another limitation of this study was the likelihood that participants may not have been willing or ready to disclose information about childhood sexual abuse, as previously mentioned. Due to the stigma of CSA, participants may have selected responses that 
indicated no history of childhood sexual abuse or responses that cannot be analyzed (e.g. no answer or non-applicable). This response pattern may have resulted in skewed data or reduced the number of participants who reported experiencing CSA.

The final limitation of the study was the sample size. Based on the power analysis, only 139 participants were needed for sufficient power to conduct the data analysis, Of the 393 respondents who completed baseline data for the parent study, only data from female respondents (242) was of interest for the present study. Among those respondents, 13 participants had missing data elements and could not be included in the final data run. These individuals did not complete the abbreviated Childhood Trauma Questionnaire, refused to answer the questions, did not know if they were sexually abused as a child, or selected "not applicable" as a response. As a result, the final sample size for the study was 229 women. Although the sample size is sufficient, a larger sample size may have led to more robust findings for several items that were just below the acceptable level for statistical significance or correlation. 


\section{REFERENCES}

American Academy of Pediatrics Committee on Child Abuse and Neglect (AAP). (1992). Guidelines for the evaluation of sexual abuse of children: Subject review. Pediatrics. 103(1), 186-191.

Adrien, A., Boivin, J. F., Tousignant, Y., \& Hankins, C. (1990). Knowledge, attitudes, beliefs and practices related to AIDS among Montreal residents of Haitian origin. Canadian Journal of Public Health = Revue Canadienne de Sante Publique, 81(2), 129-134.

Amedee, A. M., Nichols, W. A., Robichaux, S., Bagby, G. J., \& Nelson, S. (2014b). Chronic alcohol abuse and HIV disease progression: studies with the non-human primate model. Current HIV Research, 12(4), 243-253.

Amirkhanian, Y. A. (2014). Social networks, sexual networks and HIV risk in men who have sex with men. Current HIV/AIDS Reports, 11(1), 81-92. http://doi:

10.1007/s11904-013-0194-4

Amuri, M., Mitchell, S., Cockcroft, A., \& Andersson, N. (2011). Socio-economic status and HIV/AIDS stigma in Tanzania. AIDS Care, 23(3), 378-382.

http://doi:10.1080/09540121.2010.507739

Bagby, G. J., Amedee, A. M., Siggins, R., Molina, P. E., Nelson, S., \& Veazey, R. S. (2015). Alcohol and HIV Effects on the Immune System. Alcohol Research: Current Reviews, 37(2), 287-297.

Baird, D. S., Jones, L. D., Martin, F., \& Yearwood, E. (2012). Mental health of Caribbean women with HIV/AIDS. Psychology, 03(12), 1005-1009. http://doi.org/10.4236/psych.2012.312151

Banducci, A. N., Hoffman, E. M., Lejuez, C. W., \& Koenen, K. C. (2014). The impact of childhood abuse on inpatient substance users: Specific links with risky sex, aggression, and emotion dysregulation. Child Abuse and Neglect, 38(5), 928-938. http://doi.org/10.1016/j.chiabu.2013.12.007

Basen-Engquist, K., Mâsse, L. C., Coyle, K., Kirby, D., Parcel, G. S., Banspach, S., \& Nodora, J. (1999). Validity of scales measuring the psychosocial determinants of HIV/STD-related risk behavior in adolescents. Health Education Research, 14(1), 25-38. http://doi.org/10.1093/her/14.1.25

Bekele, T., Rourke, S. B., Tucker, R., Greene, S., Sobota, M., Koornstra, J., ... Guenter, D. (2013). Direct and indirect effects of perceived social support on health-related 
quality of life in persons living with HIV/AIDS. AIDS Care, 25(3), 337-46.

http://doi.org/10.1080/09540121.2012.701716

Boesten, J., \& Poku, N. (2009). Gender and HIV/AIDS critical perspectives from the developing world. Farnham, England: Ashgate.

Borwein, A., Salters, K. A., Palmer, A. K., Miller, C. L., Duncan, K. C., Chan, K., ... Hogg, R. S. (2014). High rates of lifetime and recent violence observed among harder-to-reach women living with HIV. AIDS Care, 26(5), 587-594. http://doi.org/10.1080/09540121.2013.844763

Bowleg, L., Burkholder, G. J., Massie, J. S., Wahome, R., Teti, M., Malebranche, D. J., \& Tschann, J. M. (2013). Racial discrimination, social support, and sexual HIV risk among black heterosexual men. AIDS and Behavior, 17(1), 407-418. http://doi.org/10.1007/s10461-012-0179-0

Brady, K. T., \& Back, S. E. (2012). Childhood Trauma, Posttraumatic Stress Disorder, and Alcohol Dependence. Alcohol Research: Current Reviews, 34(4), 408-413.

Braithwaite, R. S., Fang, Y., Tate, J., Mentor, S. M., Bryant, K. J., Fiellin, D. A., \& Justice, A. C. (2015). Do alcohol misuse, smoking, and depression vary concordantly or sequentially? A longitudinal study of HIV-infected and matched uninfected veterans care. AIDS and Behavior, 1-7. http://doi.org/10.1007/s10461015-1117-8

Breet, E., Kagee, A., \& Seedat, S. (2014). HIV-related stigma and symptoms of posttraumatic stress disorder and depression in HIV-infected individuals: does social support play a mediating or moderating role? AIDS Care, 26(8), 947-951. http://doi.org/10.1080/09540121.2014.901486

Bressert, S. (2013). Stress and Drinking. Psych Central. Retrieved on May 27, 2015, from http://psychcentral.com/lib/stress-and-drinking/

Brezing, C., Ferrara, M., \& Freudenreich, O. (2015). The syndemic illness of HIV and trauma: Implications for a trauma-informed model of care. Psychosomatics, 56(2), 107-118. http://doi.org/10.1016/j.psym.2014.10.006

Brown, L. K., Lourie, K. J., Zlotnick, C., \& Cohn, J. (2000). Impact of sexual abuse on the HIV-risk-related behavior of adolescents in intensive psychiatric treatment. American Journal of Psychiatry, 157(9), 1413-1415.

Burgos-Soto, J., Orne-Gliemann, J., Encrenaz, G., Patassi, A., Woronowski, A., Kariyiare, B., ... Becquet, R. (2014). Intimate partner sexual and physical violence among women in Togo, West Africa: prevalence, associated factors, and the specific 
role of HIV infection. Global Health Action, 7, 23456.

http://doi.org/10.3402/gha.v7.23456

Caldwell, D. H., \& Gryczynski, J. (2012). Computerized assessment facilitates disclosure of sensitive HIV risk behaviors among African Americans entering substance abuse treatment. American Journal of Drug and Alcohol Abuse, 38(4), 365-369. http://doi.org/10.3109/00952990.2012.673663

Campbell, A. N. C., Tross, S., Dworkin, S. L., Hu, M.-C., Manuel, J., Pavlicova, M., \& Nunes, E. V. (2009). Relationship power and sexual risk among women in community-based substance abuse treatment. Journal of Urban Health, 86(6), 951964. http://doi.org/10.1007/s11524-009-9405-0

Carver, J. W., Dévieux, J. G., Gaston, S. C., Altice, F. L., \& Niccolai, L. M. (2014). Sexual Risk Behaviors Among Adolescents in Port-au-Prince, Haiti. AIDS and Behavior, 1-9. http://doi.org/10.1007/s10461-013-0689-4

Casale, M., \& Wild, L. (2012). The relationship between social support and the health of HIV-positive caregivers of children: A review of the empirical literature. Vulnerable Children and Youth Studies, 7(3), 260-282.

http://doi.org/10.1080/17450128.2012.668232

Casale, M., \& Wild, L. (2013). Effects and processes linking social support to caregiver health among HIV/AIDS-affected carer-child dyads: A critical review of the empirical evidence. AIDS and Behavior, 17(5), 1591-1611.

http://doi.org/10.1007/s10461-012-0275-1

Castro, A., \& Farmer, P. (2005). Understanding and addressing AIDS-related stigma: From anthropological theory to clinical practice in Haiti. American Journal of Public Health, 95(1), 53-59. http://doi.org/10.2105/AJPH.2003.028563

Cavanaugh, C. E., \& Classen, C. C. (2010). Integrational Pathways Linking Childhood Sexual Abuse to HIV Risk Among Women. Journal of Trauma Injury Infection And Critical Care, 10(2), 1-15. http://doi.org/10.1080/15299730802624536

Cayemittes, M., Busangu, M. F., Bizimana, J. D. D., Barrère, B., Sévère, B., Cayemittes, V., \& Charles, E. (2013). Enquête Mortalité, Morbidité et Utilisation des Services (EMMUS-V), Haïti, 2012, 13. Retrieved from http://dhsprogram.com/publications/publication-FR273-DHS-Final-Reports.cfm

Centers for Disease Control and Prevention (CDC). (2015). Alcohol and public health. Retrieved September 1, 2015, from http://www.cdc.gov/alcohol/ 
Centers for Disease Control and Prevention (CDC). (2006). Excessive drinking costs U.S. \$223.5 billion. Retrieved September 1, 2015, from http://www.cdc.gov/features/alcoholconsumption/

Centers for Disease Control and Prevention. (2014). Alcohol use and your health. Fact Sheet CDC. http://doi.org/10.1037/0012828

Central Intelligence Agency (2013, October 31). The world factbook: Central American and Caribbean-Haiti. Central Intelligence Agency. Retrieved November 9, 2013, from www.cia.gov/library/publications/the-world-factbook/geos/ha.html

Cerdá, M., Tracy, M., \& Galea, S. (2011). A prospective population based study of changes in alcohol use and binge drinking after a mass traumatic event. Drug Alcohol Depend, 115(1-2), 1-8. http://doi.org/10.1016/j.drugalcdep.2010.09.011

Chacon Ortiz, M., Jimenez Barrantes, R.A., Comerfold, M., McCoy, C. (2014). Health and Addictions: Drugs and Health, 14(1), 27-36

Chander, G., Hutton, H., Xu, X., \& McCaul, M. (2015). Brief intervention decreases drinking frequency in HIV-infected, heavy drinking women: Results of a randomized controlled trial. Journal of Acquired Immune Deficiency Syndrome, 70(2), 137-145.

Chang, L., \& Krosnick, J. a. (2010). Comparing oral interviewing with self-administered computerized questionnaires: An experiment. Public Opinion Quarterly, 74(1), 154167. http://doi.org/10.1093/poq/nfp090

Chariyeva, Z., Golin, C. E., Earp, J. A., Maman, S., Suchindran, C., \& Zimmer, C. (2013). The role of self-efficacy to explain the effect of counseling time on changes in risky sexual behavior among people living with HIV: a mediation analysis. AIDS and Behavior, 17(2), 813-823.

Charles, C. (1995). Gender and politics in contemporary Haiti: The Duvalierst state, transnationalism, and the emergence of a new feminism (1980-1990). Feminist Studies, 21(1), 135-164. Retrieved from http://www.jstor.org/stable/3178323

Chuang, C. H., Liebschutz, J. M., Horton, N. J., \& Samet, J. H. (2006). Association of violence victimization with inconsistent condom use in HIV-infected persons. AIDS and Behavior, 10(2), 201-207. http://doi.org/10.1007/s10461-005-9046-6

Clum, G. A., Chung, S.-E., Ellen, J. M., Perez, L. V., Murphy, D. A., Harper, G. W., \& Hamvas, L. (2012). Victimization and sexual risk behavior in young, HIV positive women: Exploration of mediators. AIDS and Behavior, 16(4), 999-1010. http://doi.org/10.1007/s10461-011-9931-0 
Cohen, M., Deamant, C., Barkan, S., Richardson, J., Young, M., Holman, S., ... Melnick, S. (2000). Domestic violence and childhood sexual abuse in HIV-infected women and women at risk for HIV. American Journal of Public Health, 90(4), 560-565. http://doi.org/10.2105/AJPH.90.4.560

Colin, J.M. (n.d.). Cultural and clinical care for Haitians [PowerPoint Slides]. Retrieved from Government of Indiana website, http://www.state.in.us/isdh/files/Haiti_Cultural_and_Clinical_Care_Presentation_Re ad-Only.pdf

Collaborative Study Group of AIDS in Haitian Americans (1987). Risk factors for AIDS among Haitians residing in the United States. Evidence of heterosexual transmission. Journal of the American Medical Association, 257(5), 635-639.

Conserve, D. F., King, G., Dévieux, J. G., Jean-Gilles, M., \& Malow, R. (2014). Determinants of HIV serostatus disclosure to sexual partner among HIV-positive alcohol users in Haiti. AIDS and Behavior, 18(6), 1037-1045. http://doi.org/10.1007/s10461-013-0685-8

Conserve, D. F., Whembolua, G.-L. S., \& Surkan, P. J. (2014). Attitudes toward intimate partner violence and associations with condom use among men in Haiti: An analysis of the nationally representative demographic health survey. Journal of Interpersonal Violence. http://doi.org/10.1177/0886260514564065

Cook, R. T. (1998). Alcohol abuse, alcoholism, and damage to the immune system--a review. Alcoholism, Clinical and Experimental Research, 22(9), 1927-42. http://doi.org/10.1097/00000374-199812000-00007

Cook, S. H., Valera, P., \& Wilson, P. A. (2015). HIV status disclosure, depressive symptoms, and sexual risk behavior among HIV-positive young men who have sex with men. Journal of Behavioral Medicine, 38(3), 507-517.

Cooper, M. L. (2002). Alcohol use and risky sexual behavior among college students and youth: evaluating the evidence. Journal of Studies on Alcohol. Supplement, 14, 101117. http://doi.org/10.15288/jsas.2002.s14.101

Cortes, A., Hunt, N., \& McHale, S. (2014). Development of the scale of perceived social support in HIV (PSS-HIV). AIDS and Behavior, 18(12), 2274-84. http://doi.org/10.1007/s10461-014-0902-0

Crothers, K., Butt, A. a, Gibert, C. L., Rodriguez-Barradas, M. C., Crystal, S., \& Justice, A. C. (2006). Increased COPD among HIV-positive compared to HIV-negative veterans. Chest, 130(5), 1326-33. http://doi.org/10.1378/chest.130.5.1326 
De Cock, K. M., Jaffe, H. W., \& Curran, J. W. (2012). The evolving epidemiology of HIV/AIDS. AIDS, 26(10), 1205-1213.

http://doi.org/10.1097/QAD.0b013e328354622a

De, R., Bhandari, S., Roy, S., Bhowmik, A., Rewari, B., \& Guha, S. (2013). Factors responsible for delayed enrollment for anti-retroviral treatment. Journal of Nepal Health Research Council, 11(24), 194-197.

DeSantis, L., Thomas, J. T., \& Sinnett, K. (1999). Intergenerational concepts of adolescent sexuality: implications for community-based reproductive health care with Haitian immigrants. Public Health Nursing, 16(2), 102-13.

http://doi.org/10.1046/j.1525-1446.1999.00102.x

Deschamps, M., \& Pape, J. (1996). Heterosexual transmission of HIV in Haiti. Annals of Internal Medicine, 341-342. Retrieved from http://annals.org/article.aspx?articleid=709884

Dévieux, J. G., Deschamps, M.-M., Malow, R. M., Jean-Gilles, M., Saint-Jean, G., Marcelin, A., \& Pape, J. W. (2009). Knowledge, attitudes, and behaviors among a sample of HIV-positive and HIV-negative females visiting an urban VCT center in Haiti. Journal of Health Care for the Poor and Underserved, 20(2), 554-68. http://doi.org/10.1353/hpu.0.0141

Dévieux, J. G., Jean-Gilles, M., Rosenberg, R., Beck-Sagué, C., Attonito, J. M., Saxena, A., \& Stein, J. A. (2015). Depression, abuse, relationship power and condom use by pregnant and postpartum women with substance abuse history. AIDS and Behavior. http://doi.org/10.1007/s10461-015-1176-x

Dévieux, J. G., Malow, R. M., Attonito, J. M., Jean-Gilles, M., Rosenberg, R., Gaston, S., ... Deschamps, M.-M. (2013a). Post-traumatic stress disorder symptomatology and alcohol use among HIV-seropositive adults in Haiti. AIDS Care, 25(10), 1210-1218. http://doi.org/10.1080/09540121.2013.763894

Dévieux, J. G., Malow, R. M., Jean-Gilles, M. M., Samuels, D. M., Deschamps, M.-M., Ascencio, M., ... Pape, J. W. (2004). Reducing health disparities through culturally sensitive treatment for HIV+ adults in Haiti. Journal of the Association of Black Nursing Faculty in Higher Education, 15(6), 109-15. Retrieved from http://www.pubmedcentral.nih.gov/articlerender.fcgi?artid=2605017\&tool=pmcentr ez\&rendertype=abstract

Devieux, J. G., Rosenberg, R., Saint-Jean, G., Bryant, V. E., \& Malow, R. M. (2013b). The continuing challenge of reducing HIV risk among Haitian youth: The need for intervention. Journal of the International Association of Providers of AIDS Care (JIAPAC), 0(0), 1-7. http://doi.org/10.1177/2325957411418119 
DiClemente, R. J., \& Wingood, G. M. (1995). A randomized controlled trial of an HIV sexual risk-reduction intervention for young African-American women. Journal of the American Medical Association, 274(16), 1271-1276.

Dunkle, K. L., Jewkes, R. K., Brown, H. C., Gray, G. E., McIntryre, J. A., \& Harlow, S. D. (2004). Gender-based violence, relationship power, and risk of HIV infection in women attending antenatal clinics in South Africa. Lancet (London, England), 363(9419), 1415-21. http://doi.org/10.1016/S0140-6736(04)16098-4

Ehrhardt, A. A., Exner, T. M., Hoffman, S., Silberman, I., Leu, C.-S., Miller, S., \& Levin, B. (2002a). A gender-specific HIV/STD risk reduction intervention for women in a health care setting: Short- and long-term results of a randomized clinical trial. AIDS Care, 14(2), 147-161. http://doi.org/10.1080/09540120220104677

Ehrhardt, A. A., Exner, T. M., Hoffman, S., Silberman, I., Yingling, S., Adams-Skinner, J., \& Smart-Smith, L. (2002b). HIV/STD risk and sexual strategies among women family planning clients in New York: Project FIO. AIDS and Behavior, 6(1), 1-13. http://doi.org/10.1023/A:1014534110868

Enoch, M. (2011). The role of early life stress as a predictor for alcohol and drug dependence. Psychopharmacology, 214(1), 17-31. http://doi.org/10.1007/s00213010-1916-6.The

Fawzi, M. C. S., Lambert, W., Boehm, F., Finkelstein, J. L., Singler, J. M., Léandre, F., ... Mukherjee, J. S. (2010). Economic risk factors for HIV infection among women in rural Haiti: implications for HIV prevention policies and programs in resourcepoor settings. Journal of Women's Health (2002), 19(5), 885-892. http://doi.org/10.1089/jwh.2008.1334

Fisher, J. D., Fisher, W. a, Cornman, D. H., Amico, R. K., Bryan, A., \& Friedland, G. H. (2006). Clinician-delivered intervention during routine clinical care reduces unprotected sexual behavior among HIV-infected patients. Journal of Acquired Immune Deficiency Syndrome, 41(1), 44-52. http://doi.org/10.1097/01.qai.0000192000.15777.5c

Folkman, S. (1997). Positive psychological states and coping with severe stress. Social Science and Medicine, 45(8), 1207-1221. http://doi.org/10.1016/S02779536(97)00040-3

Folkman, S., \& Moskowitz, J. T. (2003). Positive psychology from a coping perspective. Psychological Inquiry, 14, 121-125.

Farmer, P. E. (2012). Leaders for education series. Retrieved November 1, 2013, from http://www.ungei.org/news/247_2486.html 
Fuller, A. (1999). Challenging violence: Haitian women unite women's rights and human rights. Association of Concerned African Scholars Bulletin: women and War, 55/56, 39-48.

Gage, A. J. (2005). Women's experience of intimate partner violence in Haiti. Social Science and Medicine, 61(2), 343-364.

http://doi.org/10.1016/j.socscimed.2004.11.078

Gage, A. J. (2015). Exposure to spousal violence in the family, attitudes and dating violence perpetration among high school students in Port-au-Prince. Journal of Interpersonal Violence, 1-30. http://doi.org/10.1177/0886260515576971

Gage, A. J., \& Hutchinson, P. L. (2006). Power, control, and intimate partner sexual violence in Haiti. Archives of Sexual Behavior, 35(1), 11-24. http://doi.org/10.1007/s10508-006-8991-0

Gage, A. J., \& Suzuki, C. (2006). Risk factors for alcohol use among male adolescents and emerging adults in Haiti. Journal of Adolescence, 29(2), 241-260. http://doi.org/10.1016/j.adolescence.2005.05.001

Gaillard, E. M., Boulos, L. M., Cayemittes, M. P., Eustache, L., Van Onacker, J. D., Duval, N., . . Louissaint, E. (2006). Understanding the reasons for the decline of HIV prevalence in Haiti. Sexually Transmitted Infections, 82(Suppl I), i14-i20. http://doi:10.1136/sti.2005.018051.

Galvan, F. H., Bing, E. G., Fleishman, J. a, London, A. S., Caetano, R., Burnam, M. A., ... Shapiro, M. (2002). The prevalence of alcohol consumption and heavy drinking among people with HIV in the United States: Results from the HIV cost and services utilization Study. Journal of Studies on Alcohol, 63(2), 179-186.

Glick, S. N., \& Golden, M. R. (2014). Early male partnership patterns, social support, and sexual risk behavior among young men who have sex with men. AIDS and Behavior, 18(8), 1466-75. http://doi.org/10.1007/s10461-013-0678-7

Goh, Y. W., Sawang, S., \& Oei, T. P. S. (2010). The revised transactional model (RTM) of occupational stress and coping: An improved process approach. Australian and New Zealand Journal of Organisational Psychology, 3, 13-20. http://doi.org/10.1375/ajop.3.1.13

Grant, B. F., \& Dawson, D. A. (1997). Age at onset of alcohol use and its association with DSM-IV alcohol abuse and dependence: Results from the national longitudinal alcohol epidemiologic survey. Journal of Substance Abuse, 9, 103-110. http://doi.org/10.1016/S0899-3289(97)90009-2 
Grant, B. F., Stinson, F. S., \& Harford, T. C. (2001). Age at onset of alcohol use and DSM-IV alcohol abuse and dependence: A 12-year follow-up. Journal of Substance Abuse, 13(4), 493-504. http://doi.org/10.1016/S0899-3289(01)00096-7

Gupta, J., Small, M. J., \& Kershaw, T. (2013). Gender and HIV/AIDS in Haiti: Women’s lack of power as an overarching vulnerability. In J. Boesten \& N. K. Poku (Eds.), Gender and HIV/AIDS: Critical Perspectives from the Developing World (pp. 85102). Farnham (England): Ashgate Publishing Ltd.

Hahn, J. A., \& Samet, J. H. (2010). Alcohol and HIV disease progression: Weighing the evidence. Current HIV/AIDS Reports, 7(4), 226-233. http://doi.org/10.1007/s11904010-0060-6

Hallett, T. B. (2006). Declines in HIV prevalence can be associated with changing sexual behaviour in Uganda, urban Kenya, Zimbabwe, and urban Haiti. Sexually

Transmitted Infections, 82(Suppl 1), i1-i8. http://doi.org/10.1136/sti.2005.016014

Hargreaves, J. R., Davey, C., Fearon, E., Hensen, B., \& Krishnaratne, S. (2015). Trends in socioeconomic inequalities in HIV prevalence among young people in seven countries in Eastern and Southern Africa. Plos One, 10(3), e0121775. http://doi.org/10.1371/journal.pone.0121775

Harling, G., Tsai, A. C., \& Subramanian, S. V. (2015). Intimate partner violence and HIV: embracing complexity. The Lancet Global Health, 3(6), e313. http://doi.org/10.1016/S2214-109X(15)00009-1

Hirway, I., \& Mahadevia, D. (1996). Critique of gender development index: Towards an alternative. Economic and Political Weekly, 31(43), WS87-WS96. http://doi.org/10.3201/eid1011.040252

Holschneider, S. O. ., \& Alexander, C. S. (2003). Social and psychological influences on HIV preventive behaviors of youth in Haiti. Journal of Adolescent Health, 33(1), 31-40. http://doi.org/10.1016/S1054-139X(02)00418-4

Hunter-Reel, D., Mccrady, B., \& Hildebrandt, T. (2009). Emphasizing interpersonal factors: an extension of the Witkiewitz and Marlatt relapse model. Addiction, 104(8), 1281-1290. http://doi.org/10.1111/j.1360-0443.2009.02611.x.Emphasizing

Jenkins, M. B., Agrawal, A., Lynskey, M. T., Nelson, E. C., Madden, P. A. F., Bucholz, K. K., \& Heath, A. C. (2011). Correlates of alcohol abuse/dependence in early-onset alcohol-using women. American Journal on Addictions, 20(5), 429-434. http://doi.org/10.1111/j.1521-0391.2011.00151.x

Joint United Nations Programme on HIV/AIDS (UNAIDS). (2014). The gap report. Geneva. Retrieved from 
http://www.unaids.org/en/resources/documents/2014/20140716_UNAIDS_gap_repo rt

Jones, D. L., Ishii Owens, M., Lydston, D., Tobin, J. N., Brondolo, E., \& Weiss, S. M. (2010a). Self-efficacy and distress in women with AIDS: the SMART/EST women's project. AIDS Care, 22(12), 1499-1508.

http://doi.org/10.1080/09540121.2010.484454

Jones, D. J., Runyan, D. K., Lewis, T., Litrownik, A. J., Black, M. M., Wiley, T., ... Nagin, D. S. (2010b). Trajectories of childhood sexual abuse and early adolescent HIV/AIDS risk behaviors: The role of other maltreatment, witnessed violence, and child gender. Journal of Clinical Child \& Adolescent Psychology, 39(5), 667-680. http://doi.org/10.1080/15374416.2010.501286

Kalichman, S. C., Cherry, C., Kalichman, M. O., Amaral, C. M., White, D., Pope, H., ... Cain, D. (2011). Integrated behavioral intervention to improve HIV/AIDS treatment adherence and reduce HIV transmission. American Journal of Public Health, 101(3), 531-538. http://doi.org/10.2105/AJPH.2010.197608

Kalichman, S. C., Grebler, T., Amaral, C. M., McNerey, M., White, D., Kalichman, M. O., ... Eaton, L. (2013). Intentional non-adherence to medications among HIV positive alcohol drinkers: Prospective study of interactive toxicity beliefs. Journal of General Internal Medicine, 28(3), 399-405. http://doi.org/10.1007/s11606-0122231-1

Kalichman, S. C., Heckman, T., Kochman, Sikkema, K., \& Bergholte, J. (2000). Depression and thoughts of suicide among middle-aged and older persons living with HIV-AIDS. Psychiatric Services, 51(7), 903-7. http://doi.org/10.1176/appi.ps.51.7.903

Kalichman, S. C., Rompa, D., Cage, M., DiFonzo, K., Simpson, D., Austin, J., ... Graham, J. (2001). Effectiveness of an intervention to reduce HIV transmission risks in HIV-positive people. American Journal of Preventive Medicine. http://doi.org/10.1016/S0749-3797(01)00324-5

Katz, L. M., Cumming, P., Wallace, E., Abrams, P. (2005). Audiovisual touch-screen computer-assisted self-interviewing for donor health histories: Results from two years experience with the system. Transfusion, 45(2), 171-180. http://doi.org/10.1016/S0749-3797(01)00324-5

Kendler, K. S., Bulik, C. M., Silberg, J., Hettema, J. M., Myers, J., \& Prescott, C. A. (2000). Childhood sexual abuse and adult psychiatric and substance use disorders in women. Archives of General Psychiatry, 57, 953.

http://doi.org/10.1001/archpsyc.57.10.953 
Kendler, K. S., \& Myers, J. (2012). Clinical indices of familial alcohol use disorder. Alcoholism, Clinical and Experimental Research, 36(12), 2126-2131. http://doi.org/10.1111/j.1530-0277.2012.01844.x.

Kershaw, T. S., Small, M., Joseph, G., Theodore, M., Bateau, R., \& Frederic, R. (2006). The influence of power on HIV risk among pregnant women in rural Haiti. AIDS and Behavior, 10(3), 309-318. http://doi.org/10.1007/s10461-006-9072-z

Keyes, K. M., Hatzenbuehler, M. L., Grant, B. F., \& Hasin, D. S. (2012). Stress and alcohol: Epidemiologic evidence. Alcohol Research: Current Reviews, 34(4), 391400.

Khamarko, K., \& Myers, J. J. (2013). The Influence of Social Support on the Lives of HIV-Infected Individuals in Low- and Middle-Income Countries. World Health Organization, 1-40.

Khoury, L., Tang, Y. L., Bradley, B., Cubells, J. F., \& Ressler, K. J. (2010). Substance use, childhood traumatic experience, and Posttraumatic Stress Disorder in an urban civilian population. Depression and Anxiety, 27(12), 1077-1086. http://doi.org/10.1002/da.20751

Kilpatrick, D. G., Acierno, R., Saunders, B., Resnick, H. S., Best, C. L., \& Schnurr, P. P. (2000). Risk factors for adolescent substance abuse and dependence: data from a national sample. Journal of Consulting and Clinical Psychology, 68(1), 19-30. http://doi.org/10.1037//0022-006X.68.1.19

Kingori, C., Haile, Z. T., \& Ngatia, P. (2015). Depression symptoms, social support and overall health among HIV-positive individuals in Kenya. International Journal of STD \& AIDS, 26(3), 165-172. http://doi.org/10.1177/0956462414531933

Kishore, V., Theall, K. P., Robinson, W., Pichon, J., Scribner, R., Roberson, E., \& Johnson, S. (2008). Resource loss, coping, alcohol use, and posttraumatic stress symptoms among survivors of Hurricane Katrina: a cross-sectional study. American Journal of Disaster Medicine, 3(6), 345-357. Retrieved from http://ovidsp.ovid.com/ovidweb.cgi?T=JS\&PAGE=reference\&D=med5\&NEWS=N \&AN $=19202888$

Koenig, S. P., Léandre, F., \& Farmer, P. E. (2004). Scaling-up HIV treatment programmes in resource-limited settings: the rural Haiti experience. AIDS (London, England), 18(Suppl 3), S21-S25. http://doi.org/10.1097/00002030-20040600300005

Koenig, L.J., Whitaker, D.J., Royce, R.A., Wilson, T.E., Ethier, K., \& Fernandez, M.I. (2006) . Physical and sexual violence during pregnancy and after delivery: A 
prospective multistate study of women with or at risk for HIV infection. American Journal of Public Health, 96, 1052-1059.

Krug, E. G., Dahlberg, L. L., Mercy, J. A., Zwi, A. B., \& Lozano, R.(Eds) (2002). World report on violence and health. Geneva. Retrieved from http://www.who.int/violence_injury_prevention/violence/world_report/en/

Lanius, R. A., Vermetten, E., \& Pain, C. (Eds.). (2010). The Impact of Early Life Trauma on Health and Disease: The Hidden Epidemic. New York: Cambridge University Press.

LeGrand, S., Reif, S., Sullivan, K., Murray, K., Barlow, M. L., \& Whetten, K. (2015). A Review of Recent Literature on Trauma Among Individuals Living with HIV. Current HIV/AIDS Reports. http://doi.org/10.1007/s11904-015-0288-2

Li, M., Betancourt, T., Eustache, E., Oswald, C., Louis, E., Mukherjee, J., ... Fawzi, M. C. S. (2015). Risk and protective factors for internalizing and externalizing outcomes among HIV-affected youth in Haiti. AIDS Care, 27(8), 995-999. http://doi.org/10.1080/09540121.2015.1020751

Logie, C. H., Daniel, C., Newman, P. A., \& Loutfy, M. R. (2012). An HIV/STI prevention intervention for internally displaced women in Leogane, Haiti: study protocol for an N-of-1 pilot study. British Medical Association Open (BMJ Open), 2(4), e001634-e001634. http://doi.org/10.1136/bmjopen-2012-001634

Longman-Mills, S., González, W. Y., Meléndez, M. O., García, M. R., Gómez, J. D., Juárez, C. G., ... Mann, R. E. (2013). Exploring child maltreatment and its relationship to alcohol and cannabis use in selected Latin American and Caribbean countries. Child Abuse and Neglect, 37(1), 77-85.

http://doi.org/10.1016/j.chiabu.2012.11.002

Ludwig-Barron, N., Wagner, K. D., Syvertsen, J. L., Ewald, I. J., Patterson, T. L., Semple, S. J., \& Stockman, J. K. (2014). "When you get old like this ... you don't run those risks anymore”: Influence of age on sexual risk behaviors and condom use attitudes among methamphetamine-using heterosexual women with a history of partner violence. Women's Health Issues, 24(6), 620-628.

http://doi.org/10.1016/j.whi.2014.06.007

Machtinger, E. L., Lavin, S. M., Hilliard, S., Jones, R., Haberer, J. E., Capito, K., \& Dawson-Rose, C. (2015). An expressive therapy group disclosure intervention for women living with HIV improves social support, self-efficacy, and the safety and quality of relationships: A qualitative analysis. Journal of the Association of Nurses in AIDS Care, 26(2), 187-198. http://doi.org/10.1016/j.jana.2014.05.001 
Machtinger, E. L., Wilson, T. C., Haberer, J. E., \& Weiss, D. S. (2012). Psychological trauma and PTSD in HIV-positive women: A meta-analysis. AIDS and Behavior, 16(8), 2091-2100. http://doi.org/10.1007/s10461-011-0127-4

Magee, M. M., Small, M., Frederic, R., Joseph, G., \& Kershaw, T. (2006). Determinants of HIV/AIDS risk behaviors in expectant fathers in Haiti. Journal of Urban Health: Bulletin of the New York Academy of Medicine, 83(4). Doi:10.1007/s11524-0069063-4.

Magnusson, Å., Lundholm, C., Göransson, M., Copeland, W., Heilig, M., \& Pedersen, N. L. (2012). Familial influence and childhood trauma in female alcoholism.

Psychological Medicine, 42(2), 381-9. http://doi.org/10.1017/S0033291711001310

Maisto, S., Carey, M., Carey, K., Gordon, C., \& Gleason, J. (2000). Use of the AUDIT and the DAST-10 to identify alcohol and drug use disorders among adults with a severe and persistent mental illness. Psychological Assessment, 12(2), 186_192. doi:10.1037/1040-3590.12.2.186

Malow, R. M., Dévieux, J. G., Martinez, L., Peipman, F., Lucenko, B. A., \& Kalichman, S. C. (2006). History of traumatic abuse and HIV risk behaviors in severely mentally ill substance abusing adults. Journal of Family Violence, doi:10.1007/s10896-0059012-0

Malow, R., Dévieux, J. G., Stein, J. A., Rosenberg, R., Jean-Gilles, M., Attonito, J., ... Pape, J. W. (2013a). Depression, substance abuse and other contextual predictors of adherence to antiretroviral therapy (ART) among Haitians. AIDS and Behavior, 17(4), 1221-1230. http://doi.org/10.1007/s10461-012-0400-1

Malow, R., Dévieux, J. G., Stein, J. A., Rosenberg, R., Jean-Gilles, M., Attonito, J., ... Pape, J. W. (2013b). Depression, substance abuse and other contextual predictors of adherence to antiretroviral therapy (ART) among Haitians. AIDS and Behavior, 17(4), 1221-1230. http://doi.org/10.1007/s10461-012-0400-1

Malow, R., Dévieux, J., \& Lucenko, B. a. (2006). History of childhood sexual abuse as a risk factor for HIV risk behavior. Journal of Trauma Practice, 5(1998), 13-32. http://doi.org/10.1300/J189v05n03

Malow, R. M. (2013). The impact of disaster on HIV in Haiti and priority areas related to the Haitian crisis. Journal of the Association of Nurses in AIDS Care, 21(3), 283288. http://doi.org/10.1016/j.jana.2010.02.002

Malow, R. M., Cassagnol, T., McMahon, R., Jennings, T. E., \& Roatta, V. G. (2000). Relationship of psychosocial factors to HIV risk among Haitian women. AIDS Education and Prevention, 12(1), 79-92. 
Malow, R., Dévieux, J. G., Rosenberg, R., \& Jean-Gilles, M. (2012). [Intervening with Haitian HIV-positive alcohol users: an environmental psychosocial framework]. Unpublished raw data.

Malow, R., Rosenberg, R., Lichtenstein, B., \& Dévieux, J. G. (2010). The impact of disaster on HIV in Haiti and priority areas related to the Haitian crisis. Journal of the Association of Nurses in AIDS Care, 21(3), 283-288.

http://doi.org/10.1016/j.jana.2010.02.002

Malow, RM, Rosenberg, R, Dévieux, J. (2009). Cognitive-behavioral stress management interventions for ethnic-minority HIV-positive alcohol/drug abusers in resource limited and culturally diverse communities. American Journal of Infectious Diseases, 5(1), 48-59. Retrieved from http://findarticles.com/p/articles/mi_6891/is_1_5/ai_n35703895/pg_5/

Maman, S., Campbell, J., Sweat, M. D., \& Gielen, A. C. (2000). The intersections of HIV and violence: directions for future research and interventions. Social Science and Medicine, 50(4), 459-478. http://doi.org/10.1016/S0277-9536(99)00270-1

Marc, L. G., Patel-Larson, A., Hall, H. I., Hughes, D., Alegría, M., Jeanty, G., ... JeanLouis, E. (2010). HIV among Haitian-born persons in the United States, 1985-2007. Aids, 24(13), 2089-2097. http://doi.org/10.1097/QAD.0b013e32833bedff

Margesson, R., \& Taft-Morales, M. (2010). Haiti earthquake: crisis and response. Congressional Research Service, 1-56. Retrieved from https://www.fas.org/sgp/crs/row/R41023.pdf

Marlatt, G. A., \& Witkiewitz, K. (2005). Relapse prevention for alcohol and drug problems. Strategies, 59(4), 1-44.

Martsolf, D. S. (2004). Childhood maltreatment and mental and physical health in Haitian adults. Journal of Nursing Scholarship, 36(4), 293-299.

http://doi.org/10.1111/j.1547-5069.2004.04054.x

Masinda, M. T., \& Muhesi, M. (2004). Trauma in children/adolescents: A special focus in third world countries. Journal of Child and Adolescent Mental Health, 16(2), 6976. http://doi.org/10.2989/17280580409486572

McCauley, J., Kern, D. E., Kolodner, K., Dill, L., Schroeder, a F., DeChant, H. K., ... Bass, E. B. (1997). Clinical characteristics of women with a history of childhood abuse: unhealed wounds. Journal of the American Medical Association, 277(17), 1362-8. http://doi.org/10.1001/jama.1997.03540410040028

McQuaid, R. J., Bombay, A., McInnis, O. A., Matheson, K., \& Anisman, H. (2015). Childhood adversity, perceived discrimination, and coping strategies in relation to 
depressive symptoms among First Nations adults in Canada: The moderating role of unsupportive social interactions from ingroup and outgroup members. Cultural Diversity and Ethnic Minority Psychology, 21(3), 326-336.

Meade, C. S., Drabkin, A. S., Hansen, N. B., Wilson, P. a., Kochman, A., \& Sikkema, K. J. (2010). Reductions in alcohol and cocaine use following a group coping intervention for HIV-positive adults with childhood sexual abuse histories. Addiction, 105(11), 1942-1951. http://doi.org/10.1111/j.1360-0443.2010.03075.x

Medrano, M. A., \& Hatch, J. P. (2005). Childhood trauma, sexually transmitted diseases and the perceived risk of contracting HIV in a drug using population. The American Journal of Drug and Alcohol Abuse, 31(3), 403-416. http://doi.org/http://dx.http://doi.org/10.1081/ADA-200056788

Miles, I. J., Lee, B. C., Wejnert, C., Oster, A., DiNenno, E., \& Paz-Bailey, G. (2013). HIV infection among heterosexuals at increased risk--United States, 2010. MMWR. Morbidity and Mortality Weekly Report, 62(10), 183-8. Retrieved from http://www.ncbi.nlm.nih.gov/pubmed/23486383

Ministry of Public Health and Population. (2013). Haïti: 2012 Mortality, Morbidity, and Service Utilization Survey Key Findings, 1-24. Retrieved from http://dhsprogram.com/publications/publication-SR199-Summary-Reports-KeyFindings.cfm

Molina, P. E., Gardner, J. D., Souza-Smith, F. M., \& Whitaker, A. M. (2014). Alcohol Abuse: Critical Pathophysiological Processes and Contribution to Disease Burden. Physiology, 29(3), 203-215. http://doi.org/10.1152/physiol.00055.2013

Molina, P. E., Happel, K. I., Zhang, P., Kolls, J. K., \& Nelson, S. (2010). Focus on: Alcohol and the immune system. Alcohol Research and Health: Journal of the National Institute on Alcohol Abuse and Alcoholism, 33(1-2), 97-108. Retrieved from http://www.pubmedcentral.nih.gov/articlerender.fcgi?artid=3887500\&tool=pmcentr ez\&rendertype=abstract

Moskowitz, J. T., \& Folkman, S. (2003). Positive psychology from a coping perspective. Psychological Inquiry, 14(2), 121-125. Retrieved from http://www.jsotr.org/stable/1449817

Myers, H. F., Wyatt, G. E., Loeb, T. B., Carmona, J. V., Warda, U., Longshore, D., ... Liu, H. (2006). Severity of child sexual abuse, post-traumatic stress and risky sexual behaviors among HIV-Positive women. AIDS and Behavior, 10(2), 191-199. http://doi.org/10.1007/s10461-005-9054-6 
N’Zengou-Tayo, M.-J. (1998). "Fanm se poto mitan”: Haitian woman, the pillar of society. Feminist Review, 59(Summer), 118-142.

http://doi.org/10.1080/014177898339497

Naslund, J. a., Dionne-Odom, J., Junior Destiné, C., Jogerst, K. M., Renold Sénécharles, R., Jean Louis, M., ... Wright, P. F. (2014). Adapting and implementing a community program to improve retention in care among patients with HIV in southern Haiti: “Group of 6.” AIDS Research and Treatment, 2014, 1-9. http://doi.org/10.1155/2014/137545

National Institute for Alcohol Abuse and Alcoholism. (2015). College drinking. Retrieved August 1, 2015, from http://niaaa.nih.gov/alcohol-health/specialpopulations-co-occurring-disorders/college-drinking

National Child Traumatic Stress Network (NCTSN). (2015). Sexual Abuse. Retrieved September 1, 2015, from http://www.nctsn.org/trauma-types/sexual-abuse

Ncube, N., Akunna, J., Babatunde, F., Nyarko, A., Yatich, N., Ellis, W., ... Jolly, P. (2012). Sexual behavior among HIV-positive persons in Kumasi, Ghana. Ghana Medical Journal, 46(1), 27-33.

Negin, J., Nemser, B., Cumming, R., Lelerai, E., Amor, Y. Ben, \& Pronyk, P. (2012). HIV attitudes, awareness and testing among older adults in Africa. AIDS and Behavior, 16, 63-68. http://doi.org/10.1007/s10461-011-9994-y

Neufeld, S. A., Sikkema, K. J., Lee, R., Kochman, A., \& Hansen NB. (2012). The development and psychometric properties of the HIV and Abuse Related Shame Inventory (HARSI). AIDS and Behavior, 16(4), 1063-74. http://doi.org/10.1007/s10461-011-0086-9

Neuman, M. G., Schneider, M., Nanau, R. M., \& Parry, C. (2012). Alcohol consumption, progression of disease and other comorbidities, and responses to antiretroviral medication in people living with HIV. AIDS Research and Treatment, 2012, 1-14. http://doi.org/10.1155/2012/751827

O’Cleirigh, C., Safren, S. A., \& Mayer, K. H. (2012). The pervasive effects of childhood sexual abuse: Challenges for improving HIV prevention and treatment interventions. Journal of Acquired Immune Deficiency Syndrome, 59(4), 331-334. http://doi.org/10.1097/QAI.0b013e31824aed80

Padgett, A., \& Warnecke, T. (2011). Diamonds in the rubble: The women of Haitiinstitutions, gender equity and human development in Haiti. Journal of Economic Issues, 45(3), 527-557. http://doi.org/10.2753/jei0021-3624450301 
Padian, N. (1987a). Heterosexual transmission of Acquired Immunodeficiency Syndrome: International perspectives and national projections. Reviews of Infectious Diseases, 9(5), 947-960.

Pape, J., \& Johnson Jr., W. D. (1993). AIDS in Haiti: 1982-1992. Clinical Infectious Diseases, 17(Suppl 2), S341-S345. Retrieved from http://www.jstor.org/stable/4457406

Pape, J. W., Stanback, M. E., Pamphile, M., Boncy, M., Deschamps, M. M., Verdier, R. I., ... Johnson Jr., W. D. (1990). Prevalence of HIV infection and high-risk activities in Haiti. Journal of Acquired Immune Deficiency Syndrome, 3(10):9951001. Retrieved from http://www.ncbi.nlm.nih.gov/pubmed/2398463

Parcesepe, A. M., Toivgoo, A., Chang, M., Riedel, M., Carlson, C., DiBennardo, R., \& Witte, S. S. (2015). Physical and sexual violence, childhood sexual abuse and HIV/STI risk behaviour among alcohol-using women engaged in sex work in Mongolia. Global Public Health, 10(1), 88-102. http://doi.org/10.1080/17441692.2014.976240

Pence, B. W., Mugavero, M. J., Carter, T. J., Leserman, J., Thielman, N. M., Raper, J. L., ... Whetten, K. (2012). Childhood trauma and health outcomes in HIV-infected patients: an exploration of causal pathways. Journal of Acquired Immune Deficiency Syndrome, 59(4), 409-16. http://doi.org/10.1097/QAI.0b013e31824150bb

Procidano, M. E., \& Heller, K. (1983). Measures of perceived social support from friends and from family: Three validation studies. American Journal of Community Psychology, 11(1), 1-24. http://doi.org/10.1007/BF00898416

Pulerwitz, J., Gortmaker, S. L., \& Dejong, W. (2000). Measuring sexual relationship power in HIV/STD research. Sex Roles, 42(7/8), 637-660. http://doi.org/10.1023/A:1007051506972

Purcell, D. W., Metsch, L. R., Latka, M., Santibanez, S., Gómez, C. a, Eldred, L., \& Latkin, C. a. (2004). Interventions for seropositive injectors-research and evaluation: an integrated behavioral intervention with HIV-positive injection drug users to address medical care, adherence, and risk reduction. Journal of Acquired Immune Deficiency Syndrome, 37(Suppl 2), S110-8. http://doi.org/00126334-20041001200008

Purcell, E. (2012). Poverty, inequality and power dynamivcs: women adn their role in the Haitian AIDS epidemic. The Lehigh Review, 20(Paper 38), 75-80. Retrieved from http://preserve.lehigh.edu/cas-lehighreview-vol-20/38

Rahill, G. J., Joshi, M., \& Hernandez, A. (2015). Adapting an evidence-based intervention for HIV to avail access to testing and risk-reduction counseling for 
female victims of sexual violence in post-earthquake Haiti. AIDS Care, 0121(October), 1-7. http://doi.org/10.1080/09540121.2015.1071773

Raja, S., Holland, C., Du Bois, S. N., McKirnan, D., Allgood, K. L., \& Glick, N. (2015). History of Traumatic Events in HIV-Positive Individuals: Risk Behavior Implications in an Urban Clinic Setting. Journal of HIV/AIDS and Social Services, 14(1), 110-128. http://doi.org/10.1080/15381501.2014.999182

Rao, D., Chen, W. T., Pearson, C. R., Simoni, J. M., Fredriksen-Goldsen, K., Nelson, K., ... Zhang, F. (2012). Social support mediates the relationship between HIV stigma and depression/quality of life among people living with HIV in Beijing, China. International Journal of STD and AIDS, 23(7), 481-484. http://doi.org/10.1258/ijsa.2009.009428

Rehm, J., Baliunas, D., Borges, G. L. G., Graham, K., Irving, H., Kehoe, T., ... Taylor, B. (2010). The relation between different dimensions of alcohol consumption and burden of disease: an overview. Addiction, 105(5), 817-843. http://doi.org/10.1111/j.1360-0443.2010.02899.x

Rendon, M. J., \& Nicolas, G. (2012). Deconstructing the Portrayals of Haitian Women in the Media: A Thematic Analysis of Images in the Associated Press Photo Archive. Psychology of Women Quarterly, 36, 227-239. http://doi.org/10.1177/0361684311429110

Richter, L., Makusha, T., Komárek, A., Daniels, J., \& Coates, T. (2015). Exploring the impact of childhood abuse on HIV social and attitudinal factors among adults with and without this history in sub-Saharan Africa: Findings from NIMH project accept (HPTN 043). AIDS and Behavior. http://doi.org/10.1007/s10461-015-1166-z

Rook, K., \& Dooley, D. (1985). Applying social support research: Theoretical problems and future directions. Journal of Social Issues. http://doi/10.1111/j.15404560.1985.tb01114.x

Rook, K. S., \& Dooley, D. (1985). Applying social support research: Theoretical problems and future directions. Journal of Social Issues, 41(1), 5-28.

Room, R., Babor, T., \& Rehm, J. (2005). Alcohol and public health. The Lancet, 365, 519-530. http://doi.org/10.1016/S0140-6736(05)17870-2

Rosenberg, J. S. (2011, December). Engendering Haiti’s Reconstruction: The legal and economic case for mainstreaming women in post-disaster programming (No. 67). New York University: Human Rights and Welfare. 
Royce, R. A., Sena, A., Cates, W., \& Cohen, M. S. (1997b). Sexual transmission of HIV. New England Journal of Medicine, 336(15), 1072-1078. Retrieved from http://www.ncbi.nlm.nih.gov/pubmed/21266847

Sacco, W. P., Levine, B., Reed, D. L., \& Thompson, K. (1991). Attitudes about condom use as an AIDS-relevant behavior: Their factor structure and relation to condom use. Psychological Assessment, 3(2), 265-272. http://doi.org/10.1037//10403590.3.2.265

Santana, M. A., \& Dancy, B. L. (2000). The stigma of being named “AIDS carriers” on Haitian-American women. Health Care for Women International, 21(3), 161-171. http://doi.org/10.1080/073993300245230

Sassoon, S. A., Rosenbloom, M. J., Fama, R., Sullivan, E. V., \& Pfefferbaum, A. (2012). Selective neurocognitive deficits and poor life functioning are associated with significant depressive symptoms in alcoholism-HIV infection comorbidity. Psychiatry Research, 199(2), 102-110. http://doi.org/10.1016/j.psychres.2012.05.009

Saunders, J. B., Aasland, O. G., Babor, T. F., de la Fuente, J. R., \& Grant, M. (1993). Development of the alcohol use disorders identification test (AUDIT): WHO collaborative project on early detection of persons with harmful alcohol consumption--II. Addiction, 88, 791-804. http://doi.org/10.1111/j.13600443.1993.tb02093.x

Schacht, R. L., George, W. H., Davis, K. C., Heiman, J. R., Norris, J., Stoner, S. A., \& Kajumulo, K. F. (2010). Sexual abuse history, alcohol intoxication, and women's sexual risk behavior. Archives of Sexual Behavior, 39(4), 898-906. http://doi.org/10.1007/s10508-009-9544-0

Scheidt D.M., Windle M. (1995). The Alcoholics in Treatment HIV Risk (ATRISK) study: Gender, ethnic, and geographic comparisons. Journal of Studies on Alcohol, 56(3), 300-308. http://doi.org/10.15288/jsa.1995.56.300

Schneider, M., Cherish, M., Neuman, M., \& Parry, C. (2012). Alcohol consumption and HIV/AIDS: the neglected interface. Addiction, 107(8), 1369-1371. http://doi.org/10.1111/j.1360-0443.2012.03824.x

Schwartz, R. M., Weber, K. M., Schechter, G. E., Connors, N. C., Gousse, Y., Young, M. A., \& Cohen, M. H. (2014). Psychosocial correlates of gender-based violence among HIV-infected and HIV-uninfected women in three US cities. AIDS Patient Care and STDs, 28(5), 260-267. http://doi.org/10.1089/apc.2013.0342

Scott-Sheldon, L. A. J., Walstrom, P., Carey, K. B., Johnson, B. T., \& Carey, M. P. (2013). Alcohol use and Sexual risk behaviors among individuals infected with HIV: 
A systematic review and meta-analysis 2012 to Early 2013. Current HIV/AIDS Reports, 10(4), 314-323. http://doi.org/10.1007/s11904-013-0177-5

Seedat, S. (2012). Interventions to improve psychological functioning and health outcomes of HIV-infected individuals with a history of trauma or PTSD. Current HIV/AIDS Reports, 9(4), 344-350. http://doi.org/10.1007/s11904-012-0139-3

Senn, T. E., \& Carey, M. P. (2010). Childhood maltreatment and women's adult sexual risk behavior: childhood sexual abuse as a unique risk factor. Child Maltreat, 15(4), 324-335.

Services, U. S. D. of H. and H. (2000). 10th Special Report to the U.S. Congress on Alcohol and Health. Retrieved from http://pubs.niaaa.nih.gov/publications/10report/intro.pdf

Severe, L., Fitzgerald, D. W., Deschamps, M.-M., Reif, L., Post, K., Johnson, W. D., ... Boutin-Foster, C. (2014b). "I am proud of myself, just the way I am” (Mwen fyé de tét mwen, jan mwen ye ya): a qualitative study among young Haitian women seeking care for sexually transmitted infections (STIs) in Haiti. AIDS Education and Prevention, 26(2), 158-169. http://doi.org/10.1521/aeap.2014.26.2.158

Shacham, E., Agbebi, A., Stamm, K., \& Overton, E. T. (2011). Alcohol consumption is associated with poor health in HIV clinic patient population: A behavioral surveillance study. AIDS and Behavior, 15(1), 209-213. http://doi.org/10.1007/s10461-009-9652-9

Shillington, A.M., Cottler, L.B., Compton, W.M., Spitznagel E.L. (2005) Is there a relationship between "heavy drinking" and HIV high risk sexual behaviors among general population subjects? International Journal of Mental Health and Addiction. 30(11):1453-1478.

Sikkema, K. J., Dennis, A. C., Watt, M. H., Choi, K. W., Yemeke, T. T., \& Joska, J. A. (2015). Improving mental health among people living with HIV: a review of intervention trials in low- and middle-income countries. Global Mental Health, 2, e19. http://doi.org/10.1017/gmh.2015.17

Sikkema, K. J., Hansen, N. B., Kochman, A., Tarakeshwar, N., Neufeld, S., Meade, C. S., \& Fox, A. M. (2007). Outcomes from a group intervention for coping with HIV/AIDS and childhood sexual abuse: Reductions in traumatic stress. AIDS and Behavior, 11(1), 49-60. http://doi.org/10.1007/s10461-006-9149-8

Sikkema, K. J., Ranby, K. W., Meade, C. S., Hansen, N. B., Wilson, P. A., \& Kochman, A. (2013). Reductions in traumatic stress following a coping intervention were mediated by decreases in avoidant coping for people living with HIV/AIDS and 
childhood sexual abuse. Journal of Consulting and Clinical Psychology, 81(2), 274283. http://doi.org/10.1037/a0030144

Sikkema, K. J., Wilson, P. a, Hansen, N. B., Kochman, A., Neufeld, S., Ghebremichael, M. S., \& Kershaw, T. (2008). Effects of a coping intervention on transmission risk behavior among people living with HIV/AIDS and a history of childhood sexual abuse. Journal of Acquired Immune Deficiency Syndrome, 47(4), 506-513. http://doi.org/10.1097/QAI.0b013e318160d727

Skalski, L. M., Watt, M. H., Macfarlane, J. C., Proeschold-bell, R. J., Stout, J. E., \& Sikkema, K. J. (2015). Mental health and substance use among patients in a North Carolina HIV clinic, 76(3), 148-155.

Smith Fawzi, M. C., Eustache, E., Oswald, C., Louis, E., Surkan, P. J., Scanlan, F., ... Mukherjee, J. S. (2012). Psychosocial support intervention for HIV-affected families in Haiti: Implications for programs and policies for orphans and vulnerable children. Social Science and Medicine, 74(10), 1494-1503. http://doi.org/10.1016/j.socscimed.2012.01.022

Smith Fawzi, M. C., Lambert, W., Singler, J. M., Koenig, S. P., Léandre, F., Nevil, P., ... Farmer, P. E. (2003). Prevalence and risk factors of STDs in rural Haiti: implications for policy and programming in resource-poor settings. International Journal of STD and AIDS, 14(12), 848-53. http://doi.org/10.1258/095646203322556200

Spear, S., Shedlin, M., Gilberti, B., Fiellin, M., \& McNeely, J. (2015). Feasibility and acceptability of an audio computer-assisted self-interview version of the Alcohol, Smoking, and Substance Involvement Screening Test (ASSIST) in primary care patients. Substance Abuse. http://doi.org/10.1080/08897077.2015.1062460

Sperry, D. M., \& Widom, C. S. (2013). Child abuse and neglect, social support, and psychopathology in adulthood: A prospective investigation. Child Abuse and Neglect, 37(6), 415-425. http://doi.org/10.1016/j.chiabu.2013.02.006

State University of New York New Paltz Institute of Disaster of Mental Health (SUNY). (2010). Tip Sheet on Haitian Culture. Retrieved September 4, 2012, from http://www.newpaltz.edu/idmh/IDMH\%20Haiti\%20Culture\%20Tip\%20Sheet.pdf

Substance Abuse and Mental Health Services Administration (SAMSA). (2015). Alcohol. Retrieved August 1, 2015, from http://www.samhsa.gov/topics/alcohol-tobaccoother-drugs/alcohol

Sutherland, M.A. (2012). Examining mediators of child sexual abuse and sexually transmitted infections. Nursing Research, 60(2), 139-147. http://doi.org/10.1097/NNR.0b013e318209795e 
Szabo, G., \& Mandrekar, P. (2009). A recent perspective on alcohol, immunity, and host defense. Alcoholism: Clinical and Experimental Research, 33(2), 220-232. http://doi.org/10.1111/j.1530-0277.2008.00842.x

Teitelman, A. M., Ratcliffe, S. J., Morales-Aleman, M. M., \& Sullivan, C. M. (2008). Sexual relationship power, intimate partner violence, and condom use among minority urban girls. Journal of Interpersonal Violence, 23(12), 1694-1712. http://doi.org/10.1177/0886260508314331

The Organisation for Economic Co-operation \& Development (OECD). (2012). 2012 Social Institutions and Gender Index: Haiti. Retrieved September 4, 2012, from http://genderindex.org/country/haiti

Tomaszewski, E. P. (2012). Human rights update: Understanding HIV/AIDS stigma and discrimination. Retrieved August 1, 2015, from www.naswdc.org/practice/hiv_aids/AIDS_Day2012.prdf

Troeman, Z. C., Spies, G., Cherner, M., Archibald, S. L., Fennema-Notestine, C., Theilmann, R. J., ... Seedat, S. (2011). Impact of childhood trauma on functionality and quality of life in HIV-infected women. Health and Quality of Life Outcomes, 9(1), 84. http://doi.org/10.1186/1477-7525-9-84

Ulin, P. R., Cayemittes, \& Metellus, E. (1995). Haitian women's role in sexual decisionMaking: The gap between AIDS knowledge and behavior change. Family Health International Working Papers. Retrieved September 4, 2012, from http://pdf.usaid.gov/pdf_docs/PNABY747.pdf

UNAIDS/World Health Organization Working Group on Global HIV/AIDS and STI Surveillance \& UNICEF (UNAIDS). (2008). Epidemiological fact sheet on HIV/AIDS, core data on epidemiology and response, Haiti: 2008 update. Retrieved April 1, 2012, from http://http://apps.who.int/globalatlas/predefinedReports/EFS2008/full/EFS2008_HT. pdf

UNAIDS. (2010a). Helping Haiti rebuild its AIDS response. Retrieved from http://data.unaids.org/pub/FactSheet/2010/20100226_haiti_aidsresponse_en.pdf

UNAIDS. (2010b). Outlook Report 2010. Outlook. Retrieved from http://data.unaids.org/pub/Outlook/2010/20100713_outlook_report_web_en.pdf

UNAIDS. (2010c). The status of HIV in the Caribbean. Retrieved from http://www.unaids.org/en/media/unaids/contentassets/documents/countryreport/2010 /2010_hivincaribbean_en.pdf 
UNAIDS (2013a). Global report: UNAIDS report on the global AIDS epidemic 2013. UNAIDS Global Report. Retrieved July 7, 2014, from http://www.unaids.org/en/media/unaids/contentassets/documents/epidemiology/201 3/gr2013/UNAIDS_Global_Report_2013_en.pdf

UNAIDS (2013b). Regional fact sheet 2012: Latin America and the Caribbean. USUNAIDS Regional Fact Sheet. Retrieved July 7, 2014, from http://www.unaids.org/en/media/unaids/contentassets/documents/epidemiology/201 2/gr2012/2012_FS_regional_la_caribbean_en.pdf

United Nations Development Programme (UNDP). (2015). Haiti: From recovery to sustainable development. Retrieved from http://www.undp.org/content/undp/en/home/ourwork/our-projects-andinitiatives/crisis_in_haiti.html

United Nations Global Compact (UNGC). (2010). Haiti: 6 months after..., 44. Retrieved from http://www.un.org/en/peacekeeping/missions/minustah/documents/6_months_after_ commemoration.pdf

Vetter, S., Rossegger, A., Rossler, W., Bisson, J. I., \& Endrass, J. (2008). Exposure to the tsunami disaster, PTSD symptoms and increased substance use - an Internet based survey of male and female residents of Switzerland. BMC Public Health, 8, 92. http://doi.org/10.1186/1471-2458-8-92

Whetten, K., Leserman, J., Lowe, K., Stangl, D., Thielman, N., Swartz, M., ... Van Scoyoc, L. (2006). Prevalence of childhood sexual abuse and physical trauma in an HIV-Positive sample from the Deep South. American Journal of Public Health, 96(6), 1028-1030. http://doi.org/10.2105/AJPH.2005.063263

Whetten, K., Reif, S., Whetten, R., \& Murphy-McMillan, L. K. (2008). Trauma, mental health, distrust, and stigma among HIV-positive persons: Implications for effective care. Psychosomatic Medicine, 70(5), 531-538. http://doi.org/10.1097/PSY.0b013e31817749dc

Widom, C. S., \& Hiller-Sturmhöfel, S. (2001). Alcohol abuse as a risk factor for and consequence of child abuse. Alcohol Research and Health : The Journal of the National Institute on Alcohol Abuse and Alcoholism, 25, 52-57.

Willie, T. C., Overstreet, N. M., Sullivan, T. P., Sikkema, K. J., \& Hansen, N. B. (2015). Barriers to HIV medication adherence: Examining distinct anxiety and depression symptoms among women living with HIV who experienced childhood sexual abuse. Behavioral Medicine, 4289(October), 00-00. http://doi.org/10.1080/08964289.2015.1045823 
Wilsnack, S. C., Vogeltanz, N. D., Klassen, A. D., \& Harris, T. R. (1997). Childhood sexual abuse and women's substance abuse: National survey findings. Journal of Studies on Alcohol, 58(3), 264-271. Retrieved from https://ucd.idm.oclc.org/login?url=http://search.proquest.com/docview/619069370?a ccountid=14507\nhttp://jq6am9xs3s.search.serialssolutions.com/?ctx_ver=Z39.882004\&ctx_enc=info:ofi/enc:UTF8\&rfr_id=info:sid/ProQ:psycinfo\&rft_val_fmt=info:ofi/fmt:kev:mtx

Wingood, G. M., DiClemente, R. J., Mikhail, I., Lang, D. L., McCree, D. H., Davies, S. L., ... Saag, M. (2004). A randomized controlled trial to reduce HIV transmission risk behaviors and sexually transmitted diseases among women living with HIV: The WiLLOW Program. Journal of Acquired Immune Deficiency Syndrome, 37(Suppl 2), S58-S67. http://doi.org/10.1097/01.qai.0000140603.57478.a9

Wingood, G. M., Scd, \& DiClemente, R. J. (2000). Application of the theory of gender and power to examine HIV-related exposures, risk factors, and effective interventions for women. Health Education and Behavior, 27(5), 539-565. http://doi.org/10.1177/109019810002700502

Wingood, G. M., \& DiClemente, R. J. (2002). The theory of gender and power: a social structural theory for guiding public health interventions. In DiClemente, R. J., Crosby, R. A., \& Kegler, M. C. (Eds.), Emerging theories in health promotion practice and research strategies for Improving public health, (pp. 313-346). San Francisco: Jossey-Bass.

World Health Organization (WHO). (1999). Report of the Consultation on Child Abuse Prevention. Geneva, 29-31 March. Document WHO/HSC/PVI/99.1

World Health Organization (WHO). (2003). Public-health problems caused by harmful use of alcohol, 19(1), 72-3. Retrieved from http://www.ncbi.nlm.nih.gov/pubmed/15260287

World Health Organization (WHO). (2008). Epidemiological Fact Sheet on HIV and AIDS: Core Data on Epidemiology and Response-China. Source, (December).

World Health Organization (WHO). (2015). Alcohol. Retrieved September 1, 2015, from http://www.who.int/mediacentre/factsheets/fs349/en/

Wu, E. S., Metzger, D. S., Lynch, K. G., \& Douglas, S. D. (2011). Association between alcohol use and HIV viral load. Journal of Acquired Immune Deficiency Syndrome, 56(5), e129-30. http://doi.org/10.1097/QAI.0b013e31820dc1c8

Wyatt, G. E., Myers, H. F., \& Loeb, T. B. (2004). Women, trauma, and HIV: An overview. AIDS and Behavior, 8(4), 401-403. http://doi.org/10.1007/s10461-0047324-3 
Wyatt, G. E., Myers, H. F., Williams, J. K., Kitchen, C. R., Loeb, T., Carmona, J. V., ... Presley, N. (2002). Does a history of trauma contribute to HIV risk for women of color? Implications for prevention and policy. American Journal of Public Health, 92(4), 660-665. http://doi.org/10.2105/AJPH.92.4.660

Wyatt, G., Longshore, D., \& Chin, D. (2004). The efficacy of an integrated risk reduction intervention for HIV-positive women with child sexual abuse histories. AIDS and Behavior. Retrieved from http://doi.org/10.1007/s10461-004-7329-y

Zetola, N.M., Modongo, C., Olabiyi, B., Ramogola-Masire, D., Collman, R., \& Chao, LW. (2014). Sexually Transmitted Infections, 90(3), 216-222. http://doi.org/10.1136/sextrans-2013-051244

Zierler, S., Feingold, L., Laufer, D., Velentgas, P., Kantrowitz-Gordon, I., \& Mayer, K. (1991). Adult survivors of childhood sexual abuse and subsequent risk of HIV infection. American Journal of Public Health, 81(5), 572-575.

http://doi.org/10.2105/AJPH.81.5.572 
VITA

MARIE SANDRA SEVERE

Born, Miami, Florida

2003

B.A., Political Science

Newcomb College, Tulane University

New Orleans, Louisiana

2004

M.P.H, Health Education and Communication

Tulane University

New Orleans, Louisiana

2004

Capstone Intern

REACH 2010: At the Heart of New Orleans

New Orleans, Louisiana

2004

Capstone Intern

National Library of Medicine: Medline Plus

New Orleans, Louisiana

$2008-2015$

Doctoral Candidate

Florida International University

Miami, Florida

\section{PUBLICATIONS AND PRESENTATIONS}

Gollub E.L., Cyrus-Cameron, E., Dévieux, J., Jean-Gilles, M., Neptune, S., Pelletier, V., Michel, H., Severe, M., Pierre, L., (2015) 'Men don't need to know everything': A field trial of a discreet, female-initiated, contraceptive barrier method (FemCapTM) among Haitian-American women. Culture, Health, and Sexuality. doi:

10.1080/13691058.2015.1005672 